\title{
ACERCA DE LOS ANTECEDENTES OCKHAMIANOS DEL CONTRACTUALISMO BRITÁNICO MODERNO Y DEL NEOCONTRACTUALISMO CONTEMPORÁNEO
}

Fernando Acanda Fraga*

RESSMEN - Se cserprende por "contracusalismo" la tooria poe la cual se explca y partitice el fundsmenes y la porbibded is la sociodod a parui de ua pecto ectre suat miembeos y que dosarrollado

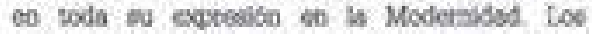
motives que coctictonatoon en la Modemidod of surgimiento de esta tacida socsal furton la secula. titactso de in socledad, gee ya habih oorsenzaso a gestrepe en ef Medioevo y uca concepcikn atoonita de is sociedis. Fartroondo los orlgenet de esta doctrina pueder mallatse desatrollos inciplentes ea ha solistus; hincho criscaido pot Platón, guienen propuabies on el estriblecirtiento de acoeedos soctales a the de evitas trifustiosis $\gamma$ dafioe entre individuoe. Ast expgid entre ins toblsbas la boa din que in grudicin ea un pacta, uoa cunverscton entre hombers y. carente do valot abschuto Otsos tedincoe del dececho $y$ del Batado, oomo Micbel Viley, colocut lel aceoto en et jepel

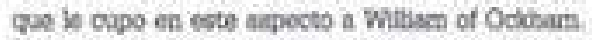
En este sentido es postble affemat qoe scbie et conteactuelsmo moderne so perelbet trfouncias
ABSTRACT - "Conteactialim" is underitood as the theory by which the socioty's foundacien and possibliny is explatoud and forthed starting toen a covenant betwoen ha terembers, moded which whs tully developod dating the Modern Ages. The secularimation of society - whict had eiredy began 10 deviolop buring the Midite Ages - and a atcenst concegtion of soctaty were the tnotives which ocenditionied toe apperance of this soctal theosy dering be Modern Ages. Tracied the oryins of this doctrine, the sophiste inclptent deviloponsot can be pentiosed; who deppte Fato's erivism, sropoeod the estublshrent of rocial covonasts in ocdes to avoid trifustico and

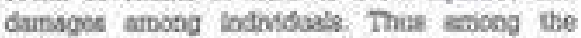
acphisha arnen the ides thet fartice ia a covenaint.

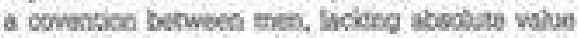
in leseld. Other theorists of law and the Stste, Hiso Michsel Vilen, steens the role of Winam the Ocitam as rogards thels covetanat, In this socse it is possibie is assett that on modern contractualiern, sct wholy potbical infixecices ase perceived,

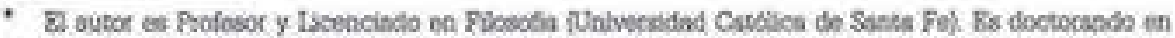

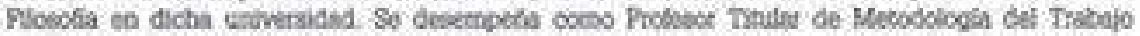

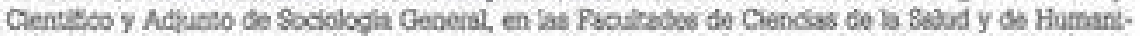
tades, Rducación y Cleocias Soctalos, reepectivamento, do is Uatversidad Advecticta dol Pata. Es

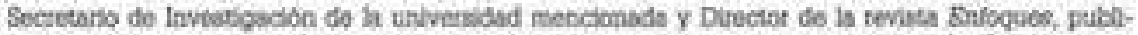

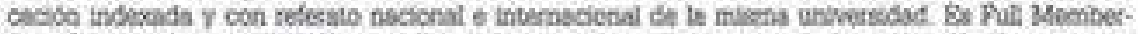

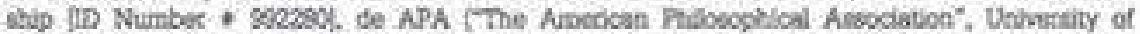

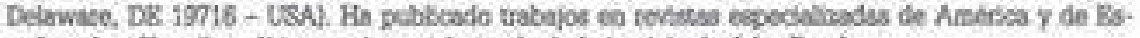
pafa sotro filoeofia polidica moderta y la teerfa do la jueticia de Jahn Rawis.

\begin{tabular}{|l|l|l|l|l|l|}
\hline VIstrTAS & Pocto Alegro & v. 45 & n. 3 & Sotembeo 2000 & p. 417.484 \\
\hline
\end{tabular}


no puraments polinicas proverieotes die ta corbes. te nomiralista fundada pot Ockham. In esta

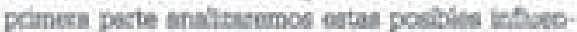
clat do indole tedrica, sobte in tlocolla politica del Maserto de Oxdord. Oetham produce una subver. the madical dol mundo elletco y antiguo. La petencia que ubero bo llego a pet reubeornida pot su pooplo siaterna, sine que orlgino che pluralidad de rendenclas gat in desertolingon coe efi trane. curpo de la Modemidad. En el plano antsopolbaloo este pensamiento is is singulat $\gamma$ is torrens conduio a que ia sulfectidid y el individuo pass. ran a pilmee plano. De aqui los supoestoe plimepes que habrla en Ockham del Sberaliermo moder: Bo. B humaniatso sert et heredero diseceso del peneamiento nominalinta. Bs potable de quo reanera, $y$ particuhemente en el eepirsu bereleico, be fue permoando erta nocita de oestacider cons. tructivista y convenefocilints de los concegeos. Esto condsco a ma afirmación do que no bay cocas buenas o malis en ai misuss, sino solo en virtud de las decretce positives de la voluntad divira. Las coeseccienclas de un pensamiento tal no liggaron a sor asumidns por Ockham, foben man. tenia en vioot is fo en Dion y en su Revoladion. pero, obviamente, sobo too nocesirio das un poquefio paso pot otros pensadores, manos bos.

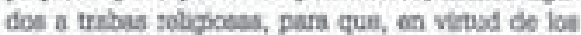
principios borminalistss, Degarat a lus poeldones inmanontiatas qoe cocncenzaron a imumpit en la Modernidsd. Bn el fimbibo de la mocal esto dara arigen al eotablecimiento de can sentido de lo tbico que la oxnciencia modema sdquiete a partir de ia percopeitio de las eoctumbres nociales. La progile. dad, por ejersplo, aparece a partit de la ruptura

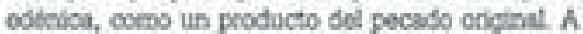
partit de entonces sara nocesario tegularia. A elo dobe sumarse la propla concepelda que tase Ockhean sobue el origen del poder politioo, que et colisea en manos de cada individue, exber lo tecithe de Dios y laepo poctan entre al coeder sal desochos a alputes groe be gobleme. Ad so va formando un sentido corrvecctonal de la motal y do la farticta

PALABIAS CLAVE - Ockham Controctualiemo. Coctrato social: Nominalismo. Socularismo. Pacto social Junticis. Corveneionaliemo. Ifberaliemo. Decoction mubiotinoin coming trom the nominclit curtent fosinted by Ockharn. Is the ferst part, thooe poeshile theoteth. cal infosecoses about the Msiter $\alpha$ Oxford well be analined. Oekhum peoducea a radical aubverilon in the Claseif and the Aneient Work. The power bo libernted cosid not be sully roabecebed by hise own ovetem. On the cootrary. is colginated a plarality of teends which kept developing in the coutse of Modernity. On the serthrogologien fivid, thit thooght about the earthly asd stroplaz made siaboctivity and the individas to be in the lime-

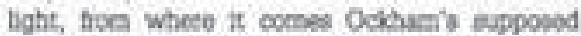
gerrns of modern liberalism. Homanism will be the dinect heit of nominalint thought. It is nemarbablh the way - parteletiaty ia Rritiah apirit - this notion of conseructivist and cocventicoalint pospanation of concepts permeated. Thia leods to Ockharri's asoertion that theve ase no good of bed things in bemactres, but jast as they telate to the positive dectoes of the divire will. The connecguenoes of such thought wese not sisumod by Ockham, who kept alive his twith ta Cod and has Rerntution, thoogh, obviously enoagh, fuet a imsil step by other thinkens less connocted to religious objoc. thora was noedad to - br virtue of nomiralistn palncigles - seach immanestiet positiens which began to burat as Modecnity went on. In the motal fold this wocht give rise to the extablatument of a sense of ethics which is acquited by modem

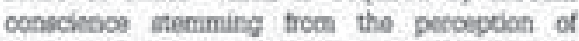
tocid babita. Property, fet tratance, appeam afied the edenle bowking-oit as a sesult of the original Ein. Fiom then an it will have to be pogulated. To all this, it should be added Oekluam's own cooeeption about the origtin of politionl power. which he places in hands of every individual, who recel. ves in froen Cod to then seach in agreereent with the other indviduale in oeder to hand over thets rigttil in behall of somecese who wit rule ove thon This a cosventional serse of moenl and fuetice keepes being locmod.

KFY WorOS - Ockhnen. Contractealem. Sochal Contrace. Neminaliem Seculariem. Soctal Covenant Justioe. Corvertionalism Liberalina Sub. jective Rights 


\title{
1" PARTE: \\ LOS POSIBLES CONDICIONAMIENTOS EPISTEMOLÓGICO- METAFÍSICOS EN EL PENSAMIENTO JURIDICO Y POLÍTICO DEL FILÓSOFO INGLÉS WILLIAM OF OCKHAM
}

\begin{abstract}
"Ahora, un Irundo de singulares precisa, no sollo de una nueva motafisica y de una nueva gnoseologia, sino tam. bshin de una nueva cioncta, cuya certeza se apoye en el conocimlento de conceptos - no de cocas - ptovenientes de objetos singulares; del mismo modo prectsa tambiter de una nueva Folvion, en la cual la polis es reducida a lus singularidodes de loe ciudadance; $y$ de una mueva Teciopia, en la cual la lolesia no es primordisimeote el papa, ni el concilio, sino Ia totahidad de aquebos cue cteen an Jasedcristo* (la negrita es mestaj).
\end{abstract}

\section{Surgimiento, motivos y origen de la teoria contractualista}

Se comprende por "contractualismo" la teorla por la cual se explica y fustifica ei fundamento y la posibilidad de la sociedad a partir de un pacto entre sus miembtos, sea este pacto efectuado en forma exptesa, con un origen histórico determ!nado 0 , por el contrario, ya sea que haya sido tnstaurado en forma implicita en la sociedad y ésta deba al mísmo su funcionamiento.

La teorla del contrato social fue desarrollada en toda su expresion en la modernidad, fundamentalmente jor Hobbes y Rousseau, si bien haciendo fusticla con el aporte de sus antecesores, como asi tambjén sumando los aportes de Locke, Hume y Kant. Ya en nuestra época, seta la concepclion de la fusticia de John Rawls, lo que lo situara como uno de los reptesentantes tipicos del neocontractualismo.

Dos motivos básiocs condicionaton en la Modernidad el desartollo de la teoria del contrato. Bn parte ésta fue producto y oonsecuencia lógica de la creciente socularización en que se hallaban inmersos el Bstado y la sociedad, a lo que debe sumarse el predominio creciente de una concepción atomista de la sociedad, por lo cual ésta era comprendida como conjunto de individuos separados entre sf, a la manera de una relación entre particulas o cuerpos independientes uno del otro.

Bastreando los origenes más remotos de esta doctrina pueden ballarse desarrolloa incipientes en los sofistas, hecho criticado por Platcon, quienes propusieron el establecimiento de acuerdos sociales a fin de evitar injusticjas y daños entre individuos. Asi surgio entre los scfistas griegos la idea de que la justicta es un pacto, producto de una convención entre hombres y caronte de valot absoluto. Tambión los epicuireos asumieron una postura similar y más adolante, en la Edad Nedia, Marsilio de Padua y Nicolds de Cusa, a partir de motivaciones no necesa-

Lais Aliserts De Boci, comerthrio introduadito a Ouahorme de Ocklarm, Logica das Termcs, Vohurse III. Trodupbo de Fernando Pso de Almeids Feck. Introduclo de Paola Muller Purto Alegte: BDIFU. Cres-Ceatro de Estusios Pranciacanos, 1999/, anlapa posterist del Heto. 
rlamente identicas a la antigua y la posteridad moderna. Otros teóricos del derecho y el Estado, entre los cuales podemos mencionar a Michel Villey, colocan et acento en el papel que le cupo en este aspecto a Wiliam of Ockham. ${ }^{2}$ En este sentido es posible afirmar que sobre el contractualismo moderno se perciben infuencias no puramente politicas, provenientes de la corriente nominalista representada por Ockham.

\section{Introducción histórica al problema del origen del contractualismo}

\section{¿Por que Ockham?}

La pregunta a la que aludimos encuentra su mejor respuesta en el ámbito de la filoestia politica; mas prectsamente cuando tratamos de buceat en las taloes de una toorla furidtico-poítica que se nos aparece bajo el sello propio de la Modernidad: me refieto ni más ni menos que al contractualismo, conitructo mediante el cual se intenta explicar la formación y el desarrollo de la sociedad en un mundo tipicamente secularizado y de corte plenamente humanista como lo es el do la Bdad Moderna. Lo curiceo de esta teoria es que, as como tampoco muete en los abores de la edad industrial, ni de la Revolución Francesa, ni, para ser concluyentes, en los confines de la Modernidad, sino, por el contrario, reaperece luego con el profijo "neo" en las últimas decadas dol siglo XX, tampoco es el amblente puramente secular e irreligioso dominante que diesa inicio a la Modernidad su más genuino origen. Lo curioso, una vez más, es que ya algunos siglos antes de los confines modievales, con más precisión durante la primera mitad del siglo XIV. alcanza su completa y plena mayoria de edad en los escritces politicos ly hasta quizás sus fundamentos en los propiamente epistemológicos y metafisicos) de: fraile tranciscano William of Ockham.

2 "Wiliam of Ockhun tob-y dil deseb setb-un teblogo Catclico. Puede esegurnese gue junto a crato.

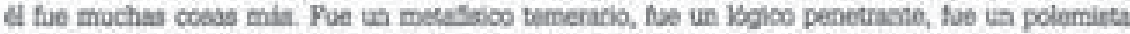

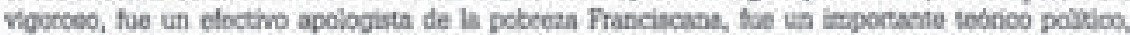

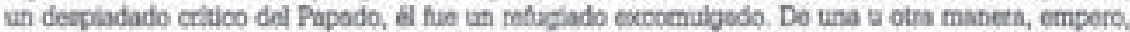

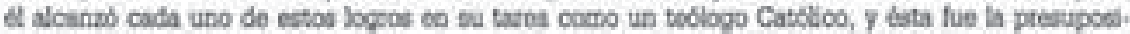

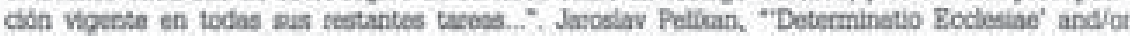

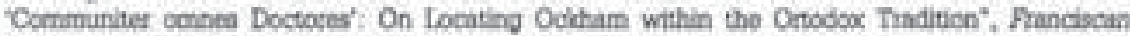
Studies, vol. \%5, 19e6, p. 37 .

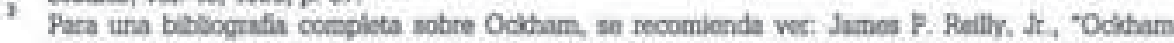

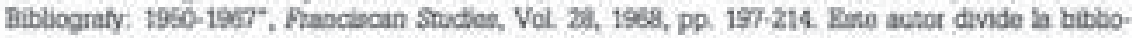

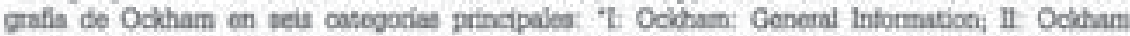

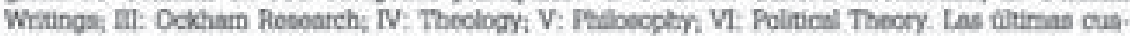

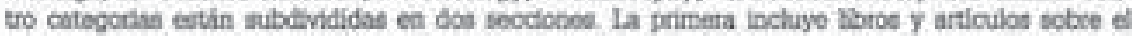
perasmiecto o eruditos en Ocktam. La segunda lista comeoposide a ciestod liteos y articuloe relovantes pars los estudios sobse Ockham", p. 197, Tumbien: A. Ghisalberts, "Biblografia su Gijtel.

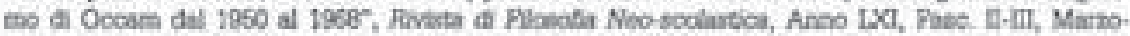
Glogno 1960, pp. 273-284.

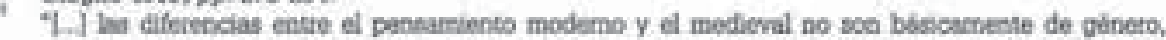
stro de grado . Deode la ara Edad Mectia en adelante, las doctrinas polinicas ae han debido a cotudocos, vedncos y flbitoloe. No ad a lo lingo del peciodo en que so elabocaton las bases de lan teorf: 
La politica, o todo aquello que tendemos a llamar con dicho término, se expreso durante la Edad Mecia dentro de lo que cabe Harnar "la ciencla de la ley", "La ley surgida de los diversos tipos de gobiemo tratabe de convertir en reabidad las metas que se tijaba la sociedad", lo cual no foe sólo privativo de las sociedades cristianas medievales, sino un hecho caracteristico de toda sociedad civilizadia, ya sea ésta pagana, musulmana, fudia, capitalista o comunista. "De ahi que la ley, en cuanto instrumento de gobiemo, persiga una finalidad dekerminada", meta que dependerá de posiciones y doctrinas preexigtentes adoptadas por los gobernantes; por todo esto es que la ley medieval era concebida como el propósito o fin de la sociodad. "Esta concepción de la ley, denomineda teleolónica, fue de suma importancia a lo largo de toda la Bdad Media"' Es éste un punto crucial, que tendra honda repercusión en la posterior elaboración de la filosofia politica modema.' Analicimosio a la Juz del desenlace contempotáneo de la Modemidad, desde nuestro propio punto de vista, comuln, por otra parte, al resto de la sociedad que nos clrounda, lo cual nos permitirá llegar a comperenderlo mejor. Hoy, nosotros estamos acostumbrados a ver las actividades del homike desde un determinado priama, clasificandolas en compartimentos estancos, absolutamente diferencsados entre si. Por ello solemos hablar de normas econónicas, politicas, religiosas, morales, etc., normas todas ellas generalmente diversas entre si, puesto que los códigos que las rigen no son idhinticos, por lo cual se llega a veces a la imposhbiadad de roconcliarlas entre si. Bute fenómeno no ocurrib durante la Bdad Media, es un producto de la Modernidad, con su caracseristica atomizaction de las nocmas que pesaron a condicionar las acciones humanas de

es polsicas poeteriotes. De los siglos $\mathrm{V}$ al $\mathrm{XI}$ son muy pocos ise ausores dodicados a exporer doc: trinas poliecas. No se escribiegon Iboos, tratades al panteces sokse los torias que en todos los tiempos ban constitudo la materia prima del poneaminnto politico. Y clo porque enan las mismoe gobernantes, los papas, teyes y emperndores, quiesen a travls de modidas de gobierno creaban. inlarmaban y aplicaban las ideas politicas. Todn doctrina polbion estaba implicita en las accioces

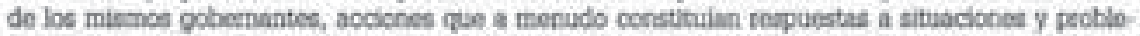

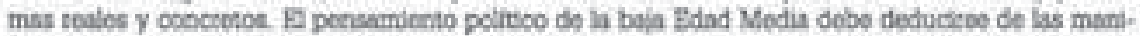

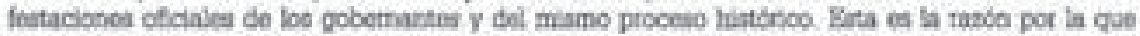
\&s periodo mita temprano do la historia do las jdeas politiclas esth estrechemente pelacionado con la histocia real de la epoca. E vehilculo a travis del cual los osbechartes expresaban sus concepoboces

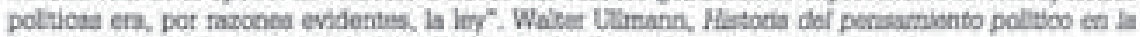
Bdad Modta, Trad de Roea Viaro Pifol, 3r edicica (Burcelora: Ariel, 1997), p. 16.

Ilid, p. 17.

Et un trabajo dedicado a in vietbn de Ockham sobce la Hbertad thint, su auter. Harry Xlocker.

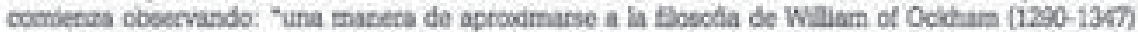

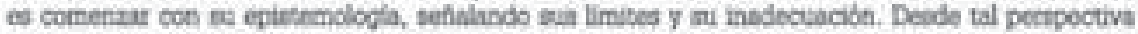

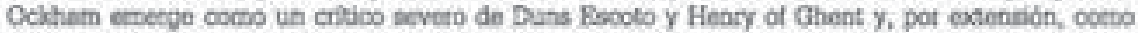

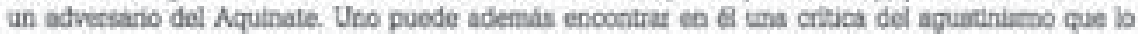
precodis y el cengen de la vla moderna ea el escolseticismo del siglo cotorce... Certumente, hay en

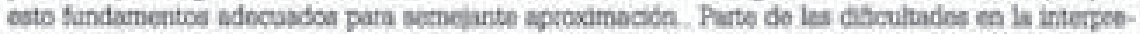

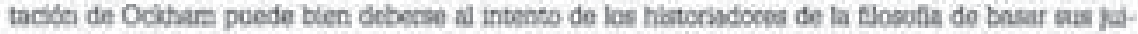
cios sobre sa sbra solamnnte en su logica, la epletrenologla y la metafiuca. Uno puede hablar do metafirica Tominta o de epistemologia Eecotista mucho mis flolimonte coe io que puede decirse

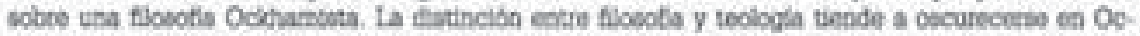

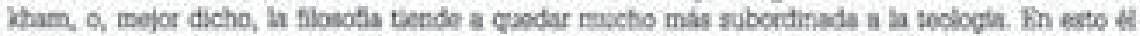
es mis aguetiniano, a pesar do su conocimiento on Aristoeres: Ockham es predominanternecto un

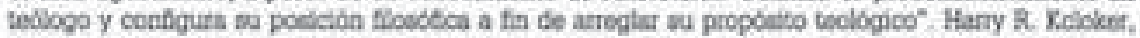

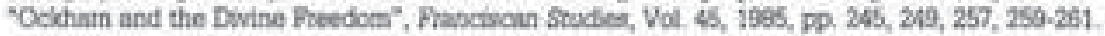


toda Indoie. En la Edad Media no excstió tal distrnbución de actividades en unos cornpartimentos disimiles; una actividad no se concebla desde angulas diversos, tales como el moral, religficeo, econódenico o politico. "La miscna ideologia cristiana se oporia a cualquier tipo de subdivision", razon por la cual la religion no se diferenctaba de la politica, ni de la moral ni de cualquier concepción economica adherda; solo importaba el hombre como totalidad, el hombre cristiano, no ya sus conductas en diferentes órdenes moral, religioso, económico, politico, etc. Sus acciones puiblicas eran juzgadas desde un mismo punto de vista que las privadas, ya que lo que habia, st, eran una serle de normas omniabarcantes que podriamos denominar como "cristianes". Bsta visión omnicomprensiva constituye el principal rasgo a tener siempre presente cuando se tematice la politica medieval, porque ello tendrá su clara y notorla repercusion en cuanto y en tanto se hable de conceptos tales como sociedad, gobierno, ley y justicla, ocnoeptos que, a raiz de tal concepcion omnicompcensiva quedan permanentemente transvetsalizados poc una misma y ünica ideologla, o cuerpo de ideas, si preferimos este tultimo término?

T. I la ley trataba de plasmat en la realidad is idea de fusticia, pero la esencia de tata dependla del punto de vista de cada gobernante acerca de que era lo justo. Las ideas politicas de ln Bdad Media puoden deducirse del contenido de las disposinlones de justicia, y el concepto de fusticla impregnaba y dabe sertido a la idectogia potitica medieval. La idea da justicia me materializaba ea la ley. A partir de ahl es ticil compeendert la cructal importancia que adquiere el problerma de entablecer dónde radicabe el origen del poder, puesto que de cllo dependin el que se conaideraeo a un gobernante capacitado o no para dictar leyes:"

Lo que af es posible hallar sobre los confines de la Bdad Media son los gérmenes de este concepto no iniversalista ni omniocmprensivo de la accion humana, elementos que se van gestando de un modo no deliberado, por supuesto, sino dentro de la propia tradicion criatiana y eclesíastica, y que a veces no han sido sino teorizaciones posteriores a la resolucion, o su intento, de situaciones particulares y concretas, particularmente en el caso de Ockham, surgidas de un espiritu critioo pot excclencla y cue no tuvo reparos a la hora de prepentar sus "singulares" posiciones frente a la tradición docninante. Ya sea que puedan perchirse en el maestro de $\mathrm{Ox}$ ford los getrmenes metafisjocs, y basta teológjoos, de sus ideas politicas, o que éstas tengan, como otros afirman, un crigen pura y estrictamente puntual y concreto, preexcistente, aunque un tanto deaperdigadas en los escritos de los canonistas de los siglos XII y XII, de quienes, a su juicio, Ockham las habila tomado con la finabidad de resolver los conflictos entre la orden Franciscana y la institución del Papedo," y de Esta, luego, con los príncipes que lo acogieron en su scno, lo cierto e insoslayable es que a el se debe el amplio desarrollo dedicado en sus escritos, en los cuales, a pesar de su incursión en interminables vericuetos (propios del estilo de la argumentación y

\footnotetext{
Walter Ulimana, Op at, pD, 17.18.

Ibid, p. 17.

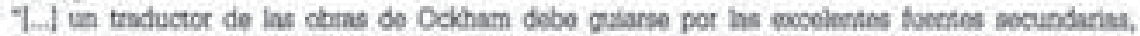

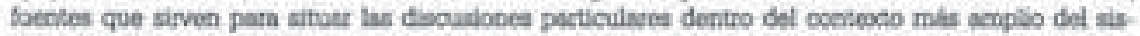

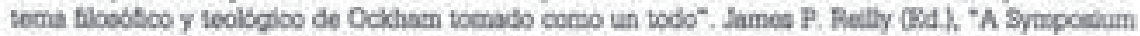
on Tex Bditing and Tranilating". Franciscan Sudies, vol 46, 1966, p. B7.
} 
la metodologia escolistica), no deja lugar a dudas, finalmente, su fillación a una postura que, por ahora - comparada coin las posteriores desarrolladas por filcsofos como Hobbes, Rousseau y Rawls, por ejemplo - hemos de considerar como de "contractualismo modarado e incipiente", basdindonos en un par de elementos basicos, que mencionamos a continuadón:

1. Bl secularismo recién comenzaba a gestarse. Aùn no se habla instalado en los ámbitco intelectuales de la época, aunque si comenzaba a identificarse desde décadas y hasta un par de siglos atrás en la vida diaria de las relaciones laborales y profesionales de quienes habitaban las ciudades, especialmente a pastir del empuje creciente de una clase que adquirin, sin cesar, mayor poder, tanto económico como politico; la burguesta. Lo cierto es que la ideología secular aùn no existla on è terteno de las idoas, pues ústas, pot lo general, eran monopolio de los escoldsticos, entre los cuales el más "osado", a un mirmo thempo que fiel a la tradielon, habla sido Santo Tomás de Aquino." Será

B caso de Toenis de Aquino es nctable, porque tedetcubre a Artentecles, coctinuando la obta

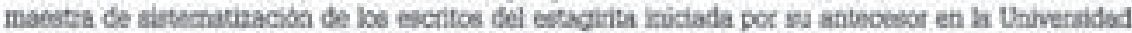

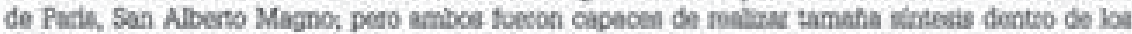

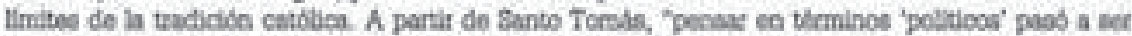

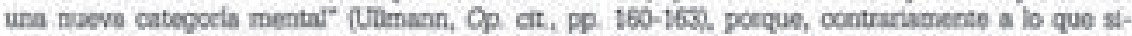
glos mils turdo hard Hobbes, desdo un terreno cultural y cientifico nadicnlmerte distinto, Surto Tomás cotrajo la idea de Batado de la propia notaraleza y ao de un artifloio creado pot el bambre. Pce

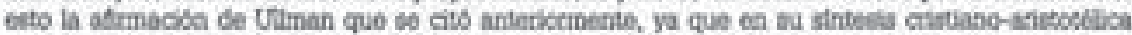

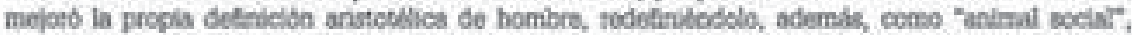

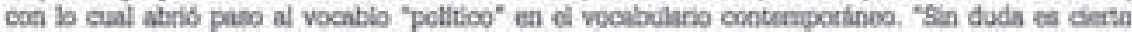
que, como ha dicho uno de las mís eminentes expocisieras en santo Temils, ni antes nil deupote

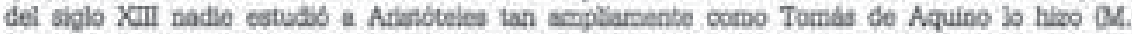

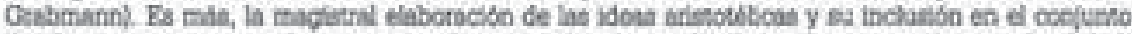
de ideos ceistiano regoeria una mente de oxtraondinaria amplitud, aguda percepeion y probundidad.

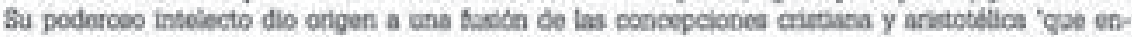
trafisto una infiridad de retiles distinciones on la sdaptacion de una toestia pagana a la coernologla crieting' (MCllwain)". Revid, p. 166.

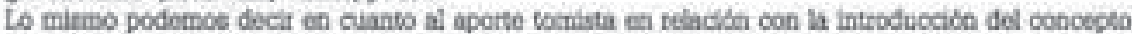

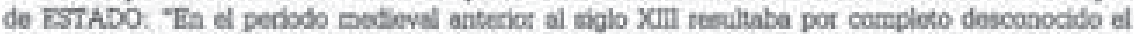

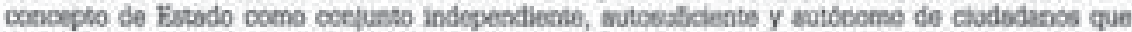

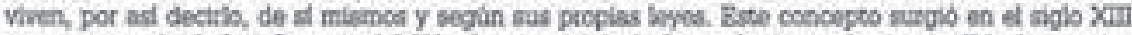

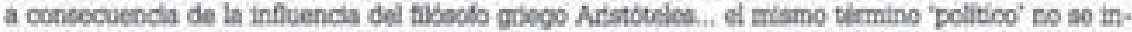
troctujo en el vocabulanio de los gobernantes y eacritores antes del riglo XIII. La ausencia de este

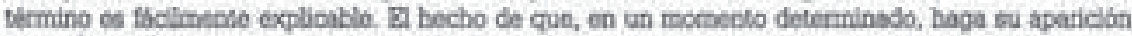

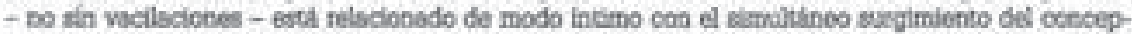
to de Futado. Coe anterioxidad no exatiun nil el conoopto de 'Fstado' ai et de 'polatico'. No se usa ban el thrming 'Fatsdo' al el thrmino 'politico', sino 'gobierno' Gobematio, gribenaculum o guber.

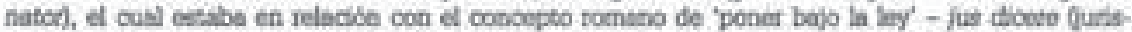

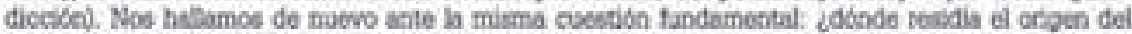

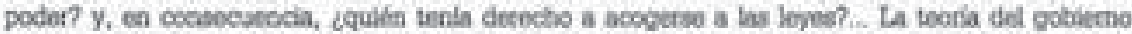
predorninactite on la Bdad Medin, la tresis del podnr desceenderte, no debe, sin emberpo, conesderae.

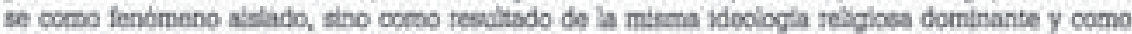

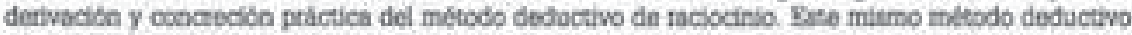

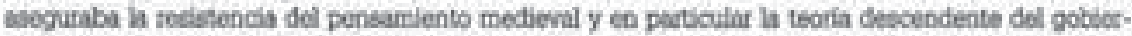
no, por casato a parti da abunos principlos univertales amplismerte conocidos o inouestionablet.

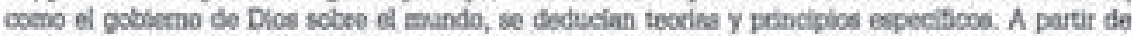

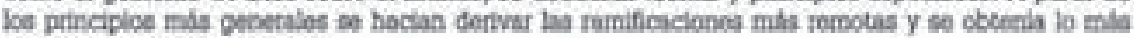
coocroto.... Illd., pp $19 \cdot 20$. 
Ockham, valiéndose en parte del lenguaje de los canonistas que lo precedieron - seguin la tesis de Brian Tlerney" - uno de los mayotes responsables de inteloctualizar, dándole un cierre formal y en languaje propiamente escolástico a un movimiento que ya habla comenzado a materializarse en las masas populates. Bsto to hata dentro do la perspectiva do tres conceptos claves, mojones del secularismo, a la vez que germenes de las nuevas ideas politicas modernas: a) su concepto de separación de poderes, temporal y espiritual, doctrina que desarrolla ampliamente en su obra politica; b) su noción de detechos subjetivos, en conjunción con su concepclón del surgimiento de la propieclad a partir do ia entrada del pecado en el mundo con Adian y Eva en el Bdén; y c) su énfasis en la soberanla del pueblo, fundamento de todo el esquema contractualista y leit-motiv del humanismo que contrae en si la esencia do esta doctrina, hasta su culminación on el individualismo moderno y contemporáneo. A estas tres ideas podra sumarse, según la hermentutica adoptada pot el conjunto de su filosofia, un campo más envolvente y base de los conceptos antes mencionados; nos referimos al ocupado por sus escritos de indole epistemologrica, metafisica y teolígica, campo de sus ideas fundantes que serin en gran parte objeso de cliscuarion del presente trabajo, a fin de analizar la ligazón entre estas ultimas áreas del saber y el exclusivamente político, dada la integralidad y sistematicidad que será imposible de hallar en el conjunto de la totalidad de sus escritos, en caso de ser factible el establecimiento de tal conexión.

2. Paralelamente a este desarrollo del secularismo debe tenerse en cuenta las numerosas marchas y contramarchas, avances y retrocescs, en que se alternaban las teorlas ascendente y descendente del poder, según palabras del historiador ingles Waiter Ullmann, quien en su obra ya citada (A History of Po. litical Thought: The Middle Ages), afirma la necesidad de adoptar un enfoque genético de la historia a fin de desentrañar el origen más temoto de las ideas politicas actuales y los porqués de sus desarrollos."

Comenzaremos por desarrollar primeramente este último aspecto, para luego sf, internamos en la maraha de interpretaciones referidas al enlace mentado y finalizaremos con un breve repeso de los tópicos más relevantes de su fllosolia politica, con la intención de que el lector pueda sacar sus proplas conclusiones a partir de lo expuesto, tratando sjempre de que lo haga a partir de un hilo conductor formulado por el autot y las pistas que intentan delinearlo.

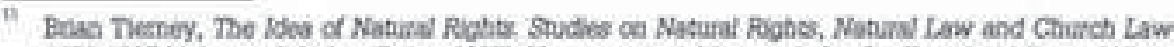

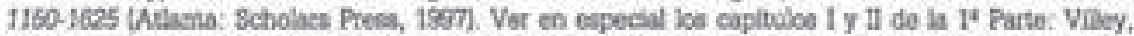

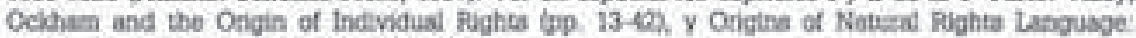
Texts and Cocteds, $1150-1250(50,43-77)$.

totnann, op ot, D. 13.
} 


\section{Preparación del caldo de cultivo: la teoría politica medieval}

Dijimos antes que fue Santo Tomás de Aquino quien le dio el gran impulso, durante el siglo XIII, a este nuevo uso del lenguaje y categorias del pensamiento como lo es el lenguaje politico. También sethalamos la importancia que el pensamiento cristiano adquirió a partir de la sintesis lograda pot el Aquinate y lo bien logrado que resulto su descubrimiento del estagirita griego del siglo IV a.C. Lo que quizds nos viene quedando en el tintero es la razón de set de la respuesta tomista y la esencia misma de su respuesta. Lo cierto es que una vez pasado el agitado periodo de invasiones de los pueblos bárbaros a Buropa, con su consigujente fragmentación del antiguo Imperio Romano, sobrevino una nueva preocupación: la de lograr una sociedad ordenada y pacifica, la regulación de la vida pública, la

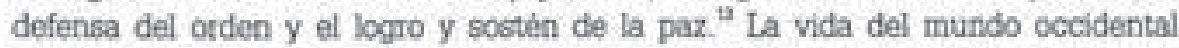
conocido vuelve a sumergirse en la problemática politica, como habia ocurrido en los aibotes de la cultura griega, donde habla llegado a set una problemítica báisica e ineladible de los cludadanos de la polis.

Ulimann, profesor de Historia eclesiastica medieval en la Universidad de Cambridge, sintetiza breve y en una suerte de explicación longitudinal, la constante puja entre las dos teorias medievales que intentaron dat una respuesta valida y coherente a este problema politico que comenzo a plantearse en el medioevo, el cual no es otro que aquell acerca de ómo se Dena el espacio del triángulo formado entre los tres vértices claves de la politica: el poder, la ley y la justicis:

"El bocnbre simrpte se ha pregruntado de dónde ptoventa ea ditima instancia el poder en materia de asuntos publicos. ¿Oué es lo que confere su fuerza a la ley?. histocicamente hablando, en la Edad Media predominaban doe formas principales do gobserno y de legislaction. Ambas coexdetieron, mas segin las epocas prestomino la una - la orra. Una de estas concepetiones del gobierno y de la ley, la mis antipua deede el punto de vista cronológico puede denominatso tooria escendente. Su principal caracteristica consiste en que el poder reside originalmente en el pueblo, en decir, en la mie. ma comunidad. Batr eta la forms de gobierno quo Ticito describib al folatar cómo so gobernaban las tribus germinicas. Puesto que el poder reaidla originalmante en el pueblo, oth lote quien es sus asambleas populares elogia a un jofe para la guerra, un ducue, un reg, ete. Dicho jele no tenia más poderes que los que la asamblea electoral le babla concodido. Se le corarlderaba como represontante de la comuridad.. En con. secuencia, existia un derecho a rusistirse a las ótdenes det gobernante en tanto que dirigente. Brte derocho de tesistencia explica in faclidad con que era depuesto y aparta. do un rey al, en opinión del poeblo, habla dejado do regresentar su voluntad. Metaforicamento habiando, el poder ascendis desde in amplis base de la piramide socint bas. ta su vértice, ocupado por el rey o duque ta asamblea popular controlaba el goblerno de sa dirigente y do becho actuabe sobse todo como tribunal. Bsta tecria ascondento del gobberno puede denocninarse también teoria popular de goblezno, poeque el poder tesidia, en su ocigen, en el pueblo." 
Trente a esta forma se dabe una concepcidn descondente del poder. B poder teside onginalmente en un ser suptemo, que cce el predorninio del Cristianismo se jdentifico con la misma divinidad. En ol siglo V, san Agurtin habla dicho que Dios daba sus leyes a la humanidad por medio de los reyea, $Y$ en el siglo XIII santo Tornis de Aquino expreso la miema idna al afirmar que el podat descondla de Dios.. Cualquier forms de podet que se diera 'mis abajo' provenia de 'arniba', puesto que, como dijo san Pahlo, "no existe mas poder que el de Dios". Pocernos hablar aqui tan sclo de poder delegado. Bra Dias quien designaba a un regkeseatante echte la tierta, y do hecho se consideraba que este representante encarnaba el origen de todo poder. Seguin esta concepción, ei pueblo no tenia más poder que el que se le habla dado 'deede arribe' y no por eloccion de una astembles populat. Ouien desempenaba la dignidad suptema era tan solo reoponsable ante Dioe. Bsta toocia del gobietso puede denomirarie también teocrítica, porque todo poder residia en Dios."

"La histocia do las ideas poitticas en la Edad Media ea en gran medida la historia de los conffictos entre estas dos toorias del goblerno... la teoria ascendente fue, por asi dectito, entertada pata no volver a emerger como posiedón tedrica hasta tines del saglo XIII. A partir de entoncos, In teorla doecendente de gobierno desaparecio progresivomeate de la stiperficte de la vida poitica hasta tal punto, que en la actualided tan solo quodan algunos restos:"

Como ya fuera señalado antes y tal como lo deja entrever el fin de la cita, no hubo, hasta bien entrado el siglo XIII, pensadores que se hayan dedicado a formulat explicitamente la teoria ascendente del podet. Asi ocurrib hasta que entre los siglos XII y XIII comienzan a surgir los primetos conceptos emanados de los doctores de la ley candrica," para confluir finalmente en las ideas politicas divulgadas por Ockham, durante las primeras decadas del siglo XIV, especifica y particularmente a colación de sus disputas con los papas de su époct, tomando partido a tavor de su propla orden franciscana y sus principes protectores, contra la trodicion establecida de la Iglesia. Lo cierto es que, además de estas, sus obras polttcas por excelencia, que en su momento repasaremos aqui, se especula con la existencia de un completo armazon de la totalidad - 0 casi - de su obra flosofica, en la cual su metafisica y su epistemologia, y hasta su propio pensamiento tooldgico, habrian sido una formulación teórica $y$ abstracta de sus ideas furidico. politicas (prácticas, en definitiva), lo cual venia a completar ni más ni mence lo que le faltaba a ese confunto asistemático de ideas que conformaban la teodia ascendente del poder. Bste sistema que aquil mentamos tesume su nombre en una

\footnotetext{
Bud, pp. 16-15.
}

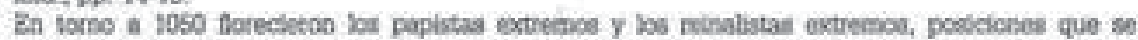
mantecian vigorosamecte hacia 1300 . Ba el sigle Xi hubo un gran conflicto enteo Jglesta.kitado

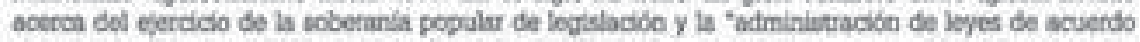
con un sistema taciocal de furispeudencia". "La intea defenas toctetics disponibie del poder mo-

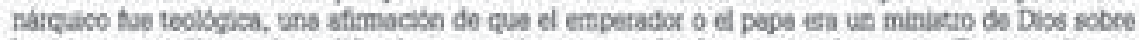

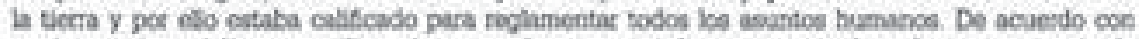
pepirtas e imperialistas wus discuedeens ectahan, por lgual, entecamente bandas en una serie de

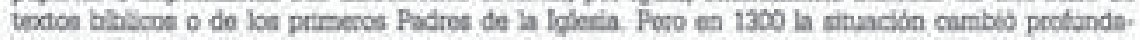

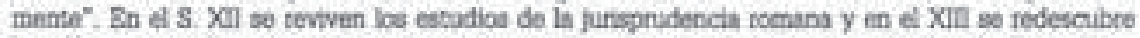

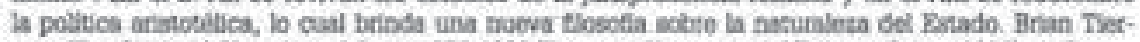

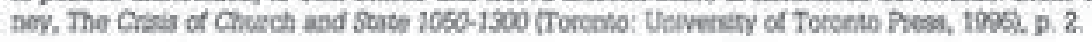


sola palabra: nominalismo, el cual - esto debe quedar bien claro - no ha sido un invento de Ockham, sino que el simplemente lo habria adoptado y adaptedo a su ptopia coemovisión.

Debe ser dicho tambien en este momento, que doe importantes escuelas de interpsetación se han disputado, durante la segunida mitad del siglo XX, la correcta cornprensión de la verdad acerca de esta supuesta conoepción omnicomprenetve de la flosolia de Ockham, especinlmente lo tocante a la relación entre la politica y el resto de su floeotla: 1) por un lado esta la escuela frarcesa, encabezada por Michel Viliay", quien afirma fehacientemente la continuidad entre las ramas tedrica y practica de Ockham, y por otro, 2) esta Brian Tiemey" como peincipal exponente, quien riega dicha continuidad, dejandole de atribuir a la obra politica del llamado Venerabulis Incoptor" la mayor parte de su oriffinalidad, al asentar su tesis de que las fun. damentales ideas juridico-politicas de las que se nutrio ya estaban en los escritos de los canonistas que vivieron en los dos siglos precodentes. Pero más adelante nos decticaremos a tratar de esclarecar esta mencionada polérnica; sólo nos interesa mencionarla a modo introductorio.

Como veremos, Villey dio origen, ya sea delberada y directamente o no, a su ptopia escuela. Más corca nuestro, en el tiempo y el espacio, comentando la edición en lengua portugruesa de la Lógica de Ockbam, Luis Alberto De Boni astimila esta idea de las ralces protomodernas del pensamiento epistemologico-politico de Ockham, al tiempo que adhiere a la interpretación formulada por Vibey, en una cita que transcribimos a continuación, mediante la cual no pretendemos demostrar nada, sino simplemente dejar clertas evidenclas de lo exctendida que ha llogada a ser este tipo de interpretación:

"g mundo moderno, como bien atimb H. Blumenberg, en su clásico Dio Legitrmutat der neven Zett, se inicíb como una ruptura oon la Edad Media. Tal tuptura habris acoctecido en acquel momento quo acostumbramos a caractetizar como el inicio do la modernidad, y que tendria en Descartes como su principal tepresentante. Todos concuerdan en que la modernidad signified una ruptura; con sodo, surgen hoy cada vez un mayor nùmeto de voces diacordantes, en lo que se telere a la fecha. C. Mensching (Das Allgemeine und das Besondore: Der Unsping dos modernen Denkens im Mittola?. ter). y tambiein J. Goldstein (Nominalismus und Modeme), muestran quo algunas contenas de affos antes se produjo una guifada, en la segunda década del siglo XIV. cuando Guillermo de Ockham ensentó en Oxford."

"La subjetividad, las implicancias facionalistas y empiriatas de la flosofla burguesa, Joe compcoentes irrociconalistas del muindo moderno, el poestivismo de varias cien-

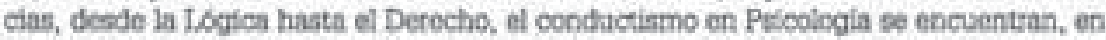
su argumentacion fundamental, anticipados en la obea del Venerabils lnooptor."

In

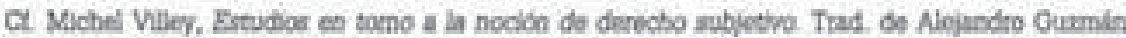

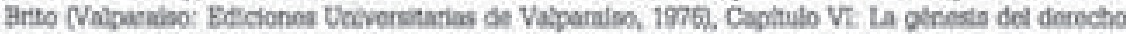
Euhjectivo en Gutllormo de Occam, DP. 199-190.

सt

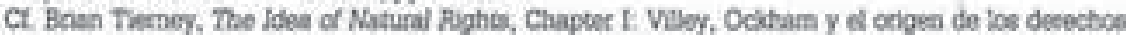

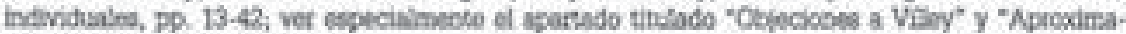
donos altertativas" : p9. $30-42$

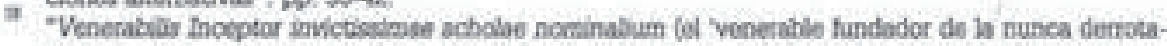

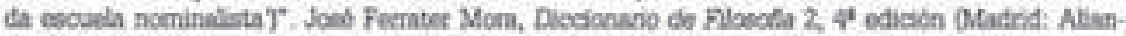
za, 1962), p. 1404 
"Al afirmar, en todos los niveles, ha peimacis del sthgular en su absoluta tadicat. dad (nulle natura realst est communtr), el estaba dejando atrats toda una tradición fliosotjca, en la cual, gracias a los resabios del platceismo, teservo un hugar peiviogiado al univecsal (OSgico, gnoseolibgico y mecafinico). Ockham, pot asi decif, fetoma a Platón. pero para subvertirla. El ser verdadero no so encuantra més en el mundo ldoel, sino en la singularidad de cada coea. Lo que ediste de hecho, en la realidad, fuera de la mente del sujeto, son los singulares. Con este presupuesto, el universal pierde la consisten. cia, adquiriendo una reatidad objetiva solo en la mente tumana que lo plensa. El probleara, pues, no 66 descubrit codno el univessal esth coctonido en el singulat, sino ex. plicar como es que el aingular, que es lo inico que realmente existe, poede engendrar en la mente, $\gamma$ tan sclo en ella, of universal."

"Ahoro, un mundo de singulares precisa, no edlo de una nueva Metaflesea y de una nueva Onceeologia, sino tambien do una nueva Ciencia, cuya certeza se spoye en el cococimiento de conceptos - no de cocas - ptovenientes de objetcos singulares: del mismo modo precisa tambien de una nueva Pollitica, en la cual la polls es reducida a las atngularidados do los ciudadanos; y de una nueva Teologla, en la cual is lelesia no es princlpaimente el papa, ni el concillo, sino la totalidad de aquellos que creen en Jo. sucriato:"

Bn definidas cuentas, el propósito de este articulo no consiste en la confirmaescrn de la viablidad de una u otra interpretación - y menos aún en la intención de pretender inclinar al lector hacia una de éstas - sino apenas mostrar algunas lineas interpretativas capeces de sefalar postbles caminos de comptensión, y en todo caso si, exponer ciertas y claras evidencins de continuidad entre la fliación politica del contractualismo moderno (y hasta del neocontractualismo rawlsiano) con el reptesentado por Ockham a través de sus escritcs politicos. De paso, queremos adelantar que se trata do un conjunto de obras, estas útimas mencionodas, por dernás complicadas y harto dificles de comprender si no se las analiza y compara en conjunto, donde unas quedan confirmadas poz lo dicho en otras, dificultad esta que evita el propio Ulimann cuando en el Pretacio del 19bro citado, aludiendo a su no inclusidn de San Agustin ni de Ockham al escribir sa Fistoria del pensamiento politico en la Edad Meclia, a través de un periodo que prevee contemplar los diez siglos del medioevo:

- El objetivo quo me propuse fue el do ofrococ una exposicida genética del pensamiecto politico que se gesto en la Edad Media y que, ea consecuencia, infuyo poderceamente sobee el mundo moderno y contribuyo a conifguratlo. Bs por lo tanto compreasible que haya insistido en especial - y sobee todo en lo referente al periodo mils primitivo - sobee las medidis do gobiemo oficinles y somioficiales que nos muestran cofeno se traduclan en la práctica las ideas pollticas. Por ollo no be dedicado ningún capitulo en eapecial a san Agustin, aparte de que otrecer lo que podriamos denominar un esquema simplificado de sua ideas 'politicas' resulta slempre peligrcso, porque se presta a confustones. Es mis, para comptender odecuadamente su pensemiento hay que estar familiarizado con sus propine premisss teoldgicas, lo cual no cabe en una descripcton del pensamiento politioo medieval. Como es ibgico, he concodido la debida importancis a deteminados olemeotoe aguatinianos. Bstas mismas advertencias son vibidas reforidas a Guilermo de Ockham a fines del poriodo estudtiado - para aprecler jastamente su 'pansamiento polldico' es prectso estar famillarizado con su noninalismo $y$ su propia

Lus Alberto De Boni, Logtos dos Termos, Volume III, solapas acterior y poeterior del Zbeo. 
toologia. Al marpen do esto, se está trabujando todavin en la proyectada edición de sus trabajos polítlocs, que debe constat de siote volimenes, do los cuales, hasta el momento," solb han aparecido los tres primeros" pa inalica es nuestral), ${ }^{\text {II }}$

\section{La navaja de Ockham y el surgimiento del espiritu laicista}

Bien sabido es que lo mas conocido del pensamiento de Ockham se reduce a su nominalismo y teoria de los universales, la jógica, su concepción voluntarista de la ley natural y sus ideas teologicas, aquello que constitiye lo que podemos llamar su "pensamiento especulativo". Mucho menos lo es su pensamiento polltico y la posible relación entre éste y aquél. Lo cierto es que sus ideas respecto de la sociedad y la politica tevelan su fliacion a una época de la floectia que se cerraba, dando lugar a una intelectuatidad que poco tiempo mis ha de apasecer en el mundo como radicalmente nueva y cualitativamente difetente de la época anterior. Tal "revolución de In mentalidad", como lo exprese Casstret," tuvo lugat entre el apogeo de la concepción clásica del derecho y el que sirvió de trasfondo a la elaboración del Derecho Natural Modemo."

Sobre esto da cuenta Paola Muller, en la introduccion que escribe a Logica das termos, de Ockham, de la relación entre la "navaja de Ockham"it y el luego tan utlizado "principio de economla":

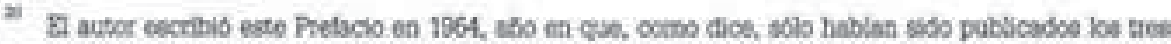

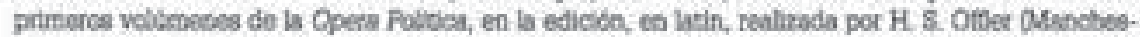
ter. Manchester Uehwersity hress, 7950 . Hasta la focha ya so han publicaso cuatro voldeneces (to-

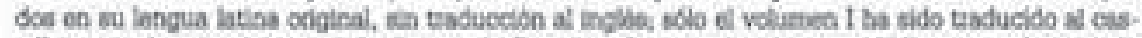

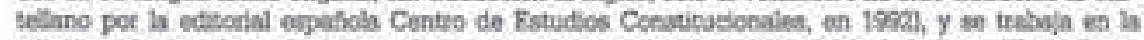

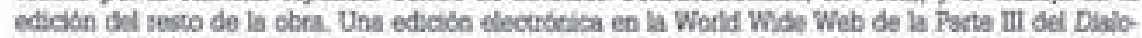
gus, traducido cemo Wainm $\alpha$ Ockham, A Letter to the Fran Mincr and coher Whinings, ed. Anthur

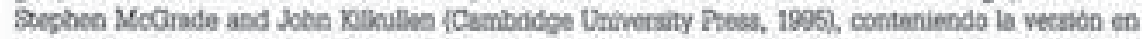
toseo latino con es traduccisa paralela al ingles, esta siendo realizada por John Kicullen y John Scott pata el "Comite de la Academia Britinica de Textos Medievales". Bt etio URL de finternet

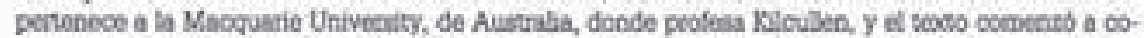

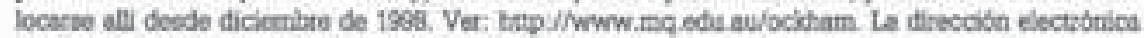

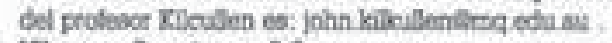

Ulimann, Op at, isp. 8-9.

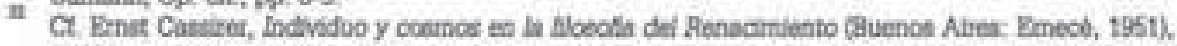
D. 160 .

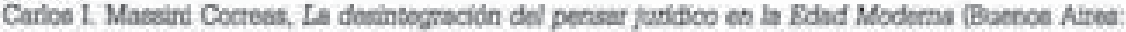
Abelodo-Pertok, 19600, p. 43.

*

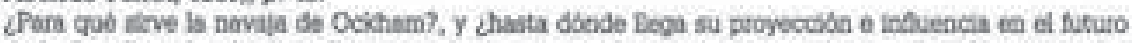
de la foeofis y dembs disciplinas que tenen algin tipo de relactob coe la betafistca? A responder equs pieguntsa que planteamos aqui se obdica Alex Obver, en un apartado de en trabajo que ba

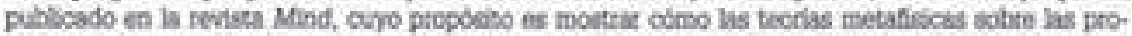

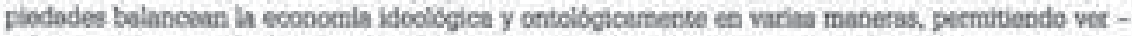

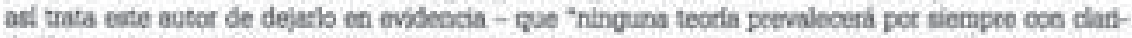
dad", pero leasnos al progio austor sokete la que el mirmo exprese al tospects:

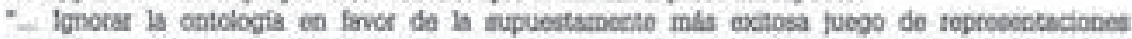

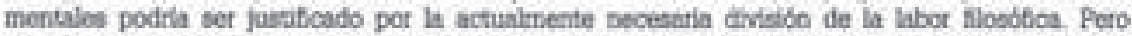

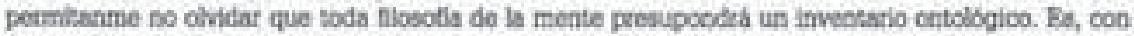
frecuencia, simplemente asumido, por ojersolo, quo hay ptopiedoder mentales. Asursalo si lo

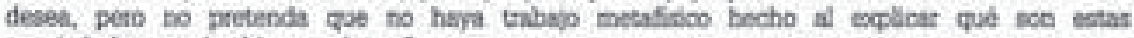
progiedades y qoe to juogan estas," 


\begin{abstract}
"Bn esta perspectiva, donde reina abeoluta fidelidad a la singulandad de 10 roal y al vaJor owcrgado a ta experiencia, se inserta el principio de eccoomla, comúnmente conocido como 'navaja de Ockham": no debec mulipilicarse los entes, st no es neceesario Inp. Asta es la formulacion tradicional, que no se encuentra en Ocicham, quicn afima "se bace invitimeate con muchas cosas, lo quo so puede hacor con pocat cosas". I. o sea, deben preferirse las explicaciones mís simples antes que las mís complejas. Tal principio de economia levi a Ockham a un rigocime del discurno filosbfico sobse el ser y a bacet criticas a las peineipales poeicicoes de la meraflsica clitsica: desde la nocion de sustancla hasta el principlo de causalidad, la causalidad final. R1 conorpto de mustancia, taticalmeate singular, no sepresensa sino una realidad desconocida, de la cual conocemos apenas las cualidades, que son manifestas en ta experiencia sonsible. Anticipando en cierto modo a Hume. Ocicham instste sobre el becho de que, del cooocimiento do un efecto, no es posible de modo alguno alcanzar la formulación del principio de catualidad an abeoluto, ni. pot otra parte, es poeible descender del conocimilento de la causa al conocimiento de las efoctos posibles, s éstos no funran anteriormante experimentadca., =
\end{abstract}

\title{
Dificultades de interpretación
}

La trascendencla especulativa adquirida por el pensamiento de Ockham en torno a la cuestión del origen de la conoepción contractualista de la sociedad, estarla dada, básicamente, y para decirlo con Villey, por su adogción de una posición nominalista en gncseologia y metafisica. Junto a ello y camo loggica consecuencia, se destaca el cambio de perspoctiva, en materia de tecria del derecho, que supone la inversión de la epistemologia vigente, cuyo desenince se verá claramente expresado, mís adelante, en la gnoseología cartesiana. Corno dice Gilson: "ya no se irá del set al conocer, sino del conocer al ser; de la res medieval se ha pasado al cogito de

\footnotetext{
"La motafaica ha sobrevivdo a numetoece atentasos de asesinato. Ba lumado de Hume a quemat

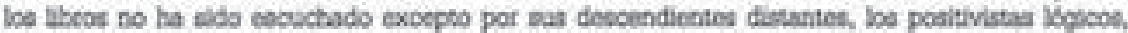
aya buta toutral do la metassica puso de rebeve un poco de disprecio maocio. Ahora lo que ae

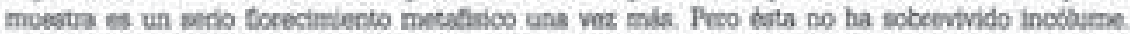

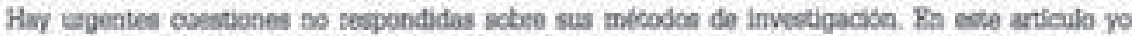
mocstro un finente de inpocer alglin oeden en algunos debates que estin actualneste vivos dentro

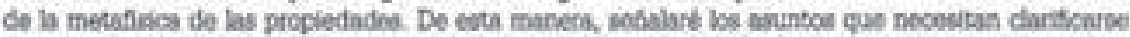
y lsa cuectiones que necestag tesponderse. Viries de estos asurtos y cuestioces bo sce espocifcas para la metafisies de las propledader, pero tienen una splicacibe mis geveral. Trambila este astoub es bectamte sobre metafisica, que es tara y got deberis set, coeno es deta es solacion cen las

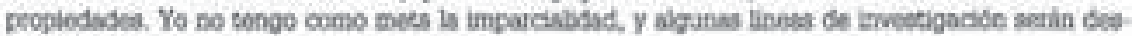
atendidas:-

Una tecis metaflsica tiene dos pectes: la cctologla y la ideologia. La oritologia consiste de las ea.

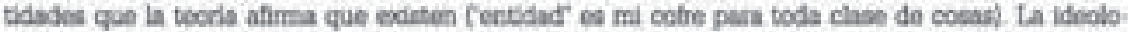
Gla constiste de las ideas que sen expesedes en la teocia usando prodicadoe. La clatificación de las entidndes dentre de ostogorias ontológrios er un asunto idoclibion, predicadoe, semejantes coeno '- Es un corjunto', sen usodos para afirmar a culi critegecla pertenece ena eeridnd. .

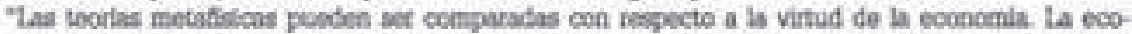
ponta ontelogica de una tocila es modida par el numbero de encidedes cactro de esa ontologia. La

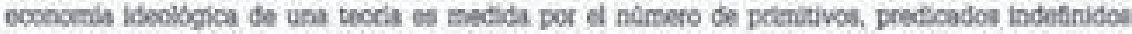
denteo de ena idoolocla. La tecela cra mayor economia ontolbgics sera preforida porque uno munotra no croer en la exastencia de entidades que no tengne buenas razoces..". Nex. Otwer, The metaptrintes of properties", Mend, v. 106, a 417, dan. 1996, p. 1.80.

Paola Mulles, introduglo a Ouflherme de Ockcham, Logica dos termos, pp, 21-22.
} 
Descartes"." De una visión como la medieval que, partiando de los objetos, la realldad extramental, se podia captar en ellos una verdad valiose, se pasa a otra en que es el sujato cogncecente quien percibe un objeto conocido y desde alli (la conciencia) es capaz de concaptualizar la realided. ${ }^{2}$

Cabe insistir aún más, sin embargo, en que tal intarpretación acerca de la interdependencia en el pensamiento de Ockham entre la epistemologia y la metafisica, por un lado, y la politica y la ética, por otro, es bastante discutida y sus comentaristas no se han puesto de acuerdo," Bntre quienes se decilicaron a annlizar esta cuestion acerca de si Ockcham apliob el nominalismo y los aspectos mís relevantes de su epistemologia en su concepcion de la sociedad y de la politica, podemos citar, entre otros, a Lagarde lLa nalssanoe de leesprit laique au décilin du Mojen Age, Paris, 1934 y Gullaume deOccam et la dibmocrate religieuse, Paris-Lovaina, 1962). Mc Grade [The Political Thought of Wisam of Ockham. Parsanal and institutional princlples, Cambridge, 1974]" y el mencionado Viley ["La genese du drott subjetif chez G. $\mathrm{d}=$ Occam", en Archives de philosophie du droit $D X, 1964,97.127$, quien bo afima enfaticamente, asignindole a Ockham un lugar primorclial entre los que produjeron el cambio de cosmovisión y su repercusión en el derecho y la politica, observando la infuencia que el maestro de Oxdord ejerció sobte Suárez, Grocio, Hobbes, Hume y Rousseau, en sus respectivas concepciones del derecho, concebido como facultad personal del individuo." Antony Black, quien destaca a Ockham como "probablemente, el teorico medieval mas dificil", "reconoclendo la gran dificultad que hay en su interpsetacion, por el contrario, cree que el acento puesto en el individuo, en materia politica y juridica, obedeceria mas blen a situaciones concretas, tales como su necesidad de reivindicar a las personas a rafiz de la disputa que mantuvo, ocmo representante franciscano, sobre la pobteza, lo cual lo habria llevado a entender al derecho natural on términos de prestogativa individual. Segin dicho intérprete, Ockham no estarla sirno haciendoee $e c 0$, en una disputa furidica concreta, de conoeptos que ya manejaban los juristas de derecho canonico del siglo XII, quianes

涉

st

$\mathbf{z}$

3

Masaini Correas, Op cit, p. 44.

Loc, et.

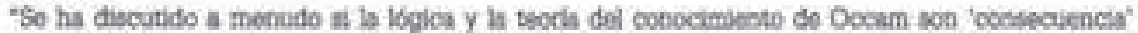

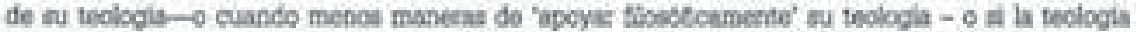
mirma es resultado do la logice y de la tecria dol conocimbienos. Bh todo caso. estas doe altumas se

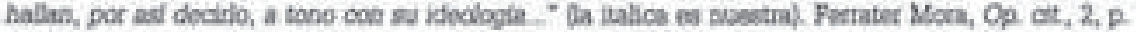
1006.

"Este autor, por su parte, cree que en wu confunto Ocibarn es apolitico, se chatante tener una propia concopcide potitica, bo cae le lova a considerar la misma cbea de Ocktham como cosidional o

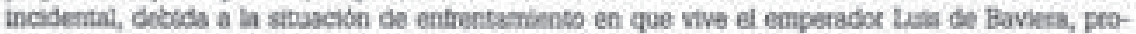

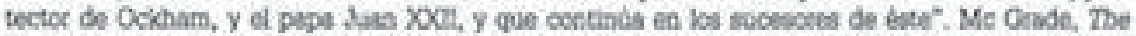

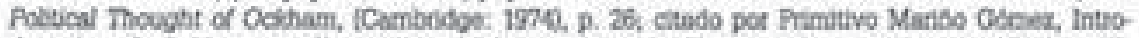

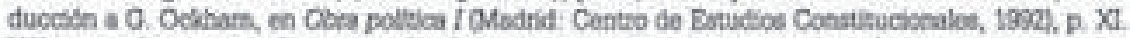
Videy se sefere, particularmense, al infojo que tuwo el nominalismo sobte el normacissmo moderno, lugar que comparte junto al lagalinmo religices prosente en la Tarah fudila, et ogurtiniamo juridi. $\infty$ de la atta Bdnd Modia y el pensamiente redormados, Villey, La pecenoton de ha Lat et du drat

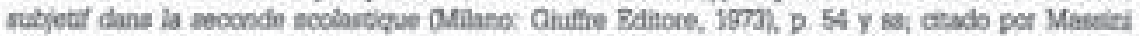
Cocreas, Op at, p. 35

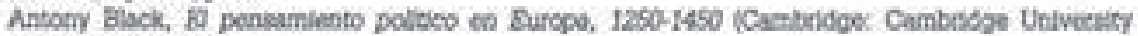
Prebe, $19561,2.110$. 
empleaban cotidianamente el vocablo ius al designar una facultad legitima. De todos modos, reconioce Black la influencia que tales sdees tuvieron en la formación del persamiento modemo, epoca en que estará plensmente instalada en la conciencia furidica la nocion de derechos inherentes a las personas."

"Ockham hablaba de ley o derecho (lex/lus) natural do una manera que algunos han considerado original, pero que resulta muy dificl de interptetar. Algunas cosas eatain claras. Hablaba - como hicieron algunos otros - de dorocho natuzal como constitutivo de la base de las relvindicaciones mocales de las personas, sin tenet en cuanta su estatus social o potitico. Tal vez debido a la disputa franciscana sobze la pobteza, tendia a ectender el derocho ratural en terminos de prentogativa individual Y. en particulas. Dios ha dado a todos las humanos dos derochos concrotos que posson por noturaleza. sin tener en cuenta si aco cteyeates cristianos o no: la libertad y la propiadiad. Los dorechos de propiedad dopenden en la prictica dol derecho a reclamer la posesión de uno en la ley lius forth Ockham empleaba el lengruaje de 'derechnce y libertades', que efa emploado en las cartas y documentos semejantes para describir los detechos posttivos otoxgados a grupos o personas o reclamedos por tstos, corno una tórmula para doseribur "los derechos y las libertades concedidos a nosotros pos Dice y la naturaleza'. La idea do unos detechos subjetivos inhesentes a las personas en un sentido notable. mente 'moderno' paroce haber sido desartoliada en peimer lugar por las furistas de desecho canónico en el siglo XII. 'El eerploo cotidiano do fus para designar un derecho. una facultad legitima, infectaba el languaje de los canonistas cuando tenian que eocribir de lus naturale' (Tiemoy). Acaso sou portble ver en Ockham una idoa do las loyes humanas de los Estados fejes ctviles y penales como formadas por la suma de los derechos individuales..." (as itslica es nuestra)."

Al respecto, Lagardo seťela cómo es posible ver en Ockham la jidea de que las leyes civiles y penales se constituyen por la suma de los derochos individualeg" "(se trata de una interesante anticipación de la filosotla de Robert Nozick, por la cual Lagatde puede tomar crólito aun cuando su interpretacidon de Ockham fuera exagerada)" "A estos comentarios de Black, quien en muchcs puntos sigue la posición de Tiemey, podemos sumar los de James Keenan, en su resehla del libro de Tiemey (The Idea of Natural Rights), donde criticando la posicibon de algunos autores contempordineos, como Maclntyre, por ejemplo, quien segin Keenan habla del "sustento irracional de los derechos naturales", afirma que "... Tambilin Leo Strauss y sus discipuios pintaron a los filbsofos del siglo XVI, mientras que otros, como Michel Villey, sehialan a Ockham y su nominalismo y voluntarismo como los fundamentos de este muy irracional y privado reclamo":

Mid, p. 62,

Did, pa. 61.62

* Ta eociedad humana, por la interaccien de cocvenios, pactos, acoendos, conosetones, tranelonen. ciss, dotisciones de todo tipo, que be hath acouldo una a otre dende el peinciplo de las tentroces, ba

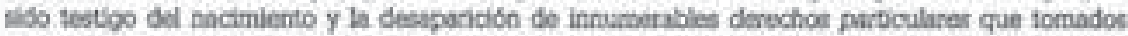
en conjunto cocatutuyea of dorecho civi. Toda la ky peivada y publica se resume, pues, en un complejo de decechse partsculares". Lagarde, Naiscanos, wol. VI, pp. 179-209 en p. 208, citado pot Back, Op ale, p. 62 .

N Black, Op at, p. 62

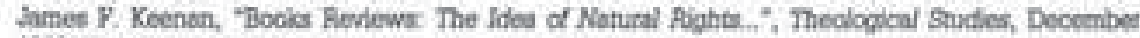
1996, Star Page: p. 729 
Therney no niega que Ocikham tuvo un rol importante en el desartollo de los derochos naturales, poro il cambla sus tupuostas coroxiones con el nominalimo y el vo. luntarismo Prancigcano. Sobve el nominalismo, Ockham no lo conecta nocesarlamente con los derechos, y como Tierney seftals, cualquier tilcootla que teconozca el valot de la persona individual es coirpathle con los derechos naturales. Sobee el voluntarismo. Teeney sotala dos puntos importantes. B concuetda con eruditos tales como Marliys McCord Adams, quien insiste an que Ockham presume que la voluntad divina aunco serd caprichcea, peto siompte razonable y comptentible. Asentar una dicotomin entse

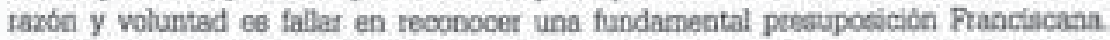
Terney ademis acusa que doduct una teoria palitica de una teologla de la voluntad de Dios "es una clase de extrapolación imaginaria'. Fara Ockham las voluntades divins y harnars son incomparables. Bn Dics, voluntad e intelecto sca tndistinguibles; todo bo que Dice desea es justo y cortecto. La voluntad humara, además, puede elegri entro of bien y el mal, adomán teta nocosita ser gulada por la tazbe. Ockhsm ha basado su posicion sobre los derechos naturales, entonces, sobre la condicidin humana, no sabve la voluntad divina. La ensekanza de Ockham sobte el podor sbsoluto de Dioe fue sim. plamnnte irrelevante para los argumentos que if ha desarrollado en sus escritos polit. cos:":

-Si el nominaliseno de Ocicham y ol voluntarismo no fuercen las foentes de sus es. critce sobre los derechos naturales, ¿cusles tueron? Aquil Tierney nos lieva a los cano. nistas del siglo XII e instate que courrio 'un cambio decitivo': miettras que los estol. coa y Cicerón reciamazon que la las naturaie era la universal y objotiva ley aatural reconocible por los setes humanos, los canonistas la dofinieton como una fuerza subjet: va, facultad, o poder inberente en la persona hamana individual. Preccupados por peoteger a los individucs, estos primeros canonistas deaarrollarou liss primeras exprestones de los detechces naturalea, no de argumentos vahuntaristas que invocaban la voluntad divina como expresada en la revelación cristiana, peco desde una concepción antropol6gica de la peteona como racional, autoconsciente, y mocalmeate responsable. De becho, coctrariameate a los reclamos de VIloy, Strausg, Maclntyre, y otroa, Ia socledad medieval estaha saturada con un interes poc los dorechos: *

"Cuando Ockharn, Junto con otros Franciscance, debatio con ol Papa Juan XXII sobre la pobteza evangelica, dotechos de propiedad, y gobierno politico, el tetorno a la jurisgrudencia creativa del sig'o XII. Bstos escritos furidicos que Cckham se apropio dentro do su édica no positive fueron la fuente do sus argumentce sobre loe dorechos naturales. $Y$, como en les trabajos canónicos, el dictado de la razón dorrina la totalidad de la argumentación."

"De acuetdo con Tierne\%, entonces, los derochos naturales se originaz en los es. critcs candricos medievales, desartoliados significativamente en el debate Franciscano sobre la propiedad y la pobeeza, y que Dorecieron en loe debates de loa concliaristas" (la negrita es nuectra)

Bn detinitiva, la mayoria de estos intérpretes si bien sehalan la dificultud "en pretender a priori la posible infuencia", no es posible negar que su etapa poltica tue condicionada por la anterior filosbfica y teobodica, aunque tampoco se pueda afirmar categóricamente lo contrario (al son de VIley y su escuela). Rs más conveniente hablar de "evidencias" que muestran la mencionada relación. Nociones tales como al derecho de propledad y de dominio, derecho divino y bien comùn. 
su idea de Iglesia como cuerpo mistico - grupo, no sociedad, conglomerado de individuos sin personalidad furidica - ropercuten en su politica, todo lo cual Deva, al menos, a tener que matizar la tesis de autores que ven el pensamicnto politico de Ockham desvinculado do su pensamiento especulativo y teológico."

Comentando la obta de Tiemey, The Idea of Natural Rights, Kenneth Penning: ton se retiere a la amplitud del area de conocimionto manejado por Tiemey, destacando que el atributo de enudición que la gran mayoria de sus comentadores le conceden se debe a que incursiona con igual solvencia en campos tan divergentes como la filosotia, el detecho, la historta y la teologia:

Diferente a la mayor parte de las discusianes antericoes, el libro de Therney chrece un Eutll, erudito, y panoramico tetrato de la evoluctón historica de los derochos en el pet. samiento furidico y teoldgico. Su libro representa el valicso servicio de determinar la actual discusićn sobse las derechos dentro del mís amplio conteoto que puoda ser halisdo en las conternportneas decisicnes de las cortes, leglshacianes, y ta jurisprudencia"

Lo que Therney intenta es realizar un racoonto sobre la evolución y el desarroDo de los Damados "derechos subjetivos", cuyo origen localiza en las escritos de los juristas del siglo XII, enunclando lo acontecido a partir de las controversias que tuvieron lugar entre los siglos XIII y XIV, oon su consiguiente reavivamiento de la jurisprudencia, y con su desenlace en las disputas religiosas entre los papas de la época, pot un lado, y la orden Franciscana, por otro. Segün palabras de Pennington "por primera vez en cualquier lengua, Tierney nos ha dado un argumento sustentado en ómo se desarrollaron los derechos y las tazones de por qué el pensamiento sobre derechos no murió en su planta", con lo cual (Tierney) es capaz de lograr "una satisfactoria y cohetente historia de la emergencia de los detechos en el pensamiento Occidental" " A esta altura de la exposición conviene que sigamos por si mismos algunos de los textos más categónicos del propio Tuernoy en cuanto a esta cuestión del origen de los derechos y su supuesta inserción en un sistema flosóbico complejo y omnicomprensivo:

"Michel Villoy ha sostenido, en una extensa serie do publicacionos, que el vordadeto 'padte de los derechics subjetivos' tue el tilbeolo Franciscaso del siglo cotorce, Willinm of Ockham. Evidentemeate hay aqul espacio para una pasterior clarificación historica. Aun ctra atea de actual desacuetdo coocierne a la relacion entre las modernas tectias sobre derechoe y las más antipuas doctrinas sober la ley natural y 'el derecho natusal clasico'. Algunos ervditos wen los dorectios aaturales esoncialmente como extrapoia. ciones de principlos inherentes siempre a la tradielón de la ley natural. Bsta ha sido la postcidn de Jacques Maritain y mis tecientemente de John Pinnis. Otros, especial. mente neo-Tomistas como Viley en Buropa, y los seguldcses de Leo Strauss en Amo. tica, niogan vehemantemante cusiquies clase de asoctación entre las dos áteas de

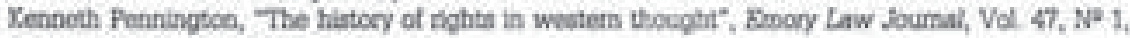

Loc. et.
} 
persambento." Escritores de este ulltimo orupo ven las teorlas di los derechos modesnos conso radicaimente destructivas de la antigua tradicion; elcos scetienen que, después de Ockham (o Hobbes, o quien sea el tanovador elegido), los detechos vienen a conformar las boses reales del discurso moral y que la ley natural ha sido tomada como algo meramente derivado, exactamente una suma de derechos individuales. Otra aproximaciben, que nosotros encontramos en las faentes medieviles y que podria auxliarnos a explicat alqunoe textos modernos, sugierea que los derechos naturales y la ley natural no son derivados uno del ctro, pero que ambos son detivadoe coeno doctripas conelativas de una miema concepción łepal de la perscalidad humana Bn esta modalidad de pensamkanto so asume que la Joy natural pormite a los individuos una eafera de autonomia donde los derechos inharentes a la naturalezs humana podrinn ser Boitamente ejercitados".

A pesar de los elogios vertidos por Pennington" sobte la obra aladida de Tierney, es posible notar en su visión - que intenta ser lo más analitica posible - la carencia de necesidad de hallar una cosmovisión (visión omnicomprensiva) en los autores medievales flo mismo que ocurrira también con los fllobotos modernos oontractualistas citedos), marcada por su fuerte tendencia - propia, por otra parte, de la mayorla de los eruditos profesionales de la historia - bacia las descripciones atomistas. Vaya esto dicho, obviamente, sin que tengamos que poner en tela do juicio su tesis fundamental de que gran parte de las ideas politicas y furidicas de Ockham estaban pre-contenidas en los escritos de los canonistas de los siglos inmediatamente anteriores; ello seria totalmente innecesario, ya que ni siquiera aportaria algo a favor ni en contra de la negación de la teais de Viley.

Vayamos ahora, a fin de fustipreciar el peso de ambas tesis propuestas, a lo que podriamos calificar como breve sintesis de la posicion de Villey al respecto,

* Para una meoha de este asunto wer V. Black, On Consacting Natural fughta Wich Natural LaW', Persona y Derocho 22 isec: $183-209$

- Tierney. The ldes of Netural Rights, DP. 3, 4-5.

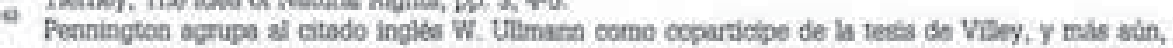

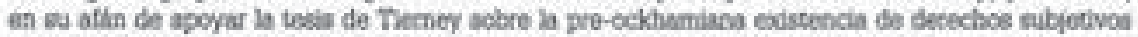

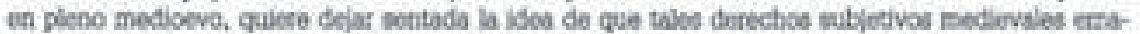

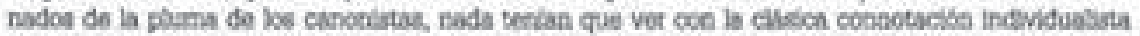

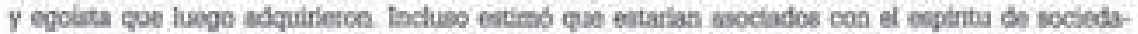
des comunirarias, al modo de las que hoy eusgen como modeice criticos de las mis puramenve libe-

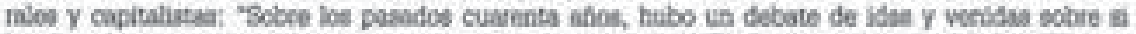

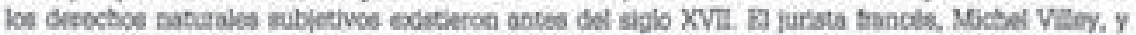

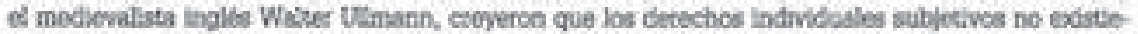
ron antes det final de la Bdsd Media. Main secientersente, Knut Wolloang Ndrt y Jean Gevodernes

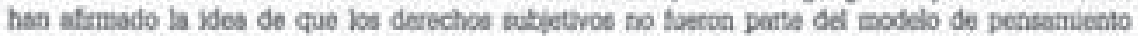

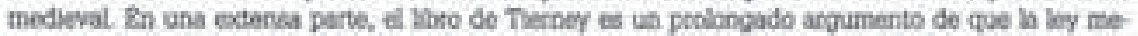
dieval conteria un ooncepto de derechos subjottvos. S Thersey esth in bo corsecto, la primera concladibe imporname que podrla ser desentratoda de este becho es que ke derection subjetivon no

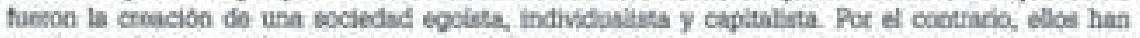
tenido una laspi estadis ao el pensarnierto Occidental. BI concepto de derechos kurgis en socieda:

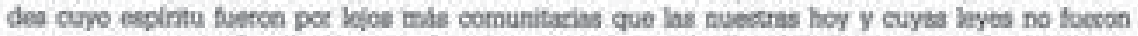
tan cercanamente identibcadas con la voluntad de la nacidin-Batads". Poniningtan, Opa cat, Start Page: 2.237. 
tan criticada por Tierney y comentaristas de su obra " En las citas de ambos autores sordin resaltadas con neyrita acuellas frases que constituyen el núcleo esencial de la polémlca entre las interpretaciones opuestas. La sintesis que presentamos se inicia con una comparacion entre el nominalismo de Ockbam y la clencia aristotélica, a partir de lo cual se habràn de erigir filosoflas politicas y juridicas (segùn Villey) sustancialmente divergentes:

- Los puntos de partida acn tadiealmente opuestca. Mientras que la Ciencia de Ariatoteles es 'de lo peneral', lanzada en persecusión de ideas gerserales, y se basa en un orden 'obmico' (del que puode inferirse la nocíh tomana de fas), la Clencta segin el Nominalismo gravita airededor del individuo. Sollo el individuo esta dotado de exis. toncia fal, \&l es of unico antro do interits, el salo es ol objeto autintico do noestro conocimiento, de saerte que no puede haber otto orden jurldico sino en el ouden procedents de la voluntad individual."

"De la misma manera, toda actividad debe teader bacla el individua. De ello se sigue que Guillermo de Occarn no puede hacerse cargo de la idea que siontertian los cilaricos sobre el obicio del Derecho... No ooncibe ia justicla 'particular' o especifica. La parte fusta en el Nominalistro, no es sino un fantastma sin fealidad "

¿Cual puede oer para Occam el tin del Arto juridico? Me terno que no pudo foxmarse una idea preciss, puesto que no tenla la ides de un orden social supraindividual: ese orden carece para el de toda reatidad. A mensodo fatrara a los modernoe la definicion do un campo espocifico del Desecho. Occam no puede imaginat, partiendo del Nominalierno, stho un Arte tesdiente, no a la busqueta de una armonia en la cludad tomada corno fin en st, sino solamecte al servicio de los individuos, orientado hacla la utilidad particulat, lo que presagia el utiltarimo del penaumiento furidico moderno, que viene a negar al Durecho toda fronteca precisa. II fin buscado parece ser el asegp. far al individuo las condicicnes de una vida bibro y plenamente individual: auncue noes parezca lo contranio al cticio del Derecho, el asegurarbe, tanto como sea posible, las ilbertudes y los poderes a los que el individuo aspira "

"Asi, la doctrina de Occam se encuentra con b que llamibamos "el punto de vista del particular'; es dectr, la tendencia de las particulates a liberarse de las trabas del Detecho naturnl objetivo, a desplegar libremente sus actividades, que ha faclitado el descrden de la Alta Edad Media y que encontrara su prolangasión en el Liboraliamo moderno. Los bombires de la Edad Media, incolitos, poco formadoe para la absuraceilon, piensin espontanearneate a partir del individuo; sobte las ruinas del Bstado romago han reconatruido burdamerte un tégimen soclal hecho de setiorios individuales, de lo oombinacida de poderes de reyos, de selfores, de visallos. Tpo de pensamiento hasto entonoes informe, como lo hemos dictio, pero que la tilosotia de Occam va a elevar a. nivel de la Ciencia: la doctrina de Occam explica, consagra, justifes estas tendenclas" (la negrita es ruestra).

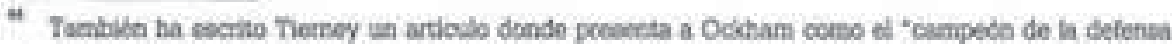

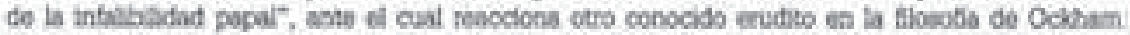

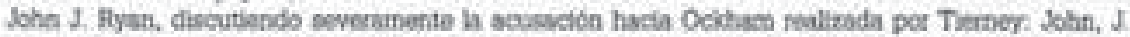

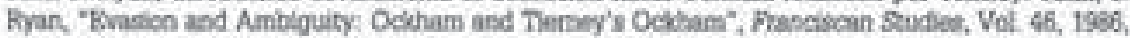

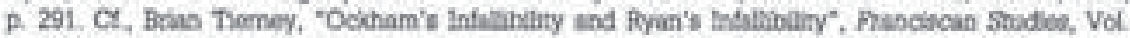
46. 1986, pp. 205-300.

M. Villey, Estudice en tocno a la nockes de derocho mubjetivo, $99,282-183$. 
A esto parece oponerse abiertamente Tierney, teplicando del modo que expondremos a continuacion, desde su misma introduccion a su obra The Idea of Natural Rights, anticipando a sus lectores la discusidin que habrá de mantener contra ef tilosofo del derecho galo en el primer capitulo, titulado: "Viley, Ockham y el origen de los derechos inctividuales" "

- varios filleolos actuales deseantan pegar que haya alguna cova tal como usa naturaleza bumasa universal o comin, una eeencia que precode y antecode bistónicamente'." Yo explicaré además que, en referencia a la naturaleas bumana, oqul y en discusionos subeccuentes, no atritsyo a los autotes comentabos doctrina alouina sobce nirguna 'esencla' abatracts supuestamente inherente en todos los seres humanos ni ninguna teotia particular de loe universaies. Las tectias medievales del derecho po fueron tipicamente derivadas de consideraciones metafisicas. Dusde loogo, ea el curso del pensarniento medieval, básicamente ideds simares sobre derechos paturales fueron propuestas por filleofos - Tornistas, Eocotistas, y Ockbumistas - quienes soetavaton muy diversas viriones sobre los universales y las esencias. $\mathrm{Y}$ en el mundo postmedieval de las doctrinas sobre derechos coratinuaron siendo aceptadss por escritctes quienes habian rochanado ol matco fintegro dol penstumiento escolístico.."

-... Brudtitoe como Micbel Vilay y Richard Tuck han hecho importantes cocatribackones a la discueson de las teorlas medievales de los derechos; pero me parece, pct razones que he de considerar mis adelante, que los atgumentos quo ellos han presentado ro son totalmente adecuados o sarialsctorice...

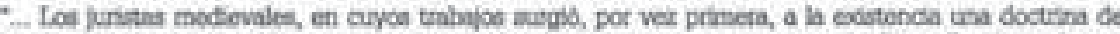

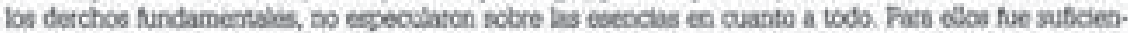

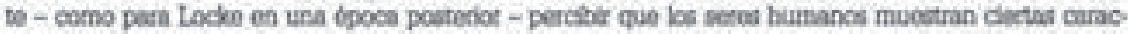

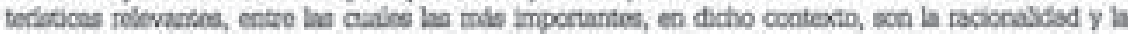

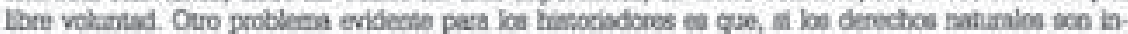

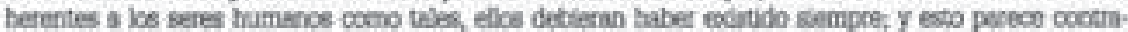

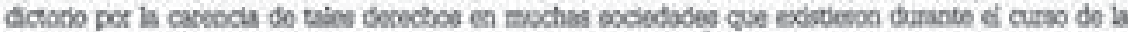

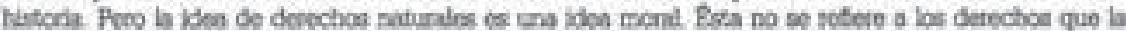

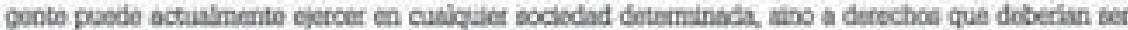

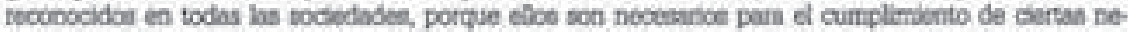

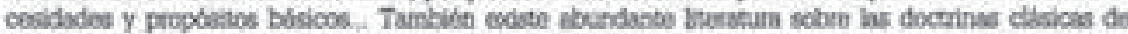

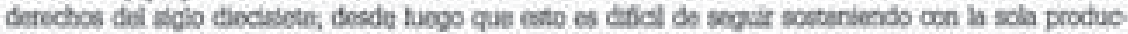

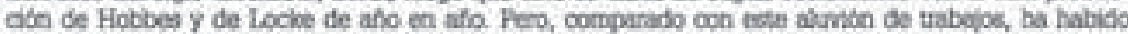

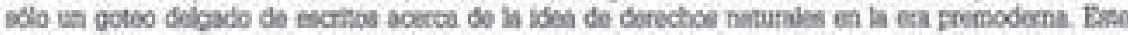

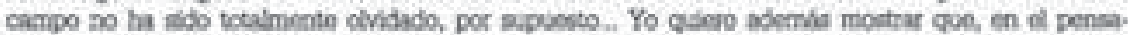

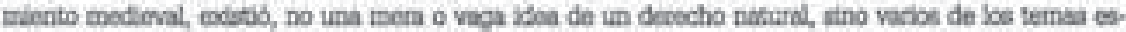

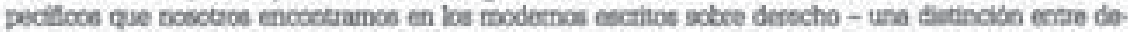

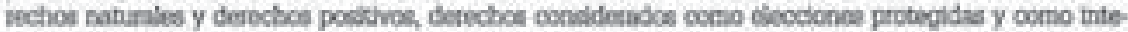
veses protegidos, defechos activos y detochos pestvas, defecheo naturabes alenables y derechos natu.

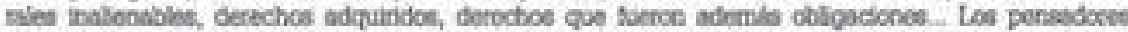

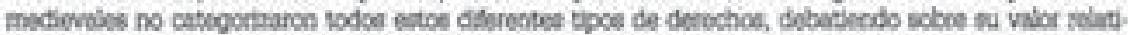

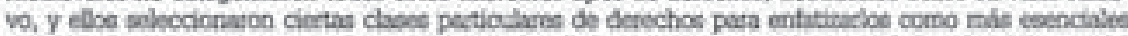

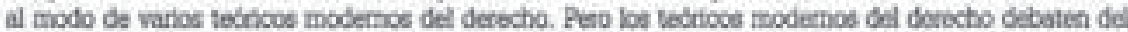

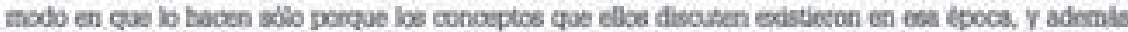

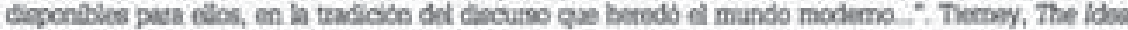
d Nanaral Rights, pp 5,5 y 7

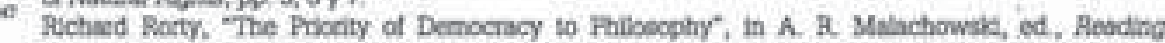

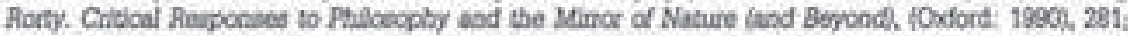
citado en nota al ple por Terrey, The Jdes of Notinal Fighes, p. 5

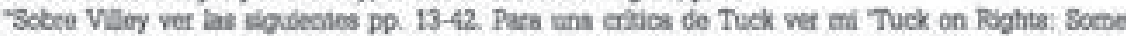

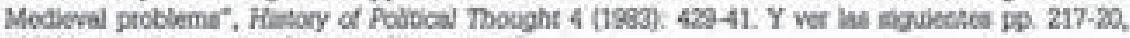
$320-24$ 's citado en nota al ple por Tiemey, p. 7 . 
*i. Tambila, haciendo un Damodo de ateocidan sobre el paraletamo entre las ideas medievales y modernas, yo no tave la intoncidn de hacer comparaciones sim. ples; yo erpero haber becho mbs inteligible a la tradicion completa de pensamiento. Ls cultura politica dei sigto diecistete tue evidentemente diferente de aquella del siglo treco, pero nosotsos no podernos comprender con exactitad calin disotente ha sido, o cdmo Dego a setlo, sin que primero sepamos que el ternprano mundo modemo heredo o se Iesprogio de la precedonte ons medieval. Nosotros no habremos de comprender complotamente coleno una cultura do detechos ha brotado en la sociedad Cocidental hasta que los estuctiosos de las modemas tearias de devechos estin dispuestos a emplear seriamente el considerable cuerpo de materialas que estio ponjendo a dispost: cida - tardiamente quilids - los modievalistas.

"Bntre los enuditos moderno6, probablemeate la exploacion mas ampliamente aceptada del origen de las teorias do los dorochos naturales sea el la expueata por $\mathrm{ML}$ chel Valay, $\mathrm{e}$ ve la ides moderna de derechos subjetivos como una innovación sevolu. cionaria, inspltada por la filoeofla nominahista y voluntarista de William of Ockham. Me libro comienza, ademis, con un estudio critico de la tests de Villey. Los enearyos so. bre la disputa de la pobreza Franciscana conducen a reconsiderat el trabajo de Winiam of Ockham en el conteseo de la vatiada literatura evocada por la controversia. Ockham es presentado en mi trabalo como una tipura importante en el desartollo de las tearias do los dotochos naturales; poto yo sostengo que sus ensetanzas caracteristicas no fueron derivades de su filooctia noeninatiata y voiuntarista, sino, en cambio, de usa ética racionalista aplicada al cuarpo de he doctrina furidica que estuvo dimponible pata el ec las colecciones de la jey canónica que ef conocib muy bien y cto trecuentemente.." Qla italica es nuestrat. "

A pesar de toda la argumentación expuesta contra la tesis de Villey por el eminente historiador Brian Tierney - apenas transcribimos un anticipo de los tomas tratados en su primer capitulo del lobro - a traves de sus dos obras fundamentales: The Idea of Notural Rights y The Crisis of Church and State 1050-1300, creemos que sigue valiendo la pena tomarse el trabajo de conocer y explorar en protundidad la tesis de $\mathrm{M}$. Villey, $W$. Ulimann y otros eruditos neotomistas de no menor prestigio, ya que, una vez mís sea dicho, creemos que la ordenada argumentación de Tiemey no alcanza a desmentir la tesis de Villey, aunçue tampoco a partir de la argumentacjón del vltimo pueda esta afirmarse sin espoculación alguna. El diloma que se plantea aqui es relativamente simple, pero esperemos a des. arrollar el propio contenido del pensamiento de Ockham, para luego intentat dat àguna explicación. Dojemos volar un poco, entre tanto, a nuestro propio juicio, a partir de las proplas palabtas del autor en cuestion y uno de sus más notables traductores y comentadores: Philothers Boehner, OF." quien asi lo introduce en la seincción de textos de Ockham por cll realizada, do la propia pluma latina del maestro de Oxfotd, en sus conocidos Philoscohical Writings:

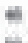

* Theny, The Jdoar of Nabutal Foghts. $50.5,6,7,8$

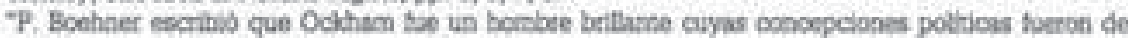
avarizada en su epoca (Tractatus de Succosshiss (St. Boouventure, NY; 1944, P. Boehner, ed) wis

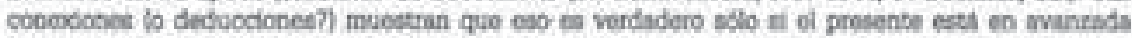
reapocto del pasado*. Mellati, Op at, p. 197 
"Sa filoeofia puede ser caracterizadla por el têrmino de 'erfitca'. Tanto Duns Scotus $\infty$ mo Ocktham rechazan la intorpretación realista de los conceptos iniversales. Puode consideratse a Ockham como la figura central de un nuevo movimiento, conocido como la escuela de los nominalistas (schola via nominatuml. El debate sobce la pobreza constituyb su peopio propdatito poitition, La infortunada mezcla entre politica y teologia Sevob a lit Orden a una gran crats de su existencin y condujo finalmente a Ockham dontro del campo de los enemigos del Papa*":

\section{De la metafísica a la epistemologia y de la ciencia moral a la política}

Un elemento importante que surge a partir de esta revolución del pensamiento que comienza a gestarse con el nocninalismo fue el hecho de la cesacralización de la Jengua. La lengua ínica, el latin medieval, que daba cuenta del Ser y del mundo en toda su dimensión saça, comenzará a ser reemplazada, en tiempos de Ia Baja Bscoláatica, por las lengrues vulgares, que irán desarrolaindcee en cada región, describiendo al Ser en aspectos referenciales, polisémicos y evolutivos, descripcion ésta radicaimente difarente a la anteriot y cue paulatinamente, insuflado por el pensamiento do los nominalistas y sespondiendo a los grandes cambios que iban producténdose en el ámbito politico y soctal, terminatra por despojar a! Ser de su previa caracterización como algo universal, modelo y medida.

\section{Una lógica irrealista de los universales (implicaciones teológicas)}

Bsta desacralización del Ser, con mayúscula, operada por la conciencia nomiralista de las postrimerias del medioevo, se inicla en torno al año 1300 . Fue W. lilam of Ockham el abandetado - más conocido - del pensamiento nominalista, el creador de una nueva eplstemología que produjo radicales cambios, no solo en torno a la comprension del ser, sino en cuestiones tales como la relacion fe-razon, la incumbencia de la teologia y de la fillosotia, el lugar de Dios con respecto a las esencias, el papel de la subjectividad en el conocimiento, el erpacio importante que adquieren las ciencias experimentales y lo que nos inveresa en particular: a partir de sus supuestos eplstemoldgicos y su concepción del ser, el caralcter contingente del orden natural y del orden moral,

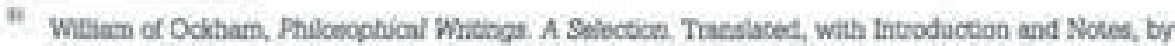

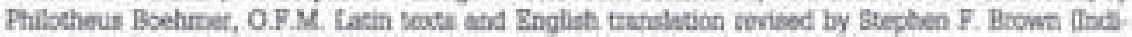
anapols, Indiana: Heckest Publining Company, 1990), Introduction, pp. DX-XIV

u

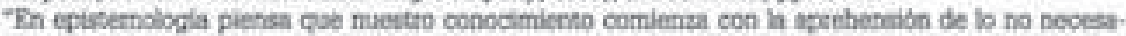

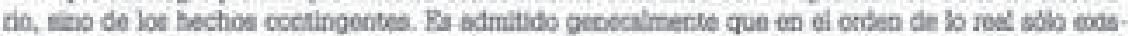

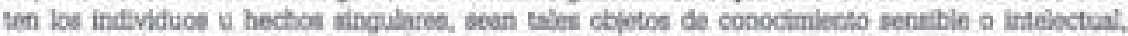

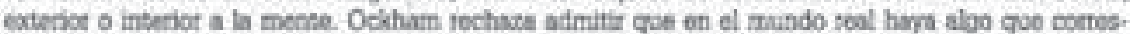

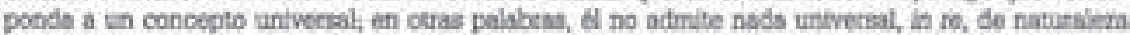

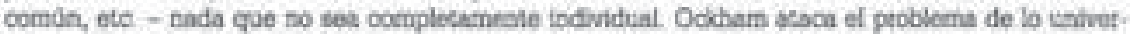
asl desde el lado do iga individuce, un cartiblo de misads tan grande cotno el que se producted a

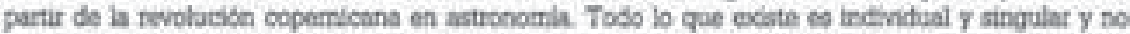

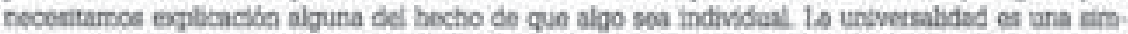
ple manera bajo la casal un conocimiecto sufciectemente gerotalirahlo y abstractivamente poede
} 
También debe destacarse la influencia que sobre él ejerció Duns Bscoto. Ockham conserva las principales tesis metafisicas escotistas: las nociones de univocidad del ser, actualidad de la materia prima, la negacion de ésts como principio de individuacion, la pluralidad de formas, el conocimiento directo del singrlar $y$ la imposibilidad de demostrar la inmortalidad del alma y la ornipotencia, providencla e inmensidad de Dios. Sin embargo, debe ser destacado que su pensamiento no derra fllas con el de Escoto. Detrás de tales similitudes se esconden grandes, como asi tambien sutiles diferenclas con su predecesor, sobre las cuales R. J. Kilkullen hace invalorables declaraciones acerca de tales distinciones en ambos pensadores, tomando debida cuenta de ellas en varios de sus articulos, Jos que por el momento $(06 / 12 / 99)$ solo están disponibles para sus lectores en su págrina web de Internet."

Sin querer abundar en detalles acerca del carácter y alcances del nominalismo ockhamiano", es importante destacar que sa posición no llega al extremo de afirmar, corno otros que en versiones extremas del nominalismo ssumen pasiciones "Terministas", que los terminos o conceptos sean simples expresiones babladas, flatus vocis, sino que tienen existencsa real, sclo que no en el sentido de los conceptos abstractos, en el sentido tomista por los cuales se representaban universales independiontes de las cosas mismas. "Bs posible probar de manera eviderite que ningin universal es una sustancia que existe fuera del alma*" "

En cuanto al principio clasico de individuacion, puesto pot Santo Tomás en la materia sigmata, estara dado, segùn Ockham, en el singulat puro: "Todo ser, pot el meto hecho de existir, es singular e individual en virtud de su misma esencia y no

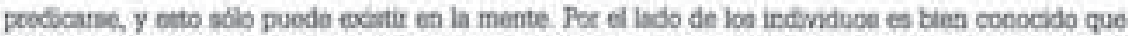

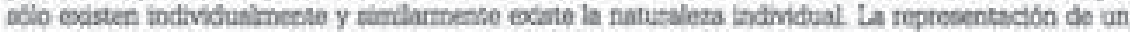
uriveral es lacnada por Dekham como une imajen mental, y por tal razdin no es mis que una So-

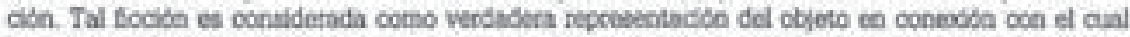

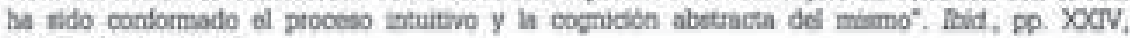
XXVI, XXVIII, XXXX.

Q

"Whether the univertal is toally outside the soul, not teably distinct bom the individual?", tumado de Whinen of Oekham, Ordinatio, L, diat 2, \&. 6. Translased by John Kleuben tom Guifelmi de

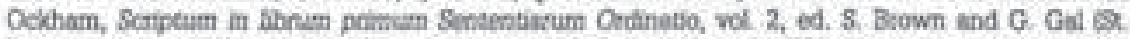

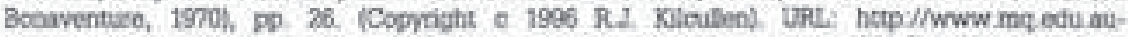

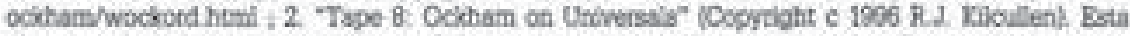
cima toporta sobre el tratamiente do Ockham del problema de los univetbales. Peea segut esta lece. turn unted nocusitari una impteubon de Wiliam of Ockham, Ordinato, L, dist 2, q 6, y Wisam of

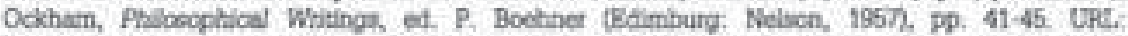

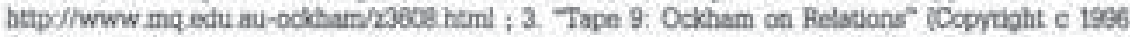
R.J. Kuculen). "Bata cinta tere que ver con la teoria de las relaciones de Ockham, a cuat cocrplementa En tooria de be universsles. Faca sogair eita lectura ustod neceedtark tener dolaste A. Hy.

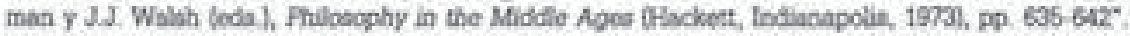
Nota del autoc. URL http-//Www mq edu su-ockham/z3s09 htthi.

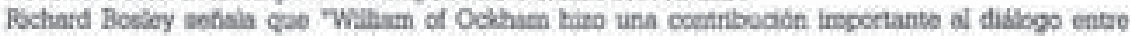

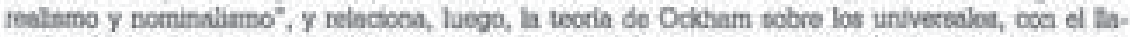
mado "Princtplo Moditicado de Asomismo" (Modiflod Principle of Asomismst. Ver Puchasd Bodey,

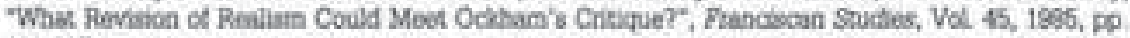
$111-117$.

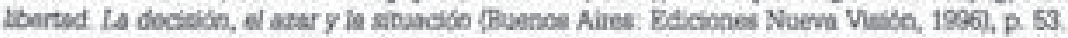


pot algo extrinseco y sobreafiadido" ["Ouaelibet tes seipea est singularis, quia singulantas immediate convenit ini culus est. Etpo non potest sibl convenite per aliquid aliud" .* $^{*}$

"Zin efocto, so puede probar con eridescta quo ningin universal es una sustancia fueta del alma . ningün universal es una sustancis singular $y$ sumericamente una. Ninguna sustancia singular, por tanto, es algo universal, sino que toda suatancin es numbkicamente una y eingular, porque toda sustancia, o es una coes ùnica y no muchas, 0 es muchas cosas. Además, si algo fuese una única sustancla existente en las gustancias singulares y dietinta de eilast, so seguiria que podtí ser sí ellas, porque toda cosa na. turalmente anterioc a otra puede, por la potencla divina, ser sin ella; pero el consecuente es abourdo. Adernits, tal universal no puede ser adminido como elgo totalmente excerior a la esencia del incilviduo, seria, por tunto, de la esencia del individuo, y. consecuantemente, el individuo se compondria de universaies, y, nal, el individuo so estia mas sengulat que univesal".

Entonces cita numerosas autoridades, en especial a Aristóteles y Avicena.

"A partir do esta y de muchas ottas fafirmactonest, se torna evidente que el universal es una intención del alma destinada a ser predicada de muchas [coeas] - Adpmis do eso, la propcaicín no exiete (eet) sino en la mente, ea el habla (in voco) o en la escrituta (in scripto): por tanto, sus partes no exdsten (sunt) sino en la mente, en el habla o en la escritura, poro las sustancias particulates no escsten (suint) de este modo. Fs clerto, por tanto, que ninguna proposicion puede ser corrpuesta de sustancias. La ptopoticlón es, pot entonoce, coenpuesta de univetsales; los univessales no sco., por tanto, subtancias de modo alyuno".

Luego refuta a Bscoto en relación con su afirmación de la excistencia cuanto menos formal del universat:"

"Si blen ha quedado claro que un universal no es una sustancia existente fuata de la mente en individuos y realmente distinta do ellos, aù algunos opinin que un universal de alguna manera excate foera de la mento en individuos, auncue no reaimente, silno solo formaimente distinto de ellos: "w

Para Ockham lo que existe son los individucs particulares, aunque ia ciencla y el conocimiento lo sean de lo goneral, en tanto y en cuanto la clencla esté consti. tuida por proposiciones generales que versan de lo individual: "debe hacerse un u90 minimo de las abstracciones" ["entia non sunt multiplicanda praeter necessttatem"1. El sentido del ser esta dado por su singulanidad. Su dificultad radica en poder explicar la naturaleza del universal. Esta, afirma, solo existe en el alma y "todas las cosas fuera del alma son singulares y numericamente unas" I"Omnis res extra animam est realiter singularis et una numero... "." Tampoco existe dentro

Oekham, I Scot 2, EP.

Ockham, Logia doe Temact, pp. 161, 162 y 165

年

CL. of apartado Boosgerated Ponlinm acd Nominalinm, en Anthony M. Matteo, "Sootas acid

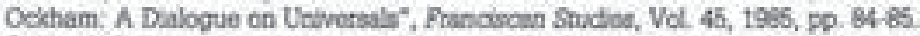

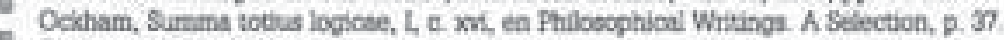

Oexham, $r$ Seet 2,60 
del alma como accidente o cualidad, no tiene realidad objetiva alguna y no es más que una ficción cuyo ser consiste en ser percibido. De modo que el universal puede tener solo tres tipos de existencia: en la mente (como concepto), en la palabra y en la escritura ["in scripto, in voce, in anima") "

"Yo scetengo que un universal no es algo real que existe en un objeto (inhetentemente), ni dentro ni tampoco fuera de la mento, pero que tete tiene set aclo como un objeto de pensamiento en la mente. Y esto puede ser lamado un universal, portue eeo es como un modolo y es relativamente indiferente a todas las coeas sthoulares que eetín tuera de la mente. $Y$ de tal modo un universal no es el resultado de geoeractón, sino do una abstraccion, is cul co solio una clase de repeeseatacion mental"?

Peso "palabra" y "escritura" son signos convencionales, por lo tanto el sentido de la palabra y los raggos de la escritura, cuando significan algo, lo hacen en virtud de la voluntad e Institucion de los hombres, quienes han querido darle tal significado."

"De estos y mucbos ottce textces es clato que un univereal es un contenido mental tan natural como puede ser prodicado de muchas cosas. Bso puedo tamblon ser confirmado racionalmente. Todos concuetdan con que cada universal es predicable de cosas. Pero sollo un contenido mental o un signo corvencional, no una sustancia, os ast do natural como es predicudo. Consecuentemente, solo un contanido mental o un signo convencional es un universal.. Bstd clato que ninquna sustancia puede natiralmente ser prodicada: si esto fuera verdad, se seguiria que una proposictón podria eotar compuests de sustanclas particulares, y consecuentemente que el sujoto podris estar en Roma y el predicado en Inglatern. Eato en abeurdo... Adernás, esta establecido que ninguna proposición puede estar compuesta do suatancias; pero una proposición esta compuesta de universales; pot tanto do ninguna manera los-univecsoles son sustancios ${ }^{-1}$

"Sostengo, ademids, tal como exactamente una palabes dicha es universal y es un péneto o una especie, poro solo por convendida, del mismo modo que el conorpto tanto mentalmeote abotraildo de una cose singulat previamente conocida como universal por su propia naturalezs...

Un concapto o una impsesión mental significa naturalmeate no impocta lo que signifique; un termino dicho o escrito, por otro lado, no silunifica nada excopto por Ithre convonelón" (la italica ca neestra)."

E

Ockham, Ordinatio, D. II. Q vol, prima rodactio, en Philosophical Watunga. A Selection, p. 41

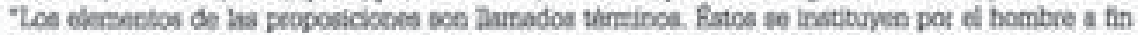
de sombear objotos en el discursa, el coul sastoruye a las cosis miamas. En la visiba de Ockham, el lenguabe en in sistema de signos artificislos. Anses de ertos signos artificiales estin los ricros na:

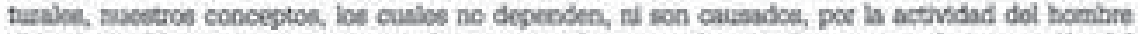

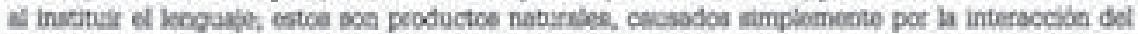
objeto y el intelocto come des partes causabes. Hablendo con proposdad, painbra y cococepto siumifl-

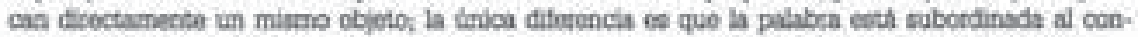

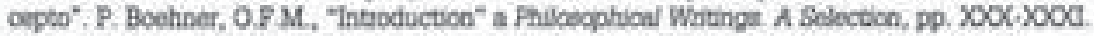

Ockhas, Summa totius bogicao, L, c. 2, en Fhilosophical Wratings. A Selection, p. 48. 
"Sobre el [terminol cornain "univessal" y ochro 'singulat', a este opuesto. digo que nada es universal, a menos que se abuse de tal vocablo, diclendo que el pueblo $6 s$ un untwersal, pocque no es uno, sino muchos; peeto eso setía pueril.

"Cumple decir, por tanto, que cualquier universal es una cosa singuiar, y, por eso, no es universal sino por la significación, porque es signo de muchss [0osas].

"Cumple saber, entre tatro, quo hay dos tipoe de universal. Uno es el universal naturalmente, a saber: el que es naturalmente signo prodicable do muchas focoes\}, al modo en que, corterpondienterneate, un humo naturaimente significa el foego, el gemido del enfermo un dolor, y la risa la alegria intecior. $\mathrm{Y}$ tal universal no es sino una in: tepcido del alma, de suerto que ninguna sustancia fuera del alma, nf accidente alguno fueta del alma es us tal universal. Bl otro es el univecoal pot institución voluntaria. Y asf una palabra proterida, que es verdaderamente una cualidad numericamente una, es universal, porque es un sigmo voluntariamento instituido pura significar muchas jocess) Asl, pues, como la palabea hablada es dicha comùnmente, asi puede set dicta univerasalmente, peco sso no provione de la nafuraleza do la cosa, etho soliamente de la con. venciban de quienes la instituyeron" (Ga italica es nuestra)."

\section{Derivaciones epistemologicas}

La ciencia puede seguir siendo ciencla de los universales en tanto éstos ocupan, en las proposiciones, el lugar de las cosas reales. Se realiza por medio de conceptos o terminos, que no son más que signos de las coeas. Las relaciones entre los entes no tienen existencia en sl mismas, sino solo en el sentido de una relacion correspondiente entro la palabra y la cosa, es decir, una existencia relativa. Se pone en duda todo tipo de cualidad ontolbgica de los entes.

"La doctrina do la vetdad de Ocitham se apoya fundamentaimente en dos elernentos: la instancia metafisica de la singularidad de lo real, pot una parte, y la teoria de la supcrickín, por la otra. Distanciandoee del tratado escolisstico de la vordad cocno corteespondencia de la cosa y del intelecto (adiequatio tei et inteilectus).

"Ockham reinterpeeta, pues, la doctrina de la verdad en perspectiva puramente logica y sarnintica, en telocido a los signos y las relaciones que se establecen entre los conjuntos de cosas por las cuales los sigaces suponen. La verdad ockhaminana, por tanto, no es una rectindo anselmiana, tan fuertemento lgada a la verdad divina. $Y$ tart. poco es una adequatbo, sil se entiende con este término la telacido privileglada entre concopto y cbjeto. Lo vetdadero, que tiepe por elemento la ptoposictón o el diecurio, es redefinido, gracias a los conceptos de término y de suposicion" Ga negrita es nues. tra)."

Tal concepción evita cualquier comprension tendiente a explicar que lo visible esté estructurado por lo invisible. Koyre comenta que "el rasgo más caractaristico en la secularización de la conciencia fue su conversión de fin trascendente en objetivos inmanentes, es decir, en la sustitución de la preocupación pot el 'otro mundo' por el interés colocado en éste"." Pero, aunque tales fueron los efectos, no begaron a ser éstas las intenciones de Ockham, como asi tampoco sus conclusio-

\footnotetext{
Ockham, Logica des Termos, po. 159, 160 y 161.

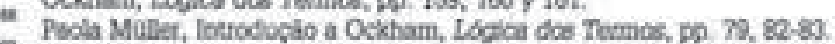

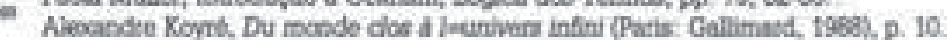


nes. Será la posteridad, ya bien entrada la Modernidad, aunque si bien contando con la precedencia cronolbgica, un tanto ingenua, de Grocio, ta que arrive a las conclusiones mencionadas. Fs entonces cuando traemos a la memoria la totalidad del sistema hobbessiano y las consecuencias politico-prácticas que tanto Hobbes como otros contractualistas y convenctonalistas llegaron a extraet del complejo metafisico-epistemoidgico-teoidgico de Ockham."

Asl es como Ockham instaura en el pensamiento el esplritu secularista, proceso un tanto paralelo al que la sociedad de su época venia sufriendo en los ámbitos comercial y económico, llevado adelante pteponderantemente por la clase social burguesa.

Cabe agregar, en el terreno de la logica ockhamiana, el resurgimiento de la lógica modal de los megárico-estoicos, lo cual agregará a su epistemologla ese tocue premoderno de carácter probabilistico que permite explicar mejor un ser que, abandonando su anterior permanencia, pasa a estar en devenif.

El pensamiento de Ockham produce una subversion radical del mundo cilasico y antiguo. La potencia que liberó inclusive no llego a ser reabsotbida por su ptopio sisterna, sino que originó una pluralidad de tendencias que se desarrolaron con el transcurso de la modernidad. Esto puede ser notado claramente en sus escritos sobre la cuestion, en los cuales entrecruza su pensamiento metafisico con el propiamente epistemologico:

-Problemas epistemologiocs: S et universat es realmente una cralidad exastente en la mente como au objeto - lo cual es uns opiníćn probuable - entonces dobe conco. desse que tanto pvede set conocido intustivamente un universal y que el misino conocimiento $e$ intuitivo y ademís abstracto, de acuerdo a eso primor sigrificodo de "abs. tracto'. Y en este sentido intuitivo y 'aburtracto' no son contrarics" (la negrita es nuestra) ${ }^{n}$

*... un universal es una cierta cualidad de ls mente predicable de varias cosas, dabe ser dicho que todo universal es vordadera y realmente un stingular. Para decirlo en palabres exactas, no ea cuanto odrmo eso corrin puede setlo por coervención, es ver-

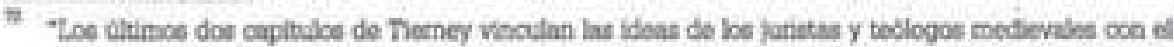
mundo moderno $\mathrm{h}$ princtpel oceducto por modio del cual ha fintecido el cosocpto de decochon na. tuedes no foo otro tedlogo, sino el jurista protedtante holandile Hugo Grotius Bn De jave belli, Gto-

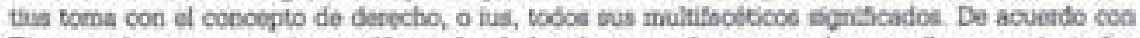
Terney, of maycur tema de este bibro sobce la ley de goecta fue para probar gee la goerra fusta foe hecha pane defender o haoer valer detoctios o condenat siolactones de elloe (Natural Righes, supna note 5 , at 325). Grocius ha explotado todos loe sigrificados de lus y los ha detindo como "una cusbdad moral de una persons, que lo capecita pora tener o para hacer algo con justicla' CA., citado de

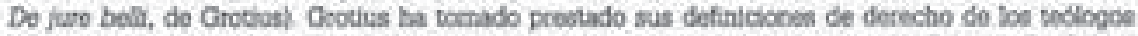

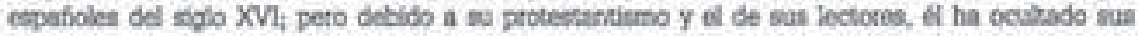
fuentes en una espesun do cits clasictat, Escocosids o no, Terney desembela el pensambento do Grucius y artegla sus deudas con la panopla de les primntos pensadocos. Grothis ha sido trecuen:

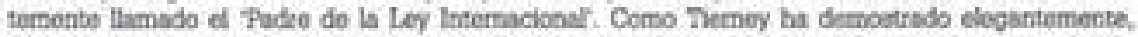

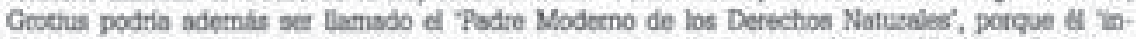

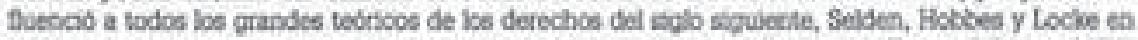

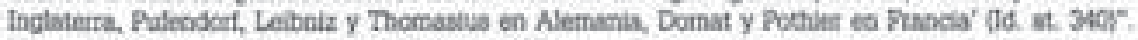
Kenneth Pennington, Op, ot, Start Page: p. 237.

$\pi$ Ockatm, Probgue to the Ondinsdo, Q. L N sq9, en Philloochical Wraings. A Selocticn, p. 22 
dadeca y realmente singular y numbiticamento uno, desde que eso es una coes y no varias, tanto como que es un contenido mental que significa varias cosas que están fuecs es verdadero y tealmente singular y numéricarnente una, deede que tata es una coes y no muchas cosas, por tanto eso signilica varias cosas.

- cada universal es por naturalezs corno un signo de, y viene a ser predicado de, varias coesas.. entonces yo digo que nads es un universal. y se abusa de esta palabra cuando se dice que una pcolactón es un universal, desde que no es una pero st alquas. - tenamos que dectr que todo universal es una cosa singular, vene a ser un signo de varias cosas. Esto lo dice Avicena en au quinto libro de la Metafisica: '- desde que el universal es un contenido en el intelecto ioualmente relativo a cualquier coea que tomes" (la itahica es nuestra) ${ }^{n}$

\section{Una antropologia diferente para un nuevo tipo de pensamiento práctico}

En el plano antropoldgico este pensamiento de lo singrulat y lo terrenal condujo a que la subjetividad y el individuo pasaran a primet plano. Los sentidos daban testimonio de la existencia y todo conocimiento empirico se basarla en la intuicion sensible, que operaba en la conciencia mediante la percepcion senstble. ${ }^{n}$ Este acento en lo empirico leva a que el Yo se vaya convirtiendo en "sujeto" del conocimiento. Se establece una distincion entre el ser propio del objeto y su percepción o, dicho en lengruaje kantiano, entre el objeto mismo y el objeto conocido, cons. truido por la conciencia. El mundo es aprehendido a travis de la lengra, aprohensión que pierde correspondencia absoluta con la tealidad en tazón del caratcter arbitrario (o convencional)" del signo lingutstico que lo expresa. Bn esta concep. cion, para Ockham, el concepto pasó a ser un mero signo y no una representación.

Philotheus Boehmet, en el cierre de su Introduccion, escrita en 1955, a Philo. sophical Writings. A Selection, en el tiltimo de los apartados que desarrollaba en ella, la "politica", ya en el útimo pérrafo, conectaba asi la concepción ockchamiana de esta disciplina con sus raices tedricas nominalistas y, a su vez, estas con el surgimiento de "la via moderna":

Ockham, Samma toktus logicae, 1, c. xtv, en Fhiloeophical Watungs. A Selection, D. 33.

Ockam, Somme do logigue (Puris: TKR, 18e9), D. 175.

"Ocihatn afirma que los terminos pueden oet mentales, crains, y escritos. A estos ultimos terminos,

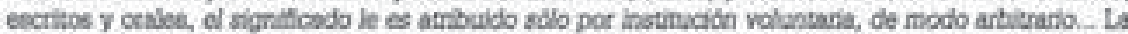
palabra depende del concopto, en el sectido de gat, al el concepto no wedatiera, tampoco edatirla la

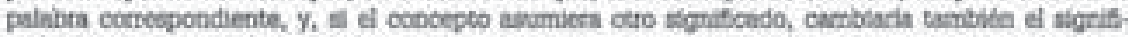
cado del sceido vocal. De hecho, nadie puedo actitrariamemte modificar el rionificado de los con. ceptos, en cuanto los temince cocaispondientes del lesgusje oral o escrito poeden vartar de sigris.

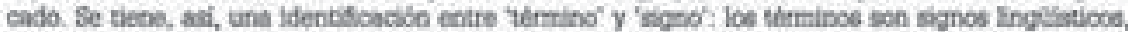
en cuanto se tomin probontes o evocas en la mente objetoe extramerhakh. Ocsham enfitita in

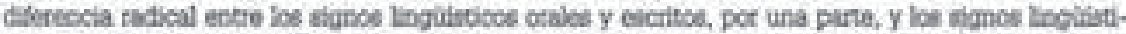
coe mentales, por oesa. Bn otras pelabras: por una perte, existen las signod lingolstioce oralos y escrisos por su nacaraleza comencionsles, por otra, los signos mernske peododidos naturalmeste a

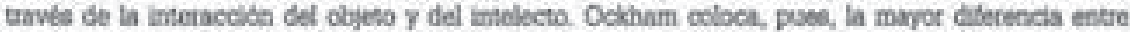

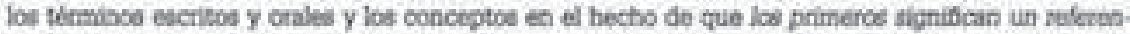

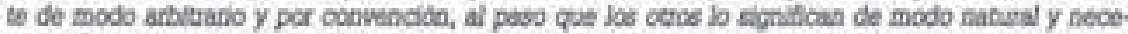

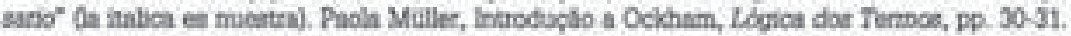


"La filosotia de Ockhazn two una enorme infuencia. Bs dificil encontrar una escuela 'Ockhamista' en el mismo sentido en que encontramos una escuela Tomista o Scotisa. Las ensehianzzs de Ocsham tuvieron un efecto estimulante. Elas despertaron a varioe pensadores independientes quenes se unieroa contre el roelismo do los viejos escollas. ticos. Taloa 'nominalistas' oconsituyen lis via modema. Bs aùn temprano para poder fuzar este gran movimiento intelectual. Un becho historico si puede entablecerso con seguridad: y es que la fisica de la via moderna fue lo que dio nacimiento a la moderna fisica: ${ }^{-1}$

Bl humanismo sera el heredeto directo del pensamiento nominalista. Se trata de una elabotación de ideas por el hombre, para si y desde el hombre mismo. Más explicitamente, el humaniamo fue la cristalización de los motivos que insuflaron el pensamiento nominalista. Bs notable de qué manera, y particularmente en el espiritu británico, se fue permeando esta noción de gestación "constructiva" y convencionalista de los conceptos. Sus más notables representantes serlin Hobbes, en cuanto a su concapción contractualista de la sociedad y convencionalista de la ley (incluida la noción de justicia), y Hume, en relación con sus conceptos de formación de la sociedad politica y de la justicia, en ambos casos de procedencia cons. tructivista y convencionalista"

Antes de cerrat esta primera parte, a fin de conectarla con la siguiente, acerca del pensamianto ético, juridico y politico de nuestro pensador, conviene repasar lo esencial de lo tratado hasta aqui, de manera que se puedan establecer, de ser posible, los lazos finales de continuidad entre lo que ha de seguit y lo desarrollado hasta el momento sobre su pensamiento.

1. No existe un mundo de ideas o esencias (o universales) en parte alguna, por tanto tampoco en la mente de Dios.

2. Bstos universales tampoco existen como una estructura inteligible por la cual el alma pueda aprehender la realidad. Bs decit, niega su existencia ante rem, in re (en las cosas), admitiéndola solo a modo post rem, como un moro concepto mental que se forma a partir del conocimiento de los particulares. Este cancepto no tiene, pues, existencia óntica ni ontolbrica.

3. Todo lo que hay, lo que verdaderamente existe, son sates singulares, individuales y, por tanto, cognoscibles como tales."

4. En la mente se forman, por abstracción, los conceptos, las ideas, las cuales son impuestas, a su vez, a los objetos externos, que pueden hacerse inteligibles, entonces, a través de dicha conceptualización.

\footnotetext{
Philothous Boehmer, O.F. M, Introduction, Ockham, Philoseghaloal Wrange A Selecticn, p. II. C. Margarta Costa, "Uha cosoepeion cocstructivista de le etica", ponencia, ne publicsida, $X$ Can-

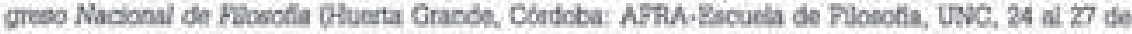
naviembe de 1999:

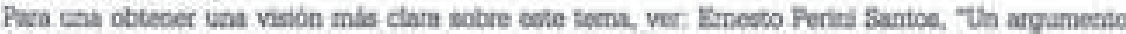
oekhaminho contra o roallamo sobeo a categoria da quantidade", Veritas, Vol. 42, n. 3, ectembeo 1997, pp 647-658.
}

$n$ 
5. Los universales no son abstracciones en el sentido tomista, para Ockharn, sino terminos que significan cosas individuales, que están en las frases, en lugar de estas cosas.

6. Puede haber ciencia; Ockham no niega en modo alguno su posibilidad, pero serd una ciencia del conocimfento de los singulares. El objeto de la ciencia son los individucs, aunque ta ciencia es una actividad de lo general, puesto que lo general supone siempre lo individual. Hay en Ockham una fuerte valorización del conocimiento empirico como fuente primordial de todo conoclmiento cientifico. De aqui al positivismo clisico no habra demaslada cistancia pot recorret."

7. De acuerdo con esto, toda la realidad es entendida a través de la captación de los particulares, únicos verdadercs objetos de conocimiento, por tanto fundamento de toda realidad.

8. La mente aprehende las cosas por una intuición, por la cual se llega a proposiciones contingentes. Se llega, asi, a una certidumbre de grado subjetivo, peto las ovidenclas son objetivas.

9. Hay en Ockham uns prescindencla de entidades, a su fuicio innecesarias, entre Dios y su creación ("principio de economia", de all la "navaja de Ockham"). Esto implica que no hay intermediarios entre los signcs o termince y las cosas, por tanto, tampoco entre la mente y lo que ésta aprehende.

10. Metafiticamente hablando, el ser no es analogo, sino univoco. El ser se predica tanto de Dios como de las criaturas, aunque no significa que Dios sea semejante a sus criaturas. El "ser" designa un concepto y no una realided de ta cual todo participa.

11. Ockham establece una separación entre teologia y fllosotia. La primera no es una ciencia, en sentido estricto. La verdad de la filosolia se obtiene por la ra20n, la verdad teolbgica pot medio de la fo.

12. Pinalmente, si bien Ockham queda situado como teptesentante de la corriente o doctrina nominalista, debe ser dicho que no lo es en sentido estricto, puesto que los signos o terminos no son simples flatus vocis, sino signos naturales, 0

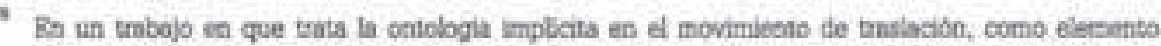

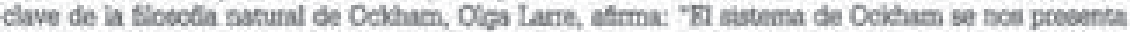

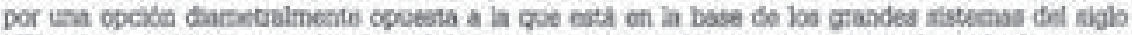

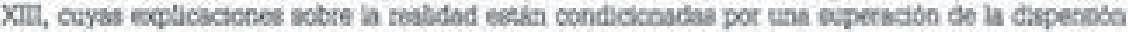

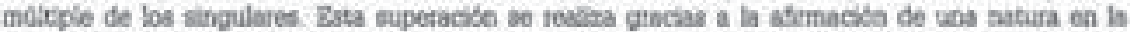

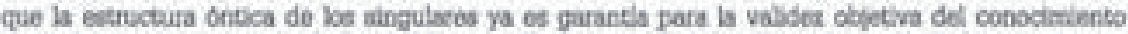

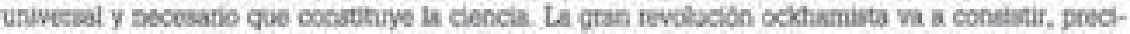

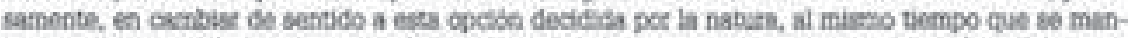

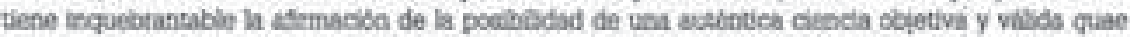
est univessalim. Bi sthgulet, ef indivitus coratituye por af mismo un dato del que es precliso pas-

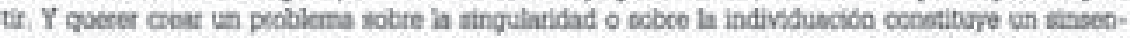

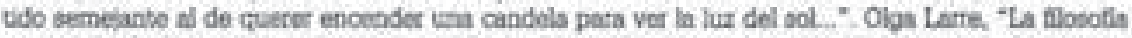

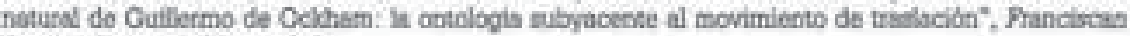
Suates, Vol 4, thet, p. 245: 
conceptos" Ockham seria entonces un nominalsta moderado. "Más que tl lo será Hobbes, uno de sus mayoses hetederos, para quien los signos de las cosas han de set meros términos puramente convencionales. De modo que podernos llegar a afirmar que hay en Ockham una clara tendencia, inciplente aún, hacia una concapción convencionalista acerca de la realidad, lo cual afectara (infultá), como veremos luego, en la segunda parte que complementa el ptesente trabajo, has esferas del detecho y la politica. Bl cardeter contractual que adquiera para Ockham la sociedad poltica, en telacion con la cuestbon de su origen, ha de ser una clara muestra de esto en el ámbito de su fito. solia politica y ético-juridica.

Queda, pues, el tema abierto, pata una próxima entrega, en la cual hernos de desarrollar el pensamiento práctico del Maestro de Oxford, con el fin de establecer, tal como lo propone el título que hemos elegido para nusstro trabajo, cuales son los ajcances de la tesis que homos ptopuesto al comienzo sobte los supuestos lazos de continuidad entre el nominalismo scstenido pos Ockham y los motivos centrales de su pensamiento práctico, más especificamente, de su teoria juridico. politica, la cual se constituye en una filoeofia politica y una etica furidiea de avanzada, en pleno siglo XIV, que preconiza el pensamiento de la Modernidad.

\section{2 PARTE: LOS DERECHOS SUBJETIVOS DE LAS PERSONAS $Y$ SU CAPACIDAD JURIDIICO-POLITICA PARA CONSTITUIR GOBIERNO A PARTIR DE LA NOCIÓN DE "PACTO SOCIAL" EN WILLIAM OF OCKHAM}

Bn la primera parte, analizamos ciertas nociones claves de la filosotla teórica de Ockham en relactón oon su filiación como perteneciente a la corriente nominalista. La función de dicho estudio fue realizada a fin de explicitar qué elementos aparecen en su filosofia que nos permitirian afimar que la faz practica de su pensamiento - la etica, el detecho y la politica - estarlan en ellos epistemológica y

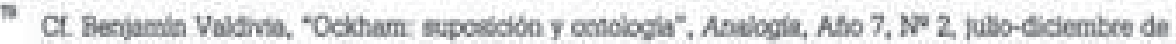
1993, pp. 141-152

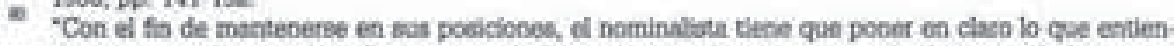

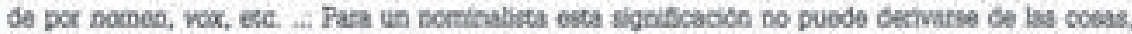

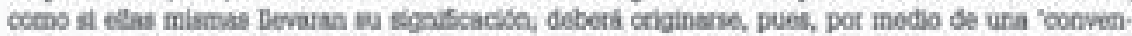

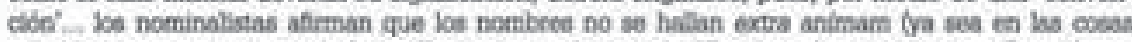

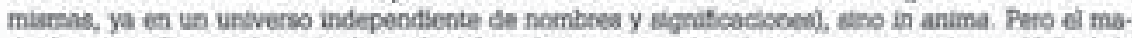
tiz do nochinshimo adoptado depende del modo coeno se eribenda este cotar in anima... Al finat de in Bdad Modia el nocrinalisma cope se impues tue el expresado por Oecam, lamado por ello el prin

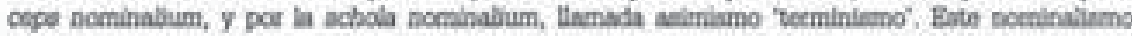
consiste groess modo en sovtener gov bs signos tienen como fancibn el suppopeto pro, es dscir, el 'estar en el lagar do' las cosas designadas, de modo quo los sigros ao mon propiamente de las ou-

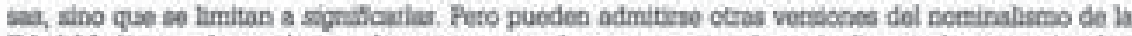

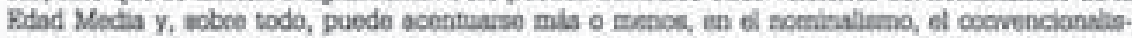
tho, el terminieno, etc. Bs tecuente leer que la flosofia moderna ha aldo fundamentalmocte neem. nalieta.:- Ferrater Moca, Op cit, 3, p. 237 .
} 
metafisicamente austentados. La cuestión, como vimos, no es fácl de tesolver, pues no es un simple hallar la clave de tesolución de la mentada extrapolación. Corno vimos, hay ablerta divergencia entre las peincipales interpretaciones de su pensamianto. Asf mismo, algunas cosas pudimos it dejando en claro a través de nuestra exposición y analisis que nos conducon a pensat en la factibilidad de sostener que la clave de comprension del pensarniento practico de Ockham, especificamente, sus nociones de pacto social y de derechos subjetivos de los individuos, serian consecuencia de su flosotia teórica, e incluso, como veremos en el presente trabajo, de su teologla. Todo esto nos estaría indicando que si bien no podemos afirmar que bay en Ockham un sistema, a la manera del sistema aristote. Bco o el sistema tomista, si habria en el conjunto de su flosofia una unidad que la atraviesa, la cual estaria asenteda, para decitio btevemente y en pocas palabras, en su revalotación ontológica de las entidades individuales y su negaclón de los universales. Comencemos pues nuestro relevamiento de su pensamiento práctico a partir de la confluencla entre la teologla, el derecho y la moral, a fin de concluir oon su flosofia politica propiamente dicha, tratando de verificar los enlaces menclonados:

\section{El pensamiento práctico de Ockham: la ética y el derecho}

Creemos que la mejor opción para encarar el tratamiento del pensamiento prdctios del Venerabilis inceptor, en comenzar por su teoria motal, debido a las implicanclas que ésta tiene en los almbitos del derecho y la politica. Ahora bien, se percibe en Ockham, que todas estas implicancias, vienen mediadas por su pensamiento teológico. Especificamente, con respecto al reflejo de la teologia en la moral, éste viene a colación del "voluntarismo"." Puesto que la exdstencis de Dios no es objeto de demostración, sino de la fe, no será pcsible probarlo, ni demostrarse la unicidad. Esto conduce a la afirmación, muy fuerte, por cierto, de que no hay cosas buenes o malas en si mismas, sino s0lo en virtud de los decretos positivos de la voluntad divina.

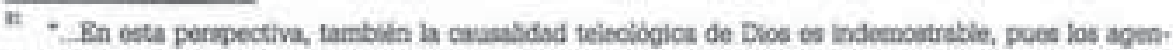
tos naturalet, que te tigen por las digidas leyes del meciniclemo, poodocen ses edectoe, indepes-

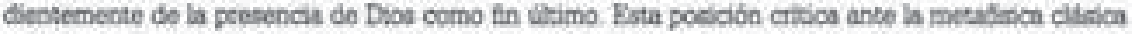

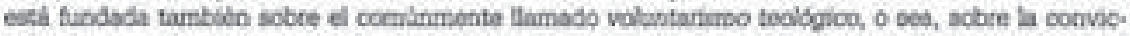

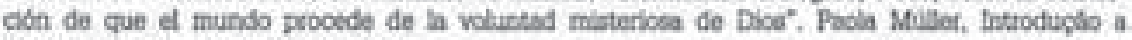
Ockham, Logica dos Termast, D. 22.

Marilyn Mocoed Adame dice, acertadnmente, goe la thoria moral de Ockharn, ael como su nominslineno, ocipa un lugat muy notorio, aungue uambila debe decirse de ella que on bestante inopm-

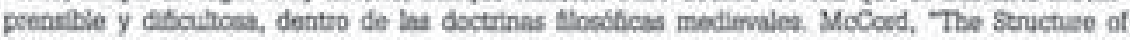

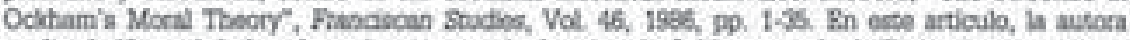
analiza la libertad de la valuntad y comgara ls doctrina de Ockhame coen la de Esooto es esto aspec-

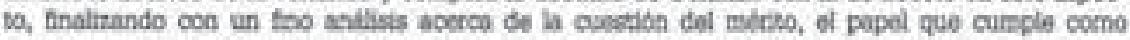
cumponente de la mocel $\gamma$ au rolacida, coeno categorta de la moral, con la volumtad divina. 
"Ockham teene una concepción voluntansta de la moralidad y de la ley naturai: el contenido de la moralidad es enteramente doterminado por la voluntod de Dice. Adnenia dice Ockham que Dios puede bacer una ley morai diderente. Aqui se invoca la distinción entro el poder abocluto y el poder ordinatio de Dice. Dios no cambia su voluntad, pero stempre puede, en clertas oporumidsdes, hacer que cambie la ley moral. Los historiadoces guetan sensacionalizst el pensamiento do Odcham, para hacetio patocer mils excitante de lo que es. La visión radical scbre eeto no esta expreseda por Odcham, de becho et dice varias cosas inconaistentes con esto, pero se supcne que se ha de sagulit de las varias otras cosas que dil dice. En este ariculo he de sugerir que quizls ceto no courra"."

Tal es uno de los efectos de la separación que establece Ockharn entre los ótdenes de la fe y la fliosolla.

"La tooria dtica de Ockham es llamada algunas veces como positivista. El sostione que un acto bumano es buens o motal, no pctque se conforme a la ley eterns, la caal existe do por si y por pobjerno de la voluntad divins, sino simplemente porque ectá $\alpha$ derado y cornasdado por la voluntad de Dics. A esto slgue que la volunesd de Dios es la norma ótica y debo ser obodocida por toda cratura. B único Dios vivionto, el cmnipotente y agraciado Dics, es la regla suptema de la ética. Hacer la veluntad do Dics O, oquivalentemante, amat a Dics, es la regla deca suprema. Las leyes éticas no eca proposiciones, sino mandatce, su fueate tituma debo estar en la voluntad y no en cualquiler coea impersonal de la esfera ontoibgica, ni en cualquier proposición de la esfera logica. En lo testanse, la eica de Ockham permaneco dentro de los Elmites genetales de la ensehianza escolsstica" (la italica es nuestra)."

\section{Moral y ley natural en Ockham}

De ia tiqueza contenida en of articulo do Kalkullen: "Natural law and will in Ockham "," pueden set resumidas algunas ideas importantes, las cuales, al tiempo

o

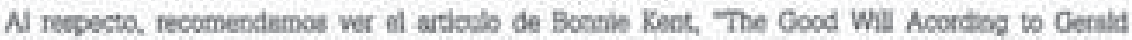

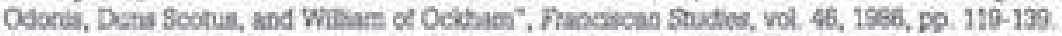

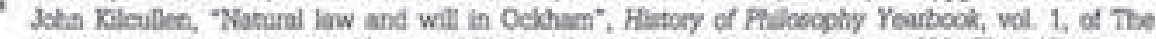

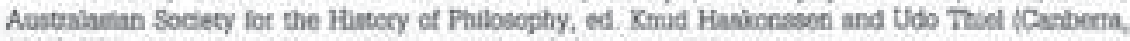

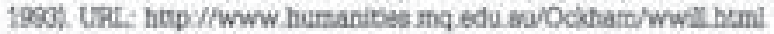

n

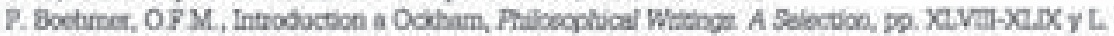

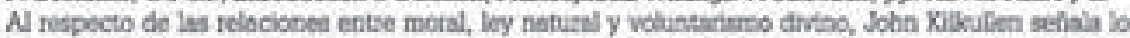

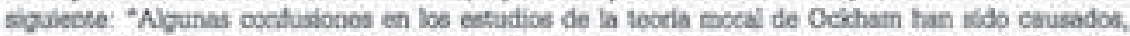

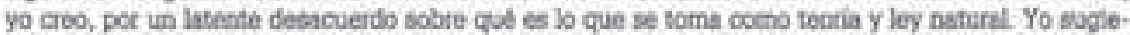

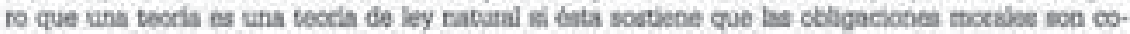

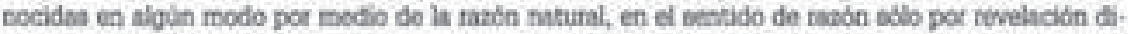

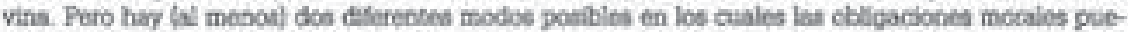
den ser conocides per ranotn satural, y adernas dos clases de teoria de ley netural 1. Algunas teori-

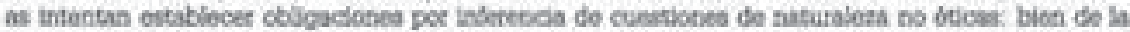

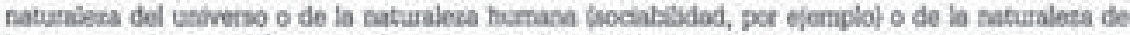

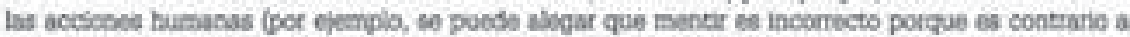

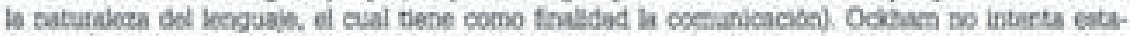

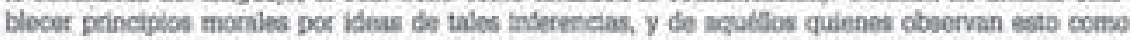

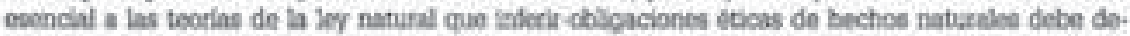

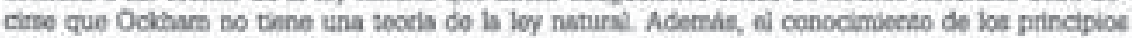


que clarifican la mentada rejacidn entre sus ficestins tedrica y práctica, 0 , mís puntualmente, entre la metafisica y la politica, permiten establecer lineas de continuidad entre su pensamiento global con la flosotia politica de los modernos, los forjadores det contractualismo y del convoncionalismo: Kilkullon afirma que el termino voluntarismo", tal como le fuera aplicado a Ockham por medievalistas e historiadotes del siglo XIX, puede asumir cuatro posiciones posibles, a saber: 1) lo contratio a la vaga tesis de que la voluntad es una facultad más noble que el intelecto; 2) la tesis de que en la visión beatifica de Dics en los ciolos, ha voluntad humana es en cierto sentido más importante que el intelecto; 3) la tesis de que las leyes de la naturaleza nos obligarn solo porque son irmpuestas sobre nosotros como tales por la divina voluntad; 4) la tesis de que la voluntad divina determina ol contenido do la ley natural, con el aggegado de che, si Dios adi lo quisiera, podria adulteratia," stn que ello sea una accibn moralmente mala " Kilkullen evalia ast las cuatro tesis propuestas:

"Las proposicones (3) y (4) son distintas. Podris ser que el contenido de la ley natural sea indepentiente de cualquier voluntad y descubierta por razota, y auin eso podrin tornarse ley vinculante y chligatoria, sclo por ser impuesta por una volumtad autocitaria Bsto se pareos a la concepción de Hobbes [e. Hobbes, Leviachan, ed C. B. MacPherson (Harmondsworth, 1968, pp. 216-7h. Duns Scotos y Williarn of Ockham umbiln parecen sos. tener la seccor tests, pero en eate trabajo yo he de acherime a la poetidon de Ockctiam en relacion con la coarta. Podra ser notado que ha Jey natural" en la edod modia sionifica ha ley moed, no las 'leyes' tormuladas por las ciencias tistcas".

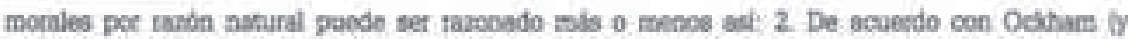

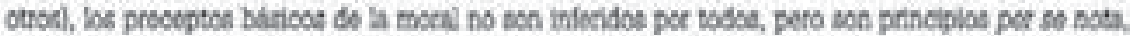

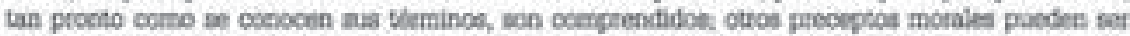

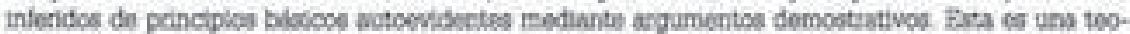

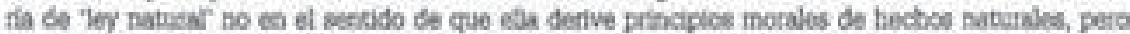

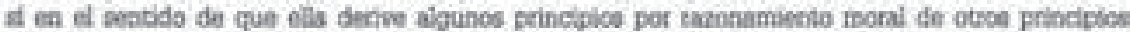
que eon autoevideatee pera la randes natural, in ley naniral esta dispocible, insediatamente o por

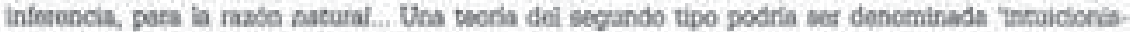
ta't es etica moderns la teorla de W. D. Roes es ena tecris de lay natursl en este sentido. Coene

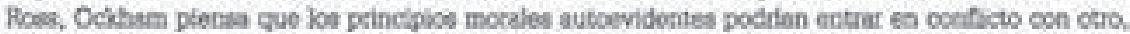

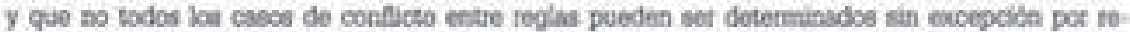
clas jiberitarias. Otra fuente de coctasion, yo creo, es la inferencia ticita de que porque (de soserdo con Oexbaml la volantad divina peevalece sobre los principlos morales, tales pirincipias b soo adio potque Dioa bo permite. Bato no se sigue. Oclhim parece soetence que hay un nlmeto de

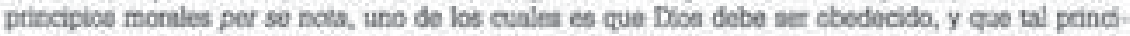
pio prevalece sobero los demia cuando entra en conflicto. Pero to we sigue de ento que be demis

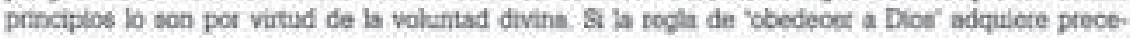
dencla sobte la reg'a 'no debes matur', esto no implica goe 'no debea matar' es aloo coligatoris

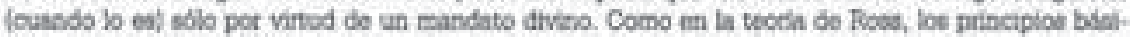
cos de la toorfa de Ockham son una phuralided y ica independientes uto de otto, desde cat veo previlece sotece los dernis en caso de corflicto", John Rlculles, "Natural law and wil no Ockham", D9. $5-6$

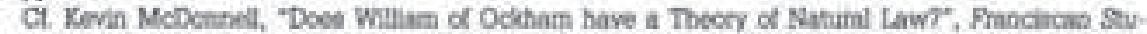
dest. Vol. 34, 1974, D. 391. AFr este autor afirma que. La maden, en la conoepeión de Ockham, esta

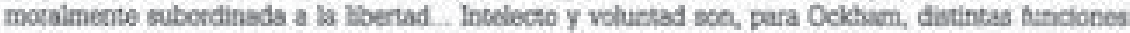

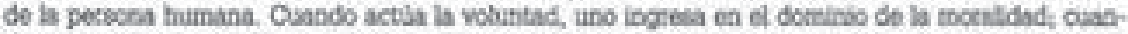

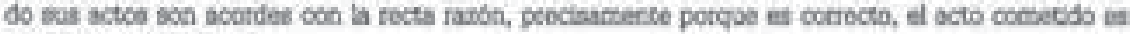
theralmente bueno.: John Kikullen, "Nahural law and will in Ockham", pp 4.5

Inid, D. 5. 
En erte mismo articulo, Kilkullen realiza un tratamiento exhaustivo acerca del oripen y el aicance que tuvieron las primeras teorias sobre la ley natural. Es imposible; por razones obvias de espacio, transcribir açuf toda la riqueza de su investigación realizada por el protesor australiano - 10 cual no desculda en absoluto la seriedad de la fundamentación basada en los textos originales de los autores menclonados - pero al menos teposaremos los tópicos más importantes. Al tratar sobre los antecedentes proockhamianos de la ley natural, Kilkullen se besa en textos de laidoro de Sevila, Gratian, Justiniano, Alexander of Hales, Bonaventure y Duns Scotus, para concluit su desarrollo con una detallada y erudtu exposición acerca de lo que Ockham entiende por ley natural, ofmo se relaciona ésta con la motal, la ley positiva, la propiedad y el pacto mediante el cual los hombres eligen su goblemo," Los textos que utiliza de Cckham son bistcamente of Quadiber y su propia edición - blinguie - del Dialogus. Repasemos brevemente lo que dice en relación con los antecesotes del maestro de Oxford:

De Isidoro de Sevilla, citado por Gratian, atirma que concibió la ley natural como una ley común a toda la gente, apoyada en el instinto natural, como por ejemplo: la posesión común de cbjetos, la unibn entre hombre y mujer, la procreación y el cuidado de los hijos, la libertad de los hombres, el poder de aptoplación de lo que sea tomado del aire, el cielo y el mar, el rechazo de la fuerza mediante la fuerza, etc, todo lo cual "sera considerado slempte como algo natural y equitatvo" y "jamás como injusto"."

Justiniano trata acerca de las similitudes y diferencias entre "ley natural" y "ley de las naciones". En efecto, en el Digest, 1.1.4, cice: "De acuerdo con la ley natural todas las personas han nacido lbres... pero despues fue admitida la servidumbre por la ley de las naciones.". Pero Haman la atonción otros textos, en los cuales parece que pretende identificarlas. Tal ocurre con los Institutes, 2.1.11-12, donde puode leorse que "por ley natural obtenemos la propledad de algunas cosas, las cuales, como ya hemos establecido, es llamada la ley de las naciones.."; ast mismo, continúa Justiniano en la obra citada, todo lo que sea tomado del aire, la tierra o el mar, pasa a ser inmediatamente propiedad de cuien lo ha tomado por la Ley de las Naciones, puesto que no pertenece formalmente a nadie, le es concectido por ley natural al primeto que toma posesion de ello (las cursivas son del traductor de las citas originales de Justiniano)

\footnotetext{
Wa idea de un pacto social primitivo es may actugua; se la retama cos Oeotus. Fero el voluntariemo

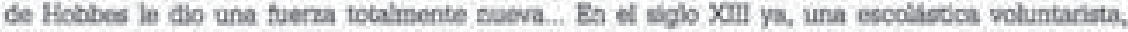
habla separado la razde de lo poal. Para Dune Soctio, el acte de la ieteloencia se termira, no en las cosas, itro en el nomber gae se ke da Esto nominalismo tenovedo por G. do Occom en ef siglo XIV, domina ef pensamiento ingles barta Hume. Reira sobire Hobbes; $\gamma$ a travia de el, sobire Rous. seau. La escolisidica voluntarista de la que dependen Subses y Grotius (oceno Doscartes) os solidaria de una cecolastica nominaliata o idealista". Fh. I Andro-Vhocent O.P., Ginosis y denariollo del vo-

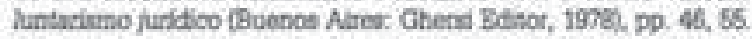

"1: Geatlan, Decrecs, dis. 1, c. "bas naturale"; ciado pot Kilkulten, "Natusal lew and will in Ockham", p. 6.

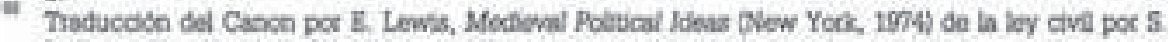

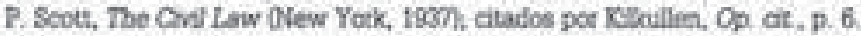


Continuta Kilkullen comentando que para los escritotes medievales, en general, "la ley natural y la ley de las naciones son distintas", stendo esta titima "tomada como parte de la ley humana positiva, aunque como una parte fundamental" " Para los legisladores civiles estabu bastante claro "que la propledad ha existido por ley natural", en tanto para los legisladores candricos y tedlogos, la propiedad se debe a una ley humana, y ésta permanece sujeta a la ley natural, por lo tanto, puesto que la ley natural proclama "la posesión común de todas las cosas", resulta cificil poder legitimar la institución de la propiedad, como asi también el becho de que la ley humana - por la cual se instituye la propleded - sea una parte de la ley natural ${ }^{\text {"I }}$ Kitkullen explica que tal contradiccion habria sido salvada afimando que "algunas leyes naturales mencs fundamentales requieten la posesión comuin de todas las cosas bajo ciertas circunstancias y requieren la propiedad bajo otras circunstancias", argumento este que permitirla resolver las mencionadas inconsistencias." Asi parecen afirmatlo tanto Alexander of Hales como Botaventure y hasta Duns Scotus y otro tediogos ftanciscanos, cuando dioen "que la ley natural beinda diferentes direcciones para diversas etapes de la historia humana". de tal modo que propiedad y servidumbre fueron contrarias a la naturaleza antes de la caida, pero no trego "Duns Scotus declara explicitamente, la inmutabilidad de las leyes naturales, pero también afima la existencla, funto a estas, de otras leyes muy consonantes, que no son inmutables - puesto que "podrlan ser suspendidas y revocadas por Dios" - como por ejemplo las reglas de propiedad, puesto que "la apropiación fue impedida antes de la caida y permitida luego"."

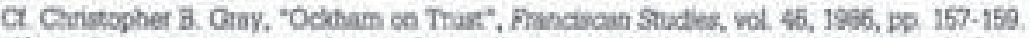

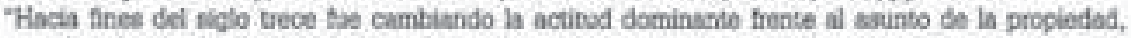

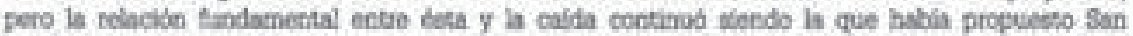

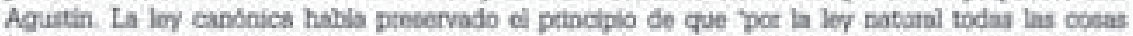

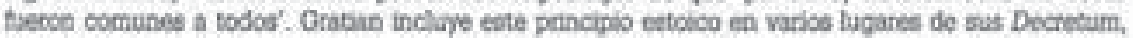
y loe canoniotha setalaseo esto pars sigrifigat que previo a la caida jambe hibo propledod privida.

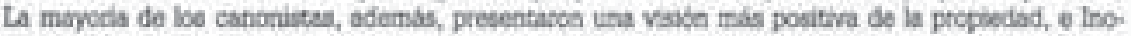
concio $N$ asocib los comienzoe de la propiedad peivada con la doctsite de Abraharn y Let de dividir

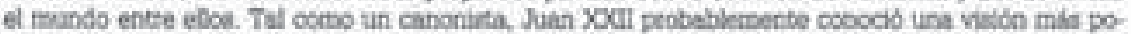

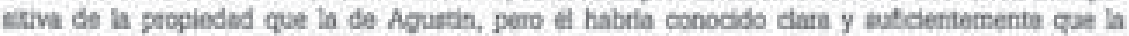

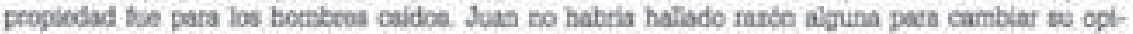

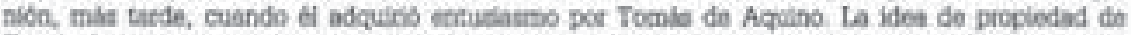
Tomis fue clenamente poetivn, y el claramecte sintib que is propiedsd ers 'hatural'. Adsemist, $E$

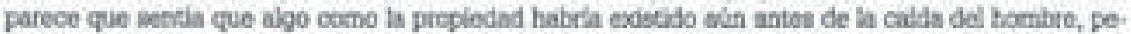

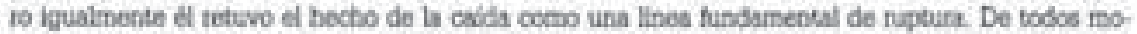
dos, para Aquino, la naturaleza de la propindad fue fandamentalmetre deternicada per la calda".

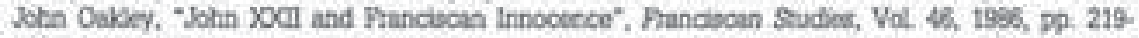
220. Kiknilen, Natural law and will in Ocktham", p. 7 .

Did, p. 7 .

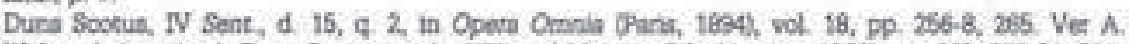

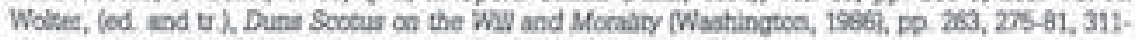
17. Citados poe Kisoillen, "Notural limw and will in Ockham", p. 7. 
Ockham "scstiene que la ley natural es un sistema demostrativo formal; esto es, que hay principics morales autoevidentes de los cuales los otros principios de la ley natural pueden ser derivados y dechucidos racionalmente"."

"De acuetdo con Ockham hay trea tipce de ley natural. Bl ptimeto scn leyes que exsten en todo lugat y stempre; el segundo pertenecan al estado de inocencia; el teroeco a otros egtados, contingentemente sobre las personas a quien conciernen. Debajo de las leyes naturajes del tescer tipo bay un procees comblnado de tasobn y decisida: Nosottos fla raza humana, o la gente de alguna comsunidadl tazonamos que, dadas ciertas coodiciones, se podrla, ademis, al bien común instituifle ciertos arteglos. St eeo es adoptado, entonces varios principics universales, condiclonales en forma, oplicesbles, y funtamants oon hechos declaradce sobre instituclones establecidas, generas obligaclones. El úrimo estadio de estn proceso es estrictarnente deductivo pero los primerce estadios no lo son. Las obligaciones generadas al final no son inmutables, ellas no son siempre $y$ en cualquier lugat scetonibles; ellas scen obligactones soblo bajo clentas suposiclones de hecho.

"Bste esquerna es presentado en III Dialogus, II, 3.6 (Dialogue betwoen Master and Student, part. III, tract II, book 3, chapter 6). Maeetro y estudiante están diecutiendo el asunto sobce at los Rornanos tienen el detecho de elegit al papa por derecho divino. El Maestro dice que a esto se responde que los flomanos tienen el detecho do elegir el papa por derecho divino, 'extendiendo derecho divino basta inclalr toda la ley natural'. Zato sugiere que puede haber casos de ley natural y que algunist iejes natu. rales pueden ser divinas sólo por aiguna extensión del termino 'divino'. Luego el estu. diante pide una explicacida".

Al satle requerida tal explicacion, el maestro distingue tres acepciones de ley natural: 1) aquellas a las que se está obligado necesariamente, tales como "no cometer adulterio", "no mentir". Se las Bama naturales puesto que se conforman con la razón natural y son, por tanto, "inmutables, trvariables e indispensables"; 2) se la llama natural a toda ley que se cumple modiante el uso de la equidad natural, al margen de cualquier costumbre o legislación humana; aquí se tetiere al estado de inocencia, antes del pecado original, estado en el cual todo es comùn por ley natural; pero ocurre que luego de la caida las cosas no puctieron continuar siendo comunes, pero la perversidad de los hombtes Ilevo a que se introduzca la propiedad, puesto que ya no vivian de acuerdo con la recta razón; ; 3 ) de un tercer modo se llama también ley natural a aquella deducida por razbn evidente de la ley de naciones u otra ley, "a menos que lo contrario sea decidido por el consentimiento de todos a quienes concierno" *

\footnotetext{
$+$

Ockham, Ouocibet II, \& 14; citado por Kibnulen, "Natural law and wll in Ockham", pD. 7.8. Revid, P. 8 .

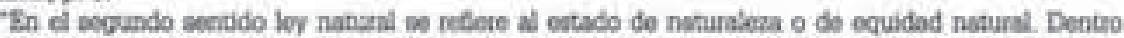

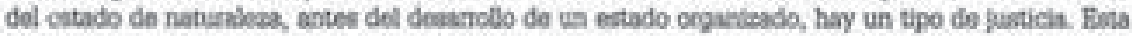

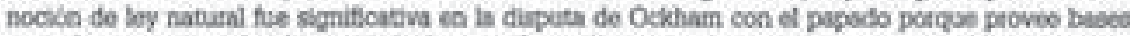

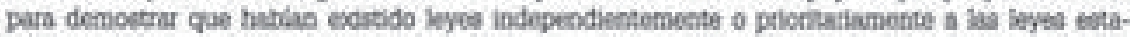

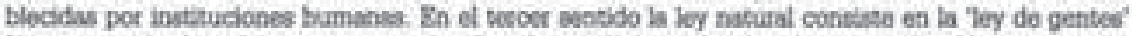

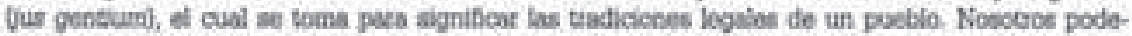

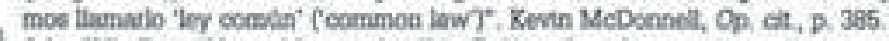

John Kilibulen, "Naturnal law and wil ta Ockham", p. 9.
} 
'Este 'concierne' serian las partes de una transaccibn, 0, en alvunos cascs, alguien, do otra manera, con autceidad sobte ellos, un supecior. Ia 'ley de las nacionea' es una ley humana o una costumbre; 'u otra ley' - cubierta o encubierta - pos otra ley humano, asl corno la ley civl, y adembs la ley divina poeitiva; por tanto la propledad, asi como la cormunidad de blenes, existe por ley humana positiva. Deductmoe por tazoh ow: dente de la ley que establece la propiedad, pot ejemplo, que al me prestas aljo de tu propledod, entances yo debotó devolvitula cuando tu la tedames - a menoe que con. trarinmente se decida por el consectimiento de aquejos a quienes conclecta (v a sil yo pregurto, puodo mantenerlo lasgamente y tu consentirlo). Oub rasones se deducea de equí es de hecho deducido no sclo de la ley de propiedad, sino también de bechos televantes, v.g. que tu me prestas esa coes. Ademals ol Masstro dicn, "dectucimos por tazcanamiento evidente de las leyes de las naciones u otras - leyes - o de ource acros. divincs o humanco:. La ley natural, en el tercer suntido es, dice el Maestro, ley natural ca suppocition. Suponiendo algùn acto, divino o bumano, podemos deduelr por razonamiento evidento que sosotros debemos actuar o bo actuar en un cierto modo excepto con el consentimianto de quienes conciarna* (la itsilica es nuestra), =

Luego, Ockham declara que la ley de las naciones no es ley natural abeoluta, en varios aspectos. Bn la ley de las naciones, dice, confimando lo que sobre esto hablan dicho sus predecesores mencionados, la propiedad, que puedo aftadirse a la ky de las naciones, "no existe pot ley natural abeohtamente... potque entonos lo opuesto nunca serla permitido, porque lo que está contra la lay natural absoluta nunca es permitido más allá de la dispensación...", quedando claro, entonces, que "la ley natural absoluta... no varia, stino permanece incambiablo e inmutable" " "

Finalmente, otro elemento importante a tener en cuenta en la teoria moral de Ockham, es su afirmación de que algunes leyes naturales pueden ser rechazadas. Claro que esto ha de tener ciertos limites; pero, por ejernplo, cuando habla en ef Short Discourse sobre la equidad natural, menciona que en uno de sus sentidos, el de equidad como impercialidad (faimess), dice que "podria regularmente observarse por todos quienes tienen uso de razon, excepto st hay alguna razón espocial pot ta cual no pueda aer observada... No solo el papa, sino tambien el emperador, y cualquiera, puede ocasionalmente actuar contra la equidad natural en este sentido* (la negrita es nuestra) ${ }^{\text {th }} \mathrm{Y}$ aqui es el momento de hacer mención de un tipo de lenguaje y semántica muy utilizados pot Ockham en sus escritos, especialmente en los más polémiocs. Nos referimos a los términos "regularmente" (regulariter) y "ocastonalmente" (casualitor), los cuales se vinculan estrechamente en sus escritos politicos con el tema del pacto y el consentimiento. "Bstos términos son un modo muy usual de Ockham (ver, por ejemplo, Short Discourse, IV.4, p. 112) para marcar el hecho de que algunas reglas estain sujetas a excepción en algunos casos.-." Bllo permite obeervar que en Ockham "la regla puede set puesta aparte no

and. D. 9.

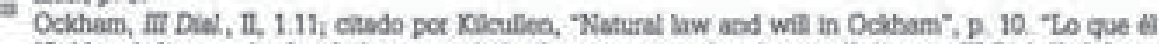

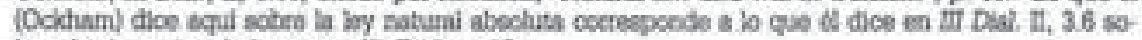
hoe el primet tipo de loy naturat. Ibid., D. 10.

ate Ockham, Shart Discourse, Book 2 , chapter 24, p. 69, ctade por Kilnilien, "Natueal law and will in Ockhem", p, 10. 
sólo pot el consentimiento de quienes les concierne, stino también contra la voluntad de una parte en una época de necesidad extrema" =

Kulkullen concluye su articulo acerca de la idea de ley natural y de voluntad en la teotha moral de Ockham, negando el supuesto voluntarismo atribuido por algunos de sus historiadotes, tratando de clarificar su noción de independencia que posee la etica ockhamiana, 0 , en todo caso, declarando una bésica y fundamental dependencia procedente de la razón natura:

"Bn varioe lagates Ockbam dice que loe peincipice bastoos de motalsded son evidentes a la razdn natural. El nunca dico que la moralidad descansa sobre el mandato de Diofi. Los pasajes de las cuaies ciertos histociadores han inferido que el debe o habria mostrado que la moralidad descansa sobro el mandato divino ao implican esto. Bato moetraria que la teoria moral de Ockham no es voluntarista"

Las consecuencias de un pensamiento tal no llegaton a set asumidas por Ockham, quien mantenía en vigot su fe en Dios y la Revelación, pero, obviamente, sollo fue necesario dar un pequeh̄o paso por otros pensadotes, menos ligados a trabas religiosas, para que, en virtud de los principios nominalistas - 0 en todo caso "conceptualistas", si queremos matizar un poco el etiquetamiento de su pensamiento - legaran a las posiciones fnmanentistas que comenzaron a imumpir con la Modernidad.

\section{Los escritos políticos}

\section{Alcance y repercusiones de su pensamiento politico}

En 1328 Ockham se vuelca hacla los escritos polémicos, abandonando los puramente floedticos y teobogicos." Desde ese atho, hasta el final de su vida, trabaja en función critica a partir de su visión de las tiranias ejercidas por los papas John XXII y Benedics XII. Ast, penetra en asuntos eclestásticos, tales como el estudio de la naturaleza y la estructura de la Iglesta Cristana, las funciones y poderes dal papa, y en filosotia politica." Sus escritos en eatos tems son de gran interts para estudiosos de la historia de ia religion y de historia de la fiosolla poltica."

Klikullen, en la introducción al comentario sobre el Dialogus de Ocicham, no deja de captar la relacion entre los escritos politioos de Ockham y el posterior

\section{bid, P. 10 .}

Buid, D. 14.

Acerca de la astenticidod de loe escritos politicos de Odiham, ver: Vadimir Rochter, "ta Seetet of the Histocioal Ockcham: Histodcal Literary Retmarks on the Nuthentiaty of Ockhern's Wnings", Franciscan Studins, vol 46, 1965, espocifcamente el sogundo apartado, titulado: Bscritos poliboos. pe. $99 \cdot 101$

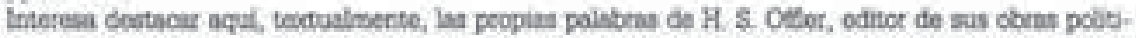
cas, en un pierafo introdactotio al $2^{*}$ valumea de la Operu polifica, donde etcribo acetca de "las

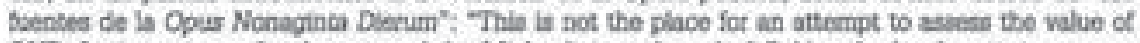
OND. Its importance fat the story of the Mchaetst revolt and of Ockbarm's development as a po:

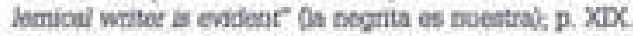

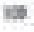
Joba Kicullen, "Ocktam and his Dalogue". Version 1, Septernber 1996, The Britinth Academy. p. 1.

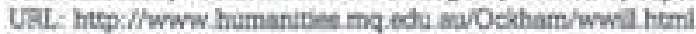


pensamiento liberal, que surgirá pocos siglos despues, y afirma, cautelosamente: "Seria anscrónico llamarlo 'Tiberal' a Ockham, pero hubo elementos en su eclesiologia y en su flosofia politica que anticipaton las concepciones de Locke, Min ${ }^{10}$ y los liberales modernos. Por ejemplo, el sostiene": 1) la no infalibilidad de sector alguno de la Iglesta (incluidos el papa y el consejo de Iglesia; 2) la libertad que posee todo cristiano para emitir y defender sus propias opiniones, aunque éstas fueran etróneas, en oposición a los puntos de vista del papa, consejos de Iglesta o cualquier otra entidad oficial establecida de la lglesia; 3) "que un papa que intente imponer falsas enseĥnnzas a la Iglosia, o que viole seriamente los derechos de los miembros de la Iglesta u otros, puedo ser depuesto"; 4) que ninguin establecimiento del Cristianismo puede afectar ni interferir en los derechos de los no creyentes, como, pot ejemplo, los derechos de gobernantes, particularmente sus desechos de propiedad; 5) en relación con el papel de la mujer, que es tan miembro de la Iglesia como el hombre, por lo cual estaria habalitada a tomar parte del consejo de Iglesia; 6) "que el poder de los goblemos saculares no depende de la aprobación de la Iglesia"; $"$ 7) en relacion con los podetes y derechos de los sulbditos, elemento clave dentro del dogma liberal, que todo legislador secular, sean éstos emperadores o reyes, o quien sea, debe respetarios, puesto que ningùn gobemante - ni legisladot - 10 e6 en modo "absoluto", 8) como lógica consecuencla de esto, un ultimo elemento, de corte claramente contractualista, al modo de Locke, por supuesto, y no tanto el de Hobbes: "que un gobierno tiránico puede ser depuesto" por sus súbditos, obviamente, gi asi lo prefieren, si es que les está resultando perjudicial para éstos continuar dándole su consentimiento. Todos estos puntos enumerados son señalados explicitamente por Kilkullen como gérmenes primitivos, insertos en la filosofia politica de Ockham, de un liberalismo que babria de venir en un futuro mediato."

Seflalado esto, debemos dejar constancla aquí de que lo que realmente ncs importa en este trabajo, no es tanto la captación y ómo desarrollo Ockham los

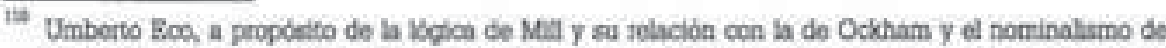

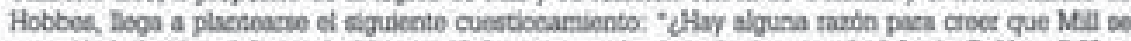

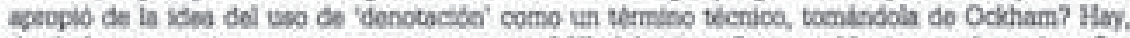

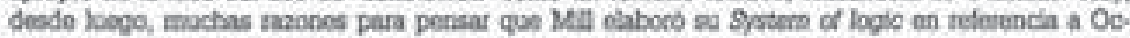
Wham o al menos a li tendicibe Ockhamista. Is generalmnnte cococido que Hobbes depende de Ockhum tanto corno Mell depende de Hobbes.". Umbecto Boo, "Gigniffcation and Denotation froer

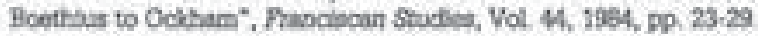

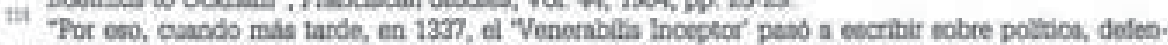
diendo la indepeondecicia del poder imperialsecular contrs las intoomiriones arbitraciea perpetradae por el Papedo, eatabe convencido de que combatla a hesejes que invocundo una teocla de ia Plect. tudo Potestatis', de cou se hallabeh tanto en el derecho de reintergiretar y modiscar las deteruina.

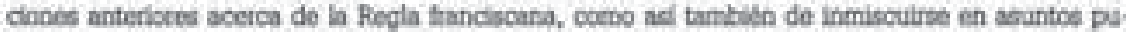

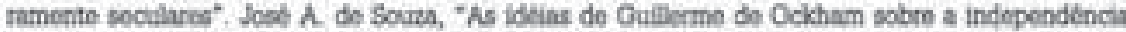
do poder imperial". Franciscan Stadies, Vol 46, 1986, P. 265 John Xicullen, "Ocibam and his Dialogue", p. 1.

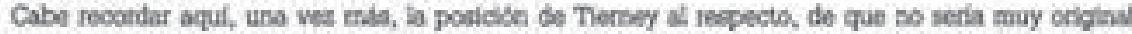

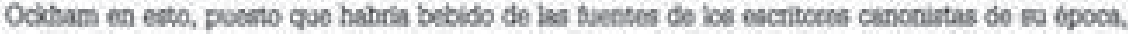

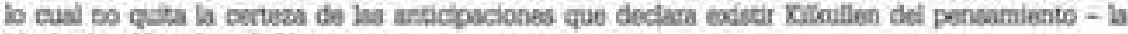
iscologia - Iberd en Ockwar. 
tales supuestcs gérmenes del pensamiento liberal, sino, puntualmente, su concepclón acurca del origen del gobierno, en concreto los elementos contractualistas dispersos en la totalidad de su fllosotia politica y como el Venerablils linceptor los fundamenta y defiende."

Paola Muller trmbién se hace eco sobre la supuesta relación entre las pertes teorica y práctica (metafisica y politica) de los escritos de Ockham, destacando, a su vez, cuáles habrian sido los propositos de Ockham al tomar parte, tanto de la polémica inictal con el papa Juan XXI, como asi también durante el resto del derrotero seguido en sus escritos politicos, donde destaca, especialmente, su clata Intención de separar las esferas espiritual y temporal, adjudicalndole al poder eciesiastico una soberania estricta solamente en la primera de estas $y$ al poder secular en la ultima:

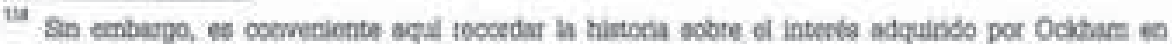

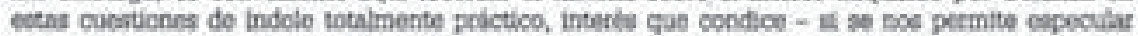

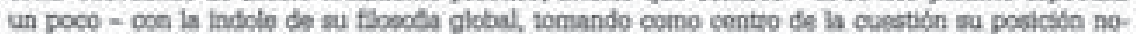

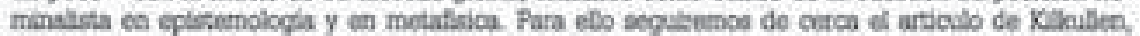

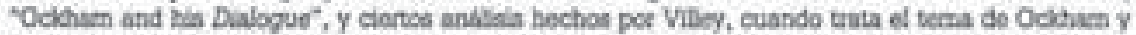

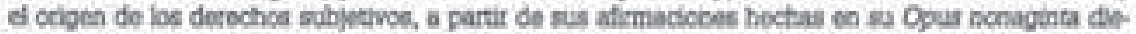

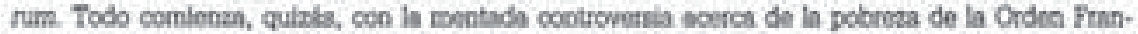
ciscana. Bsth claso que deriteo do la Ordea no babta un persamsento monolitico scbee esta asunto,

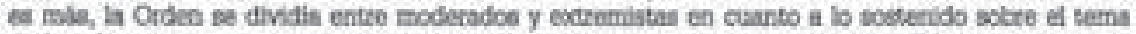

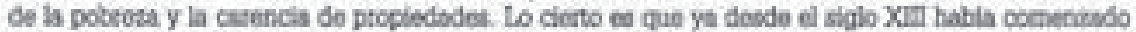

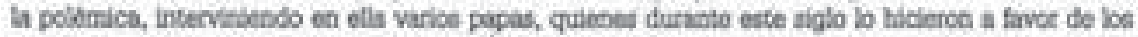
Fanciscasos y en coetra de Bas ctricos. Butos se dodloarca a atacar la Ouden desde fuera, no pesutaglodoee solo a mas practicas, sino tambile al joded soutendo, "alegando que tal punto de visti

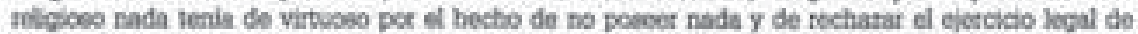

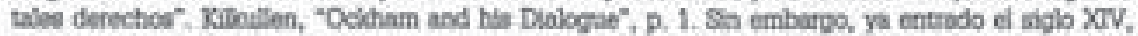

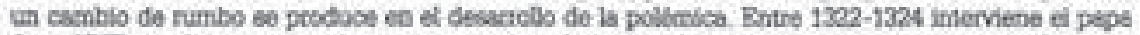

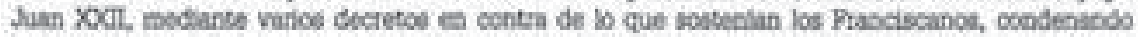

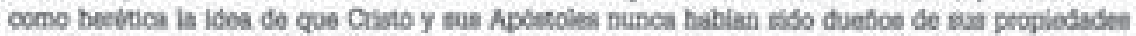
y doclarando que les Frasclecanos deblan aduetarve legakrsente de las ptopiadades de las que

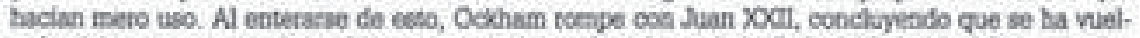
to berkcico, procese ea lo cual es acompanado por il cabers de la Orden, Michael of Cesena y de-

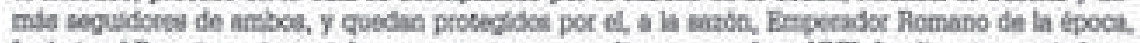

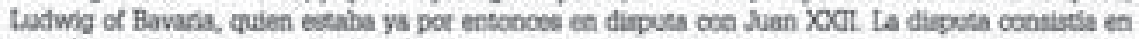

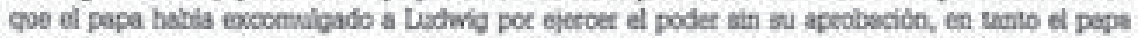
sostenfs que nade podia legar a sor Empesadot Roemano uin su anuencla y Ludvio babia logado hablendo rekclabdo electo pot la tnayoria do los principes Electores del lmperio, odomia de baber vencido a su coetrincante en uns batalla. Ast tse coeso en Munich, residencie de la corte imperial on Ludvig of Bevank, ballo Ockham trasgulbad fisica y ergiritual, permaneciendo por el resto de was idoss en la cladad alemans, produchendo mintiples escribos contfa Juan XXII y Benedicto XII,

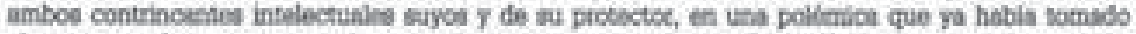

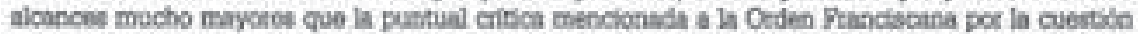

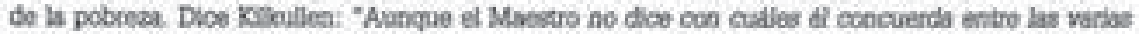
cpinjones que el prosenta, esto no es normalmebte use difleultad para que podarnos conjenuraf; 0

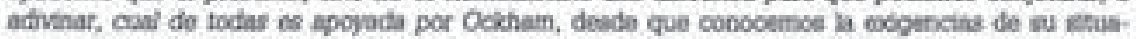

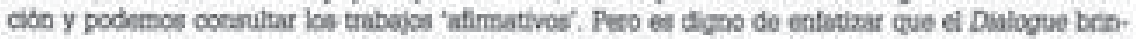

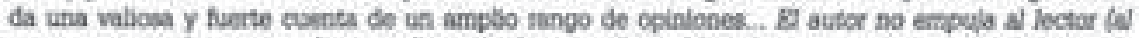

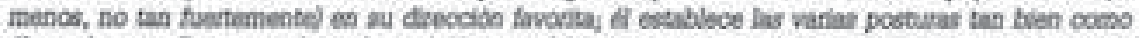

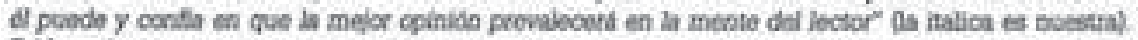
Ibid, 0,4 . 
"El confrontamiento crition con las posictonos precodieates y la afirmscido de la inds. vicualidad de lo real estan en la base también de las obras politicas do Ockham, concertradas en el segundo periodo do su vida. Los tomas aftroatados en estas obras giran en torno de dos polos de interés; uno tecibgico (pobrezas de la Iglesia) y uno verdadeto y proplamente politico (la satuzaloza y las caracteristicas del papado y del imperio). Ockhnm defiende tenazmente a pobsezs de la lglesia, teafirmadn con firmeza por las Ordenes mendicantes, legitimandoto a traves de troctos del Nisevo Testameato. As: también corno un decidido ataque a la hierocracta y al goblerno eciesiástico, debende la autconcemia del poder civil nate el poder espiritual: Iglassa y Bstado son dce esteras autánomas, cada cual soberana ea su pecpio dembito fap. M. Dal Pra, en su estudio "Sul fondamento della dottrina teocratica" (en: M.T. Fumagalli Beonio Btoochleri. La chiess invisible. Mlano, 1978), trata sobee el nexo entre la concepclón naminalinta de Ocktham y ef desarrollo do mas tecrias sobre la lolosia y la sociedad|" tas

Tal vez resulte más aptopiado afirmar, junto a Paola Muller, citando a Btocchieri, aún asumiendo la tesis de Tierney sobre el origen - canónico - de las ideas furidicas asumidas por Ockham, aunque sin pretender negar las investigaciones de Villey sobre la relación de Ockham con los derechos subjetivos de los Franciscanos, esta ultima parte de su cita, la que coloca el énfasis en la separación de esfetas, politica y religiosa, que pretende dejar asentada Ockham. Pot supuesto que el fundamento juridico y metafisico de tal separación estaria dado, según los desarrolos que hemos analizado de la totalidad de su pensamiento, por su insepatable adhesión al nominalismo. Asi lo estaria indicando el poder terrenal que Ockham declara posee cada ser humano, lo cual se manifiesta en el ejercicio de sus derechos (naturales?) a elegir sus propios gobernantes, prenrogativa que le es otorgada por Dios a partir de la entrada del mal en el Bdén, funtamente con la introducción de los derechos - naturales? - a la propiedad.

Culzás seria demasiado simplista sostener con Villey que todo el desamollo de la flosolia politica de Ockham comienza a partir de su polimica delensa de la Orden Franciscana, contra el papa Juan XXII, sobre el problema de la pobreza," la cual aparece expuesta en los primeros capitulos de Opus nangginta dienum." No seria

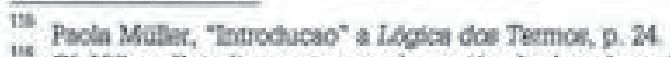

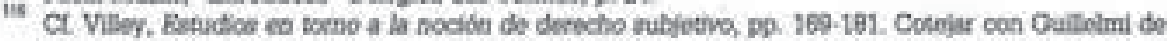

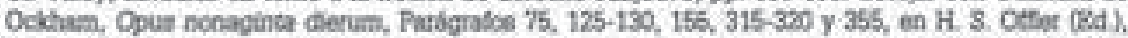

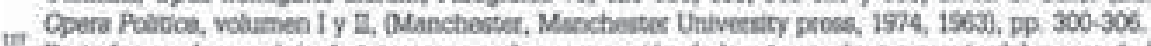

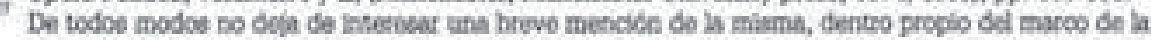

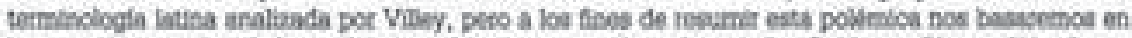

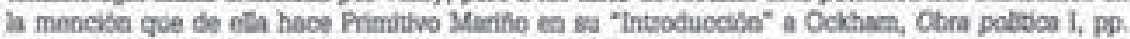

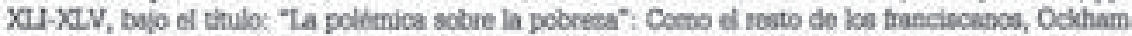

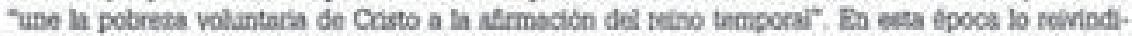
cado pata Cristo ena el dominio "emibente", el derecho "princlper" sobre las cosas y no un mero

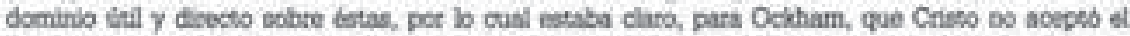

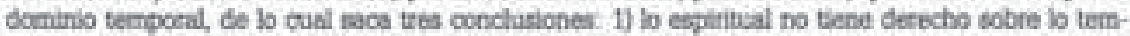
poral, por ebo la teripocal no se deriva del poder espintual; 2) Cristo no viene peenogativas acbore io temporal, por gtopia voluntad, 3 Como Cristo se someth a fa autecidad del Celat y de Pato, tarn.

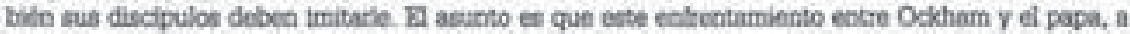

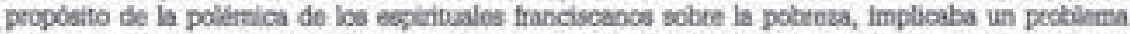

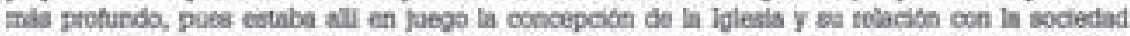

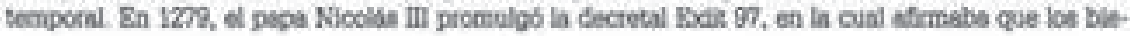


demastado logjico concluir de esta pequeta cuestion tan puntual y eventual que el gran desarrollo y dedicación que asume Ockham en sus eecritos politicos no se deba a cuestiones más amplìs, que ya venlan siendo problematizadas - coincictiendo con Terney - cada vez con mayor fuerza, tanto por doctores en derecho como par filibsofos politicos, entre ellos su contemporaneo Marsilio de Padua (1275-1343), cuyas intenciones fueron notablemente más secularistas ${ }^{\text {nil }}$ que las del propio maestro de Oxford, ${ }^{17}$ como ast también fue mucho mayor su independencla del poder del papado (casi inexistente), con bo-cual el énfasis puesto en las cuestiones politicas y sociales polemicas con la Iglesia fue considerabiemente mayor. ${ }^{\text {." }}$

Dee entregados a traile menorts pasaben a propiedad bo la Sede Apostollec. Los fralles creian que el bocho de tenet propledsd foe el resultado de la ousda do Adin en el pasalso, per lo tanto stio pretendian el cio do los bienee a fin de vivit la pobreza evangetics. Joan XXI, no compartiendo tel

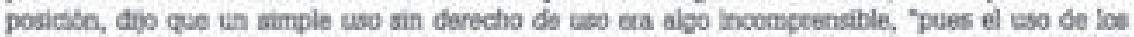
bleose consumibles por el uso no prode tepasarse de la propiodad", conchyondo el papa gue tanto

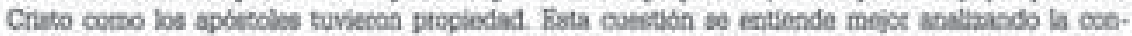

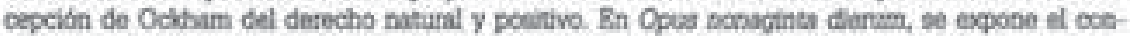

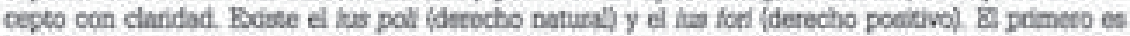

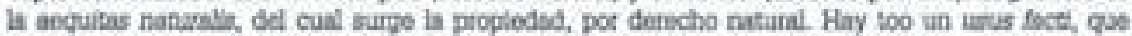
significa uat be tienes con denecho natural primigenio, el mismo quo edatia artios de la caida, en donde todo era cochiln e innecesaria, pot ello, la propiedad. II decocto poeitivo, jus fart, derva del natural, lue poll, gue no se coctrindice con aquet ni cea el divino positivo. Y edste un tetcet dete. cha, el fus ountium, derivado del fus poll, que too es derocho peeitivo y no puede ser pontrario al

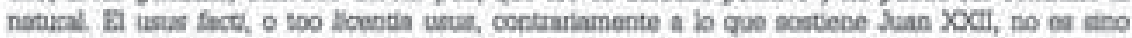
una potestad, un "decocho rubjotivo", como afirma viloy, io cunl no serla exclartwo de Ockham, II:

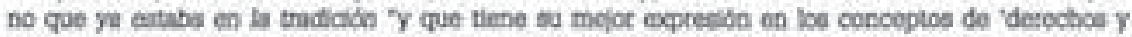
Ibectadeo' que tanto guesa Ockham de repetir en alu Ocho cuestines'. Segta Viber eute derecho

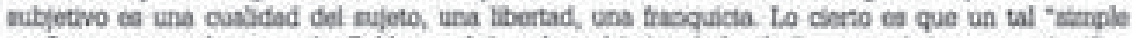

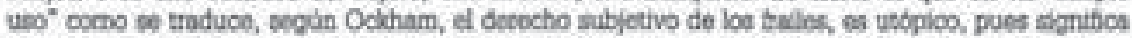
welver a un estadio provio al de la cabsz original. Ockham ptetendla li voeita a un estado de liber.

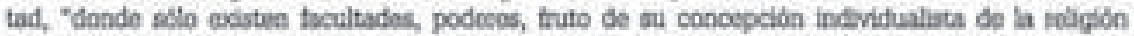

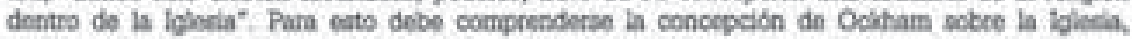
opuesta a la tradicienal eve la ectiende como cuorpo mifrico, moral, oge peesconlidad furidica, con

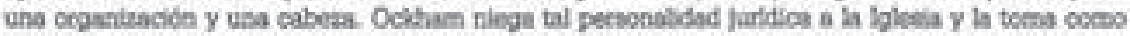

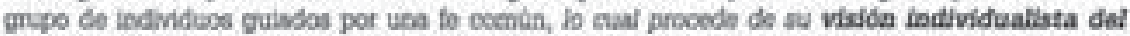

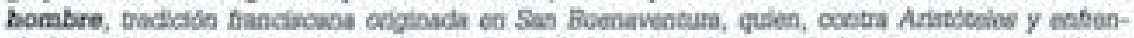

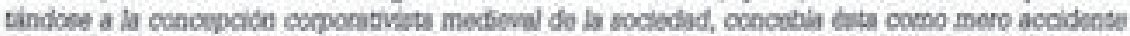

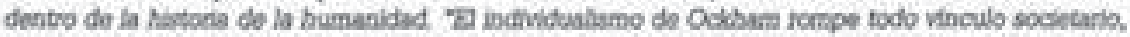

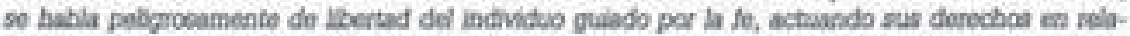

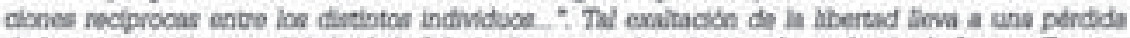

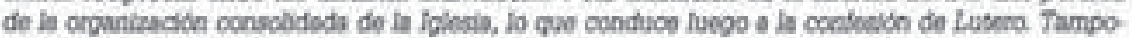

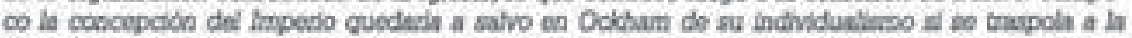
sociedad cove enu concepcida toolobica andicuiporativista.

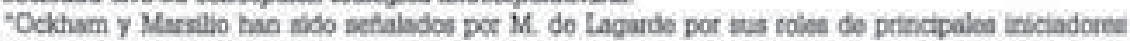
ded Batado socular modecno, y ea este trabajo es Ockhare quien, contrariamente a la opinido uvasl, fuega el mayce papel Bato es debido a que, dice Laguede, el intelocto de Oclhum estuvo más ca. pacitado para hacer uso de la tecdencias do la osclodad ecleatistica y secular del sifolo catorce, las

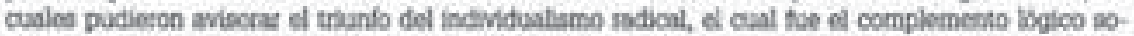
cil para su tioecla", John B. Morn?

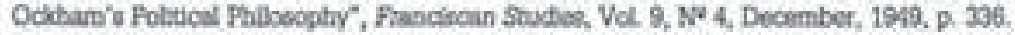

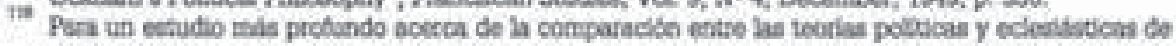

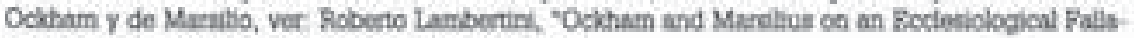
of, Pranciscian Studies, Vol. 45, 1966, pp. 301, 313.

C. Marsilso de Padas, Defeneot Puds. 
Si consideramos aspectos no tan puntuales y concretos como la polemica aludida antes, entre papas y franciscanos, "I dando su comespondiente credtito a to mencionado por Paola Müler al final de su ultima cita expuesta - que por otra parte no deja de ropresentar una visjón integralista de la flicsolia de Ockham - tal como hemos tratado de demostrar en este trabajo, apoyados en toxtos de todas las disciplinas aludides sobre el pensamiento del inglés de Oxford, Degamos al punto de vista abstracto denotado en otros aspectos politicos concretos y particulares. Nos reterimos a la postura ascendente sobre el otigen del goblerno y de la sociedad, lo cual expresa Ockham en un lenguaje que ya es cuasi-furidico, sea o no verdadera - no hace a la esencta de la cuestión y menos a influencia que Ockham pudo haber proyectado sobre los contractualistas modernos - la mentada infuencia ejercida sobre éte de los canonistas de los siglos XII y XIII."

Resumiendo y clarificando lo que intentamos dat a entendet, el recorrido de Ockham en su pensamiento politico podria set puntualizado como sigue:

1. Ockharn, mis fel a su Orden de los monjes Pranciscanos que a la institución del Papado y al propio papa Juan XXII, polemiza con tste, sin cortapisas, dejando en claro su posicion respecto del devenir de los hechos, desde los tiempos del Bdén hasta su epoca, deteniéndose a tematizar la cuestión en un momento importanto de quiebre en relación con el concepto de propiedad ${ }^{\text {t2i }}$ Bate quiobre histórico esta constituido pot el acontocimiento de la entrada del pecado en el mundo (pecado otiginal). Aquí establece las diferencias terminologicas que el consideta aptopladas, en cuanto a su comprension de las ideas de "dominio", "dominio comuin, propio y precario", "derecho natural", "derecho de gentes", "detecho celestial", "uso y consumo", "ley natural" y "ley positiva".

In "Permeneciendo en Avignon dutante todo aquel tiempo, Ocktam tuvo una ocablon de enterarse respecto de dos grandes pollmicas que agisaban ls Cristiandad occidenal Una te ellas, que co-

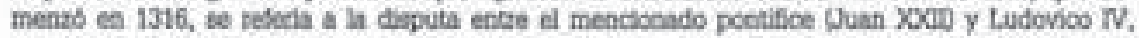

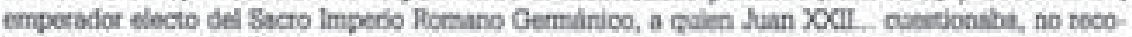
nocidodolo como tal La otn querells tambien envolvia a aguel papa y la Onden Pranciscaca so tra-

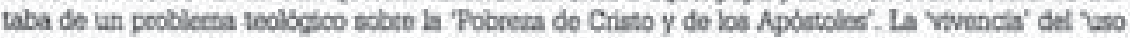

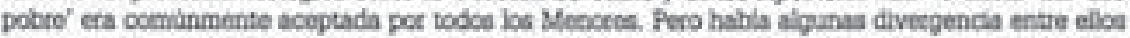

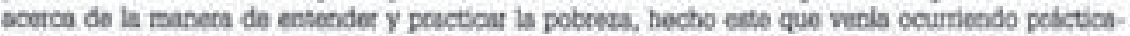
mente desde la segubds mitad del siglo XIII. Algunos papas, como Nloolis III y Clemicto C, intentaren, a traves de sus bulas pecmulgadas, 'Boeit cal seminat' (1269) y 'Bovil de Paradioo' (1312),

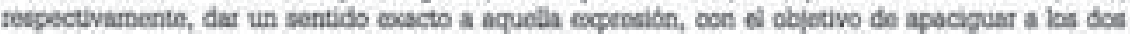
grupot que habian aurgido ea el seno de la Opden poe cauna de la cuestión antes clitada. Amboe

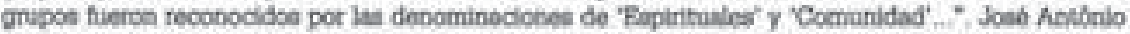

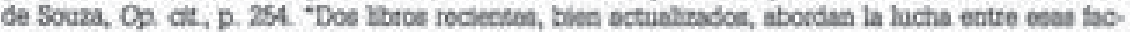

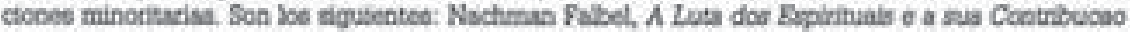

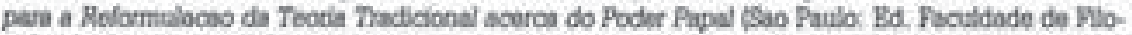

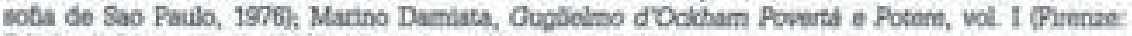

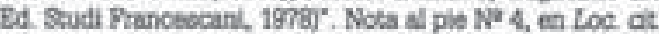

Con vespocto a esto. MoGrade ha teallisdo un exhaustivo estudio, sintetizado en su theo The

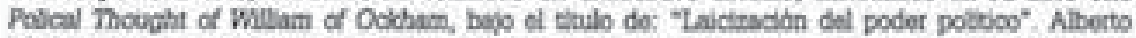

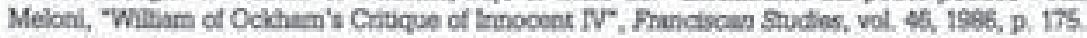
OMer, "Inteoduction", an Opera politia L DD. XV-XDX. 
2. Al afimat esto, en defensa de su Orden Franciscana, entra en franca coalición contra los papas de su época, especialmente Juan XXII, Jlegando a la conclusibn de que este cae en herejifa a ralz de las declaraciones bechas en su con. tra. ${ }^{21}$

3. Ockham tecibe el apoyo de varios principes anticlericales que se disputaban, contra la institución del Papado, el poder temporal del Imperio, entre ellos, el principal, Luls de Baviera, ocronado Bmpetador en 1328, por traslación directa del pueblo al emperador, ya que "recibe la corona de manos del pueblo romano" (la italica es nuestra), ${ }^{\text {ra }}$ La curia eclesiástica reacciona contra la secularización del poder imperial - ya hemos visto que antes el único capaz de coro. nat al Emperador era el Papa, cuyo principal precedente problemático estuvo en lis asunción de Carlomagno."

4. Juan XXII excomulga, como logica consecuencla de tal acto, a Luis de Baviera. A partir de este hecho Ockham deduce do la "institución regia", que no es necesaria consagración alguna en la sucesión hereditaria, pues los derechos, originariamente emanados de la voluntad popular, pasan de uno la otro sin medisción alguna. "Bsta puede surgir por voluntad popular, segùn el derecho de gentes; puede también ser una creación del emperador o de otro tey que tenga varias provinclas sometidas y ve la necesidad de creat un nuevo teino por el bien comuln". Esto lo dijo a propdeito de la excomunión que sufrió Luís de Baviera por no someterse al examen de Juan XXII."

"... Peto tal vez dira alguno que, aunque el papa no pueda por lo regular constituir un tey, el, lo puedo oventunimente, a saber, en caso de necosidnd, como nuoedís cuando Pipino tue constituido rey de los francoo.. Pues la creación de reyes competia al emperndar; $y$ sid late fue negligente, la potestsd de crear reyes no era devieita al papa, que de acuerclo con la autondad del Apdstol antos alegada y de los sagrados cinoDes, no dobe entrametarse en asuntos seculares, sino que se devalvis a los fornancs. S Estos toras neghigentes, hublera sido devielta a los trancos en caso de necesidad; y al faltar todoe estos, hubiera sido devvelta al pupa, quesen en caso do pecosidad, puedo suplir ta negisgencia de equellos a quienes pertenece con prionidad la potestad de bacer alpo.

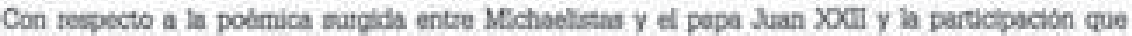
Oekhain tarvo en elis, of. Geotge Koryha, "Odham's Avignon Period: Hibliographicai Rocidcotions".

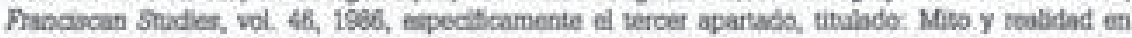
relacion con su salida de Avlence, p. $77-84$.

in

Pirmitivo Martio, "Tntrodsoción" a Ocklam, Cora policioa 1, a. XXXXII.

Luego (Ockhim) enumera ens serie de lugses donde es un enpafo que el pepa haya trasladodo

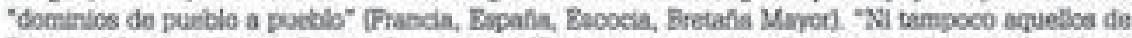
Bectaha Mayor gutrieton lamar al aumo pondifoe para una trasheion, dectitudion o inetitucion, y

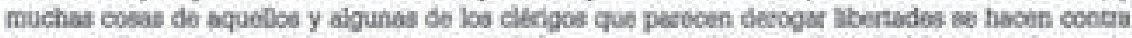

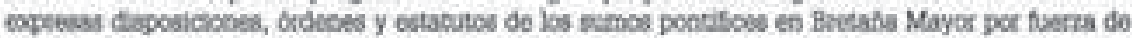

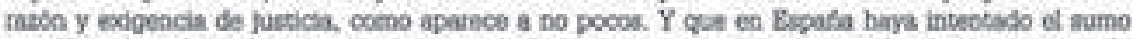
portifico el tralado del reino de Asagen, muchce plenean que fue inicas y de elegin modo puda

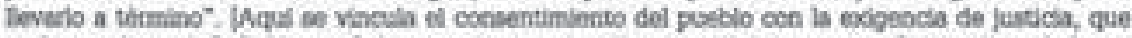

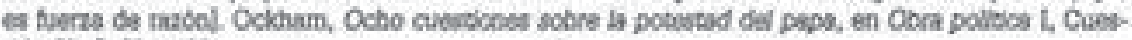
Uion $2^{\circ}$, C. X, p. 89.

Primilivo Maritio, Op. at., p. XXOXVill. 
Y $\mathrm{Y}$ si se preguata por quien fue trasladado el Imperio do los gringos a Carios, se respondo que sobre ollo hay distintas opiniones. Una ea que dicha traslacion fue hecha por el papa... Otrce dicen que la tresiación aquella tue hecha principaltnente por el pueblo romano, una de sus partes en el papa y otra el clero. Tales palabras parecen decir que el papa Lode corcób a Canlos por woluntad y orden del pueblo rcenano al que competia dispocet sobre el Imperio. Por ello, la traslactón ded Imperio de Grecta a los alemanes fue hecha por el pueblo tocnano ain excluaion dal papa y del clero; ello pateco probatne asf: Compete peincipalmente la traslación del Imperio, sf es que debe transferirse, a equelios pot quienas tue establocido el lmperio. Los romancs, y no el papa, instituyeson el imperio. Luego por los romanos debe bacetso la traslacion del Imperio. Esto se confirma: La traslacida del Imperio portenece a la potestad temporal. Pero el papa en cuanto papa de ninguln modo, al mence da manera regular, debe entrometerse en lo tempceal, no sea que parezca derocar los derechoe de los seglares.. Luego ya que, como es claro de la ceónica alegada, los romanos estuvieron dispuestos a transferir el lmperio, el papa no pudo transferiflo con autoridad propla. porque ef papa corcnó emperador a Carlos cos la autoridad de los tomanos, o porçue el pueble tornano atribuy $\delta$ al papa como persona mis clevade entre elloa ln potestad do transfoiflo. " Ca italica ee nuestra),

Aqui queda demostrada, a traves de la exposición de las diversas y secuenciales instancias de decisión, a quien pertenece la soberanla y como se la puede traspasar.

5. Ockham, quien ya dijimos habia tomado parte a favor de la causa de Luis de Baviera, escribe abundantemente acerca de la teoria de la separación de poderes, temporal y espiritual, asignandole con plenitud el primer poder a los gobernantes terrenales y el ultimo a la institución del Papado. Prente a la posicion monista del Papado, Ockham sostiene un dualismo de poderes (con ciertos matioes) al modo de Marsilio, quien ya dijimos, es mucho mas secularista que aquel, hablendo llegado incluso a separar el derecho natural del derecho divino, pero está clazo que pera ambos fibsofos medievales el gobiemo tiene su origen en el pueblo mismo, quien detenta la soberania que Dios le otorgó para que pueda elegir a sus proplos gobernantes. Primitivo Marifo, en su Introduceion clvada, comenta lo siguiente con respecto a la $2^{2}$, de las Ocho cuestianes sabro la potestad del papa, en la cual aparece nitidamente la noción de pacto creado por artificio humano, fundado - a diferencka de Hobbes y demas contractualsstas modernos y neocontractualiotas contemporánecs - en la soberania que Dios le ororgo al pueblo:

Tos dos principlce que sustentan la eleociob del emperador ramano san la soberania del pueblo, hablando en términos más modernos, y el pacto de constitucí́n. Dos prin. cipice que la dogmática moniru techazabs. Bl primero es tundamental para entendet también la potestas en Marsilio de Padua, pero en éste con la consiguiente subordi. nacion de la potestad empiritual a la verrporal, lo que no sucede en Ockham quico sigue distingulendo las dos potestades. La soberania reside en ol pueblo, es principio democration, esta es la única manera que puode conforit la potestad, la fufiediceide. La potestad es, pues, una creacidn, una ardinatbo humans. Pero es necesarlo que el 
pueblo acuerde dar la potestad, es lo que se llama el pacto del pueblo para crear una autaridad, pocto implicito en la aparición de la autoridad, y pacto historico en el lrnpe. ro Rcrnano, la elecoson imperial rocmana antes de Cristo por el seoado y el ejército" la negrita es nucstra),

6. Con esto se da por sentado que a partir del pecado original, con la irrupción del daminium y los derechos de propledad, cedidos por Dios a los hombres (el pueblo), estos retienen la potestad (potestas), que no es otra cosa que un artificlo humano. El trastondo del derecho natural = divino, ${ }^{10}$ queda claro que permanece en Ockham, y que gula siempre al pueblo en la elección de sus gobernantes, pero... ¿quién garantiza después del pecado original, con su natural desenlace en el egolsmo bumano y la necesaria división de la propiedad, la dirección divina del pueblo al pactar entre sil la eleccion de sus gobernantes? Nos estamos quedando ya con un artificio - el cual es también el fundamento de la fusticia - que si bien por ahora es plenamente natural (en Ockham), no obstante, asi mismo, llega a serlo tambien plenamente humano, aunque no sera Ockham quien derive a tamahlas consecuencias. ${ }^{\text {in }}$

7. Hay en Ockham, en el origen del goblemo, una concepción explicita del pacto. Luego, al igual que sucederá més adelante en Hobbes, el pacto se torna implicito. Pero la gran diferencla con Hobbes es que en éste el pacto no podtá ser revocado, no habrá postbilidad de deponer a un tirano. Las propias leyes contractuales ast lo declararán explicitamente. Bn Ockham, en cambio, debido al lazo que aùn mantiene entre el pueblo y quien originariamente le ba otorgado el poder, Dios, a lo cual se agrega que el detecho natural sigue siendo el fundamento de todo poder y de la detentación de la soberania, hay ple. na posiblidad, in extremis, de revocar un mal gobierno, deponer a quien lo detenta por hacer un mal ejercicio del mismo y reorientar un nuevo contrato social en función de los intereses del pueblo, quien, por derecho natural inberente, nunca pierde la soberania que Dics le otorgó. El pacto de unión está claro, el procedimiento de ejecución es siempre el mismo, la difetencia esencial, aqui, todavia, radica en su atributo de revarsibilidad. Bsto lo expone, no sin dificultades interpretativas, en su obta Ocho cuestiones sobre la potestad

Primitive Marifo, Op at, Ds XXXVIE-XXCXX.

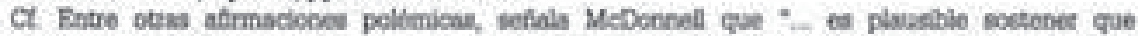

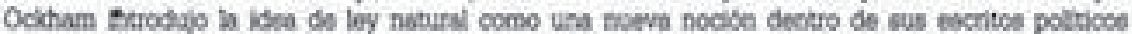

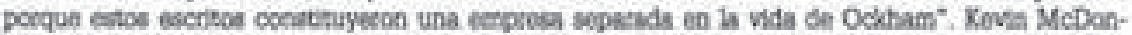
Dell, Op ct, D. 383

the pecto de coestitucibo de la autoridad goe para Ockham ea una de las forman de crear una auto-

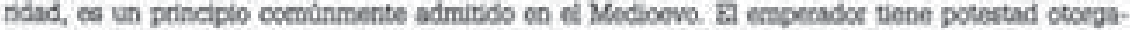
da; no ticen el lmperio es propiedad, porgue ef pusblo da su soberania a la dignidad imperial no a

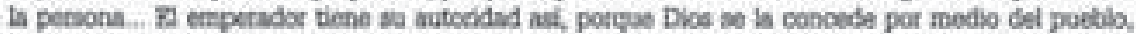

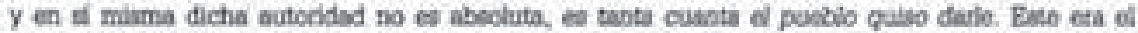
modo de sente do los juristas en ol Mediowe. For elo tambion la autonded es istranderible, indivi.

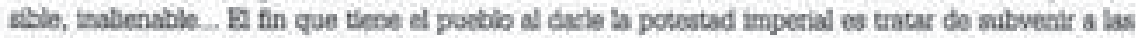

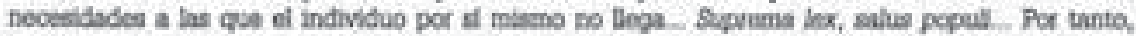

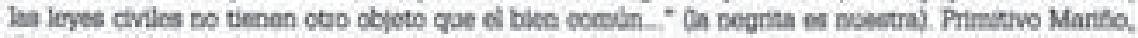
Qpa ci, p. XXaX. 
del papa." Lo trata especificamente en la $2^{4}$ Cuestión, Cap. II, donde se refere a un torcer modo de inmedlaté - sobre lo cual volveremos luego, a fin de determinar algunas sutilezas del pacto, estrictamente ockhamianas - afitmaciones éstas que quedan plena y definitivamente confirmadas en el inconcluso Breviloquium y en el Dialogus: ${ }^{\text {in }}$

"Peto hay un tercer modo de intrediatez de Dios; el pueblo per equildind natural ve que lo es necesaria una autoridad y elige un coudilo, el emperadot, para que nja sus destinos y le ayude a cosseguir el fin de la sociedad. El pueblo cedo tods la autoridad al empoctador o roy, pero ya no lo conserva el, porque la confiere a la dignidad que elige" - en terminos escolisticos esto se lama "couisa initrumental": "Ios eloctores en la elección del pepa y del emperador, y el pueblo en el principio detnoctatico de eleocion de un emperadot en el Imperio Rocnano son inatrumentos de los que se sirve Dlos para infundir directamente la autoridad.. La autoridad sigve excistiendo, aunque actíe mal, Ii ha sido bien constitulda; puede, no obotante, petder la legitimidad y set de nuevo abeorvida por el puebla. Dentro det torteno de li corrocción que puede necesitat el ecnperadoc al desviazse del fla pot el eual tue creado, tanto Ockham, como antes Marslio, dicen que es el mismo puebla que be cred a quies conrespande dicha correckida" Ga negrita es nuestra). ${ }^{24}$

8. Queda claro que en esta concepcion del poder, también la autoridad imperial esth sometida al derecho. De modo que el derecho natural es ejercido por quien estipula $y$ establoce la fusticla, pero ésta, en última instancla, le corresponde, por mandato divino, al pueblo, quien se la otorga al "principe"; con ello Ockham nos introduce en una antesala dol absolutismo de corte hobbessiano, puesto que, según el maestro de Oxdord, un soberano único es quien mejor puede atender a los intoreses del bien comuin de los súbditos, en tanto y en cuanto ptactique la justicia natura:

"En la Bdad Meda se habia ertudiado en protundidad la relacion entre el derecho y is justicla. Si bien el emperador, rey o principe esta scbre las leyes, no prede legisirt en contra del detecho natural. El detecho poeitivo dado por el principe no puede estar en contradicokion con el derecho natural. Se repetira constantemonte que el principe es lex animata, eccarnación de la ley, en cuanto que practica la fusticia.. El conocimiento do

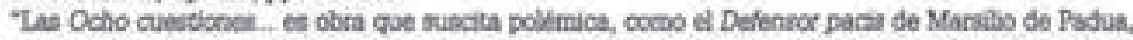
escrito entro 1324 y 1306 , aunque basa tiene tundactentot mas radicales que la det semeroso Celhinm. Temetceo decimos, pues ante la amenaza de una centura ecleatiantica que ya habla pendido sobre el por thadth de sus loctones seclogricas en Oxfort, Ockham hobla do un mbleodo en lat cutationos que aquil se plantoan, que Do es otro que 'recitat cpiniones' can inimo de exhavativi.

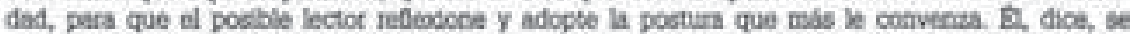

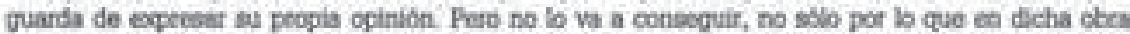

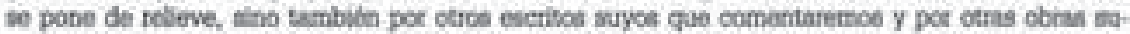
yas, como es el caso de sa Broviloguio sobre el gobiemo tirainico del pepa, cber que acabs de aparecer aboes en lengah castellana. Otles, el eteror y estudioes de la cbera pelitica de Octham, ia que

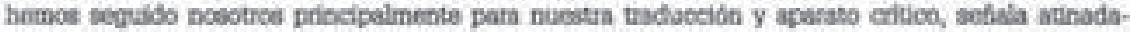
mente to que parece ser pensamieano propio de Ockham en las Ocho cuestiches, que no en otro

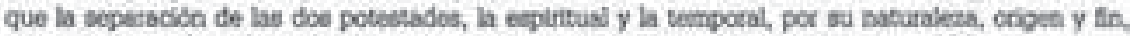
peso sia detmo de enfrenkarlss, sha de coondinarlas". Primitivo Marka, Op. elt, p.XVI

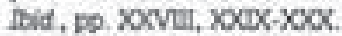


Aristoteles actua de dotonante para romper et moniemo aobce el origen de lie autocidad - iniciar la secularización de la sociedad. Se ahonda más en el derecho humano, natutal: este derecho bumano se encuestra en la sociedad y en sus peincipes que lo posttivizan mediante leyes" :

9. Ockham, Aristcteles y Hobbes: Cabe en este punto establecer algunas comparactones, siguiendo, en parte, la pluma de Primitivo Marifio. Ockham, buscando el bien comùn de los subditos, como Aristcteles (y también lo hará Hobbes) cree en el principado único, la monarquia (como Hobbes), pues esta institución es capaz de reducir mejor los conflictos entre poderosos de la sociedad. Bn la propia naturaloza humana radica la razon última de existencia de un único emperador. Ockham toma en cuenta el principio dado antes por Marsitio de una "comunidad de los que pueden tener union entre si". Ockham thene en mente el primado de la defensa del bien comín y critica al gobierno aristoctático bajo el motivo de posible pérdida de paz. "Aristóteles habia hablado de la sociabilidad natural de los bombres para constituit una sociedad, pero no hablaba de pactos" - porque al ser el hombre un animal politico no necesita de pacto alguno para unirse en sociedad ni es necesario tenerse a raya uno al otro, tal como luego fundamentara Hobbes - "sino que expresaba tan soblo el finalismo natural", Ockham defiende la forma y realidad historica del gobierno del Imperio de los romanos, por lo cual le resulta dificil justificar el nacimiento del Imperio mediante el pacto constitutivo, hecho por el consentimiento de todos los pueblos del orbe. Tampoco lo justificaria por una supuesta unidad del mundo; la historia del Imperio narra una serie de conquistas, guerras y pueblos sometidos por la fuerza. Pero el hecho es que Luis de Baviara, protectot de Ockham, cotonado emperadot en 1328, "recibe la corona de manos del pueblo rousano". La curia eclesiastica teacciona, entonces, contra la secularización del poder imperial.

10. Las sutilezas de su tecria politica. En sus Octo quaestiones de potestate papae, a pesar del método usado por Ockham, el tipico de la disputa escolástica, mediante el cual pretende dejar constancia, oon la mayor objetividad posible, todo el abanico de opiniones relacionadas con la polémica cuestión sobre la separación de poderes (terrenal y espiritual) detentados por el papa, a pesar de todo este aparato de ideas que va tejiendo $y$ entretojendo junto a los argumentcs y conttaargumentos presentados a favor y en contra, alternativamente, de una y otra posición - y en ocasiones también de una tercera - Efnalmente se logra interpretar cual es su propia opinión sobre el tema, sobre la base de la lectura de otras de sus obras politicas, particularmente el Dialogus y el Breviloquium, donde prácticamente expresa sus opiniones sin ninguin tipo de tapujos,

Coesentando el valor que posen, dectro del conjunite de los escritos polivicos de Ockham, su chra

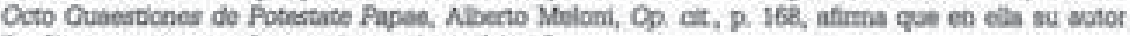
"realita mia mayoos obeernaciocos statotnicicas". 
"En clento sentido es congruente con el derecho naturnt el que el emporador no soa juet cedinario del papa y el pepa no aed en to temporal fuen ordinarlo del emperador. Por ello, adi natie es juez supremo de todoa los seles sin excepcion de nadie.. el papa por lo regulat no puede deponer a otros reyes por is potestad que le concedis Criato. así no puede pox lo segular depocer al emperadox, comocuiers que sea morecedot do ser depsesto por cualquiet falta o delito que no haya que computar entre los delitoa

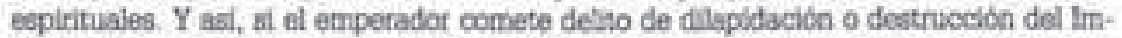
perio o de negligencia condenable oxn peligro del Imperio y de tiranha, o cualquiot otro abechutamente merocodot de ser depuesto, los tomanos o aquelios a quienes loe tomances dieron su potestad deben deponerio, y no el papa, a no set que aquelios a quienes compete le entregaran su potestad, o a no ser que aquellos a quilenes compete, no quisieran o no pudieran bacer complemento de justicia, y fuere inminente el caso ea al que seria nectsario ejorcerse justicla contra el emperadort" th

De este modo quiere dejar constancia de que la rebelión estaria justificada por parte del pueblo, quilen pacta con el rey, al tempo que sethala que es el pueblo, titular originario de la soberanila y, por tanto, ejecutor del pacto, quien tiene en sus manos el derecho "natural" de deponerlo si fuete necesario por su propio bien. Durante el tratamiento de la Cuestión $2^{4}$, Ockham parece que quisiera explicar los sucesivos pascs en el proceso de secularización, mostrando ofmo antes el pueblo retiraba su consentimiento consultando al papa, to cual tinalmente, en su epoca, ha dejado ya de ser; el cambio ha sido notable, pero Ockham lo explica como un proceso cuyo desartolio ha sido por demas natural y obvio, Por ejemplo, afirma Ockham que el rey de Francia:

-.. no reconoce en absoluto superiot en lo tempotal. Lo que no solo el tey sontiene, sino también los habitantes del teino comünrente sortienen. Por lo cual no creen que el papa con autocidad propla pueda deponer a su rey fuera del caso de necesidad, si eilos no son negligentes... Luopo aquelios francos, dudando quizis de sa poteotad. consultaban al papa coeno a sabio., preguntaban si les exo licito segin Dios deponer a su rey. Pero en nuegtros tiempca, bo dudando en abeoluto de su potestad, alpunos depusieron a sa rey mediante sentencia sin llamar al papa, porque, como dicen éstos, no competo al papa constituir ni destituir reyes, cuando las pueblos no pasecen ser un peligro en la constitucioin y destruction de sus teyen, nil sen negligentes condenables:"

Como bien to expresa Primitivo Masifio, en su Introducción cltada, hacia esta época de los confines del Medioevo nos encontramos a Ockham "inmerso en plana disputa sobre las dos potestades" ". Lo debatido es el terna de la autoridad, particularmente lo que Ockham pretende es reducir la potestad del papa a lo puramente espiritual. Esto dará por demás motivos para influir sobre el movimiento de la Re. fcrma y tal recorte de autoridad ternporal hecha a la instutucico del Papado no harl sino poner mis claramente de manifiesto el fenomeno tipico que se viene dando en la sociedad civil de esta época: la secularizacicn de las instituciones y de la sociedad tods.

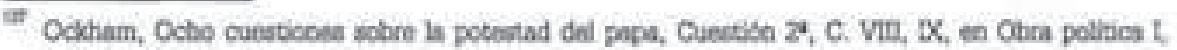
a. $\mathrm{PD}, 85,86$.

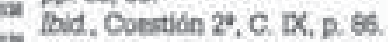

in Pamitivo Marito, Op er, $\mathrm{p}, \mathrm{X}$
} 
El sigio XIV es una época muy critica, siquiendo las huellas de Marsitio, en su Defensor Pacis, pone de relieve la soparación entre lo temporal y lo espiritual, entre el derecho natural y el derecho divino, aunque ambos con origen comuin: Dios; el primero conocido por la tazón y el último por la revelación. "No se contradicen, pero se la ha denominado "concepción secularizada del derecho", trente a la que presenta la ciencia romana, que no separa la revelación de la naturaleza, por lo tanto tampoco el derecho natural del divino, ni la sociedad laica de la lgiesia. Bs ésta última una posición monists, frente al dualismo de Marsilio y de Ockham. El enfoque de este es reducir la autoridad espiritual para realzar la temporal, negándole y reduciéndole atribuciones al papa, para otorgírselas al poder temporal.

Ockham se confronta con la teocracia sacardotal, aunque no lo hace desde una posición tipicamente extrema, sino que formulara las excepciones que prefiere mantener vigentes, lo cual lo coloca en clerta actitud mediadora entre dos posturas slempre irreconclitables, ${ }^{\text {"e }}$ Como ya señalamos los vocablos que emplea para mantenerse en esta mencionada posición un tanto mediadora, son regulariter y casualiter," ${ }^{10}$ con los cuales trata de salvar cierto grado de excepcionalidad en el mencionedo recorte de poderes terrenales a la institución papal. ${ }^{\text {in }}$

iei Otfer, "Introduction", en Ockham, Opere polition It, D. XXX.

ie ibid, D. XCV.

ie is ene sectido es que Joet de Souza fisaliza sa arsiodo, haclendo una contundente apoloyta sobre la intervescide polticar de Ockbam y la opeider asumida por tete en sus cecrivo: "... queda pabente

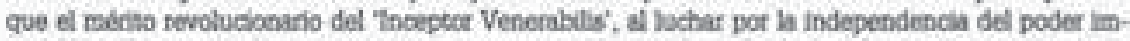

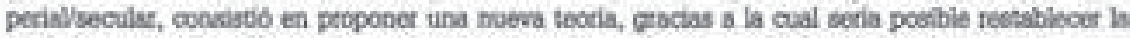

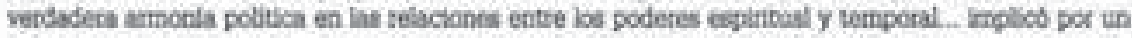

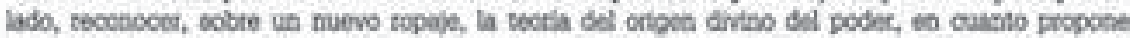

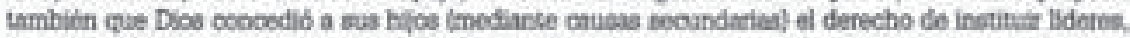

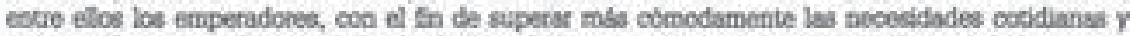
vivir pociscamente. Por otso lado, implios tambuth eo esorimir el detecho de libertad do las perso-

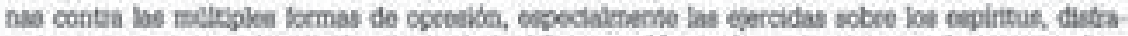

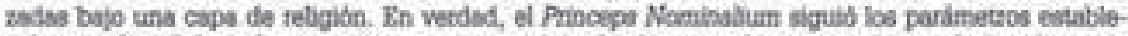

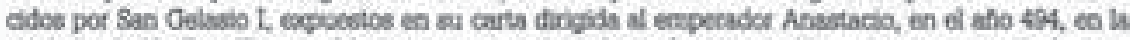

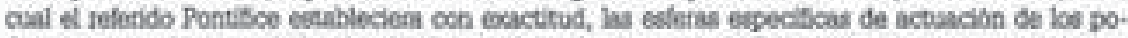

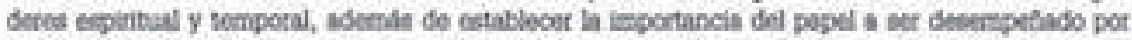
cade uso de ellos. Por lo taceso, El consideramos los eventes de aquolia epoca, adimas do las merat aparienciss, noe cotrvencarensos de que fa aliacta ente Cokham, sus compafietos rebeides y Lado. vico IV, el emperadot rechazado, no nacio exctarivamente per motivos interassdos, mino principal.

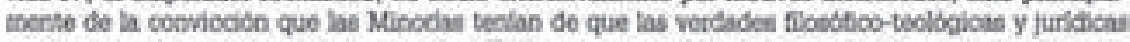
estaban siendo negadas o no rerpetadas. En bese a coto, el Pashetecano Inglis y sus compahieroe so fueton, en abeoluto, uthizados por Ludovioo IV, en favor de su causa, pot el coctrana, ssumieron consdertemente el papel quo les cablia como lindagadoret permanertes' de las verdadns, Nabural y Fevelada": De Souza, Op at, bD, 283-284.

va - En us intenta por armonitas ins dos concepeiones det Divino y el popular crigenes de la sobera. Dla imperial, Ocktam adopta ef recurse de la dastincke entse poder 'regular' y 'cssual', J, Morral, Op. at, p. 365 .

m

C. A. Meloni, Op at, D. 170. 


\section{Cómo fundamenta Ockham teologicamente ol derecho contractual perteneciente al pueblo}

Lo aborda, no sin dificultades de interpretación, como ya dillimce, en la "Cuestion $2^{*}$ de las Ocho cuestiones., en donde se extiende ejemplificando blbilicamente y alguna que otra vec acudiendo a la Tradición de la Iglesia. También lo hace en su Consulta sobre causa matrimonial, ${ }^{\text {is }}$ un pequefio tratado en el cual se expresa "... sobre el grado de consanguinidad o afinidad entre los lastres Luis y Margarita, quienes desean unirse en matrimonio, por tanto esto tendrd implicancias sobte los posibles hijos que procreen". Ockham sebiala que la causa matrimo. nial corresponde a la juristioción de los emperadores - aunque sean tstos infieles -porque "No quita lo mortal quien da lo celeste" ve

En la Cuestión $2^{a}$ de las Ocho cuestiones.. aparece el asunto del pacto del pueblo, con suma nitidez, al presentat Ockham la argumentación scetenida por "una tercera opinion", la cual primeto ptesenta suscintameate, para luego fundamentar biblicamente, la existencla de la voluntad populas y del mutuo consentimiento, asuntos ambos, segùn Ockham - que termina asumiendo esta tetcera posición - de "equidad natural":

-... sostiene (la tercera cpinida) que ni del primer modo ni del sogundo la potestad laica suprema tiene propiedad alguna que le es ptopia inmediatamente de Dios, sino solo de un tercer modo, porque la tiene por donackin del puablo y no por sola donación de Dios. Porque el pueblo no stio ctdeno que hublera una scla potestad stprema ni solb eligio un emperador. sino que ordeno y establecio (el puebla) la suprema poteotad laica, otorgindole de sus bienes peopios, y se los dio a la dignidad, no a la persona... Asil pues, esta afirmacion contiene dos cosas. Primoro, que la potestad laica suprema no thone la propiedad que le es propia inmediatamente de Dios del primet modo ni del sogundo, sino que in tiene inmodiatsmente de Dios de un tercos modo.. Pves, como por la Becrtura divinamente tevelada, seguin Gibesis 1:28.30, consta que Dios dio al gineto humino en coenin el docminio de los bienes termporales, y no es necosario que solo Dioe haga la adjudicacikn de cualesquiera biones de modo espodial, ein el consentimiento y la voluntad de aquelios a quienes so les ha dado ef dominio en comin, we coecluye que no hay que sostener que una aproplacikn tal haya

16

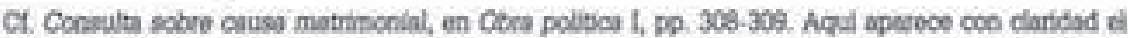

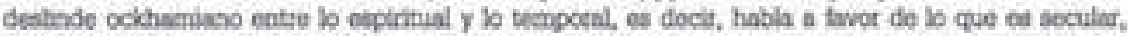
como secruirs hacitodolo a coctinuaciba, a piopbatto de las prersogativas del peez seculac, del puebio que da su consentimiento al pobierno del pelncipt, o el emperador, curya potestad fue tranaled. da por \& pueblo, con be cual Ockham tonarma definitivamente goe toda potertad temporal deviene

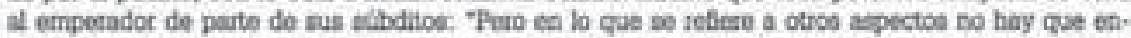

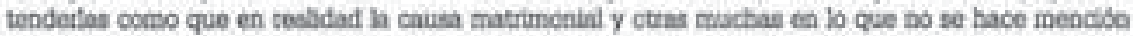

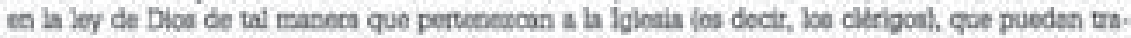
tarlas elos por la autocidod qae en erpecial les coccosdib Cristo, sobre todo cunndo lo roclame o b prohibe el juoz socular o el poeble, athe que puedan deciditlas pet autceidad del peinctpe o del pueblo en virtud de costumbre introducida a sabiendas y corsectimierato del priscipe o del puebila. Per lo cual, el emperador, al que el pocblo tracisfino au potestad, poede reclamar taies carass, aobe todo per culpa de les cilrigos, y con rasten, percue se sabe que tel potestad la ha tenido al rgual

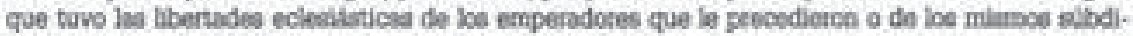
to6". Inid, D9. $308-300$.

16

meid, po, 301,302 
sido hocha por Dios sin la volurtad de aquellos a los que se les ha dado el dominio en comùn, a no set que de ello conete pot tevelisciba divtna., de eato nada tenemon en las divinas escrituras, en las que se inscriben revolaciones divinaa. Luego no hay que sostener que el imperio tiene alguna propledad inmediatamente de Dios del ptimero o del segundo modo.

"Pero de quieses coligen que Cristo al decir: "Lo que es del Clesar, dádselo (Mareo 22:21y, asi cbtuso el Cesar algo inmediatamente de Dios, pues lo mando Cristo, a esto se responde que Criato pot aquelis palabras nada tio de manera especial al César, s. Do que mando se lo devolviarn al César lo que antes habla sido dado pot ordenactón bumana, y por ello no diso 'Doy algo al Clsar', sino 'dadle lo suyo', a saber, aquello que le fue dodo por los hombres. Pues aquelios que constituyeron al emperador o a su predecoscr, ordenaron de modo general o espocial lo que por razbon de la potestad laica suprema debila relvindicar, $y$ esto to aprobo Cristo. $Y$ quien aprueba, nada nuevo cons. tituye, como quien oonfirma, ninguin derocho nuevo confiese... lo que sortiene esta opinibia es que la potestad laica suprecna tiene la propjedad que le es propla inmediatamente de Dias de una tercera maneca... Pues al asignarle aquella propiodact, todo derecho positivo que terian en ela, lo transterian por lo regular por ellos mismos a la su. prema potestad instituida por Dlos... porque Cristo no viso a quitar ni tamapoco a im. pedir el doeninio de teyes o de emperadores, segin teatimonio de Aguatin (Joann. Bvang, tr. CXV, 1-2 PL XXXV, col, 1939)... con lo que enth do acuerdo el papa Loón, cuando dice: De Selor del mundo no busca reino tempocal, porque da el eterno (Lodn Magno, Sermo XOXX, in Bpiph. Sollemn. 1. PL LVV, col. 236).. Tambien porque antes de Cristo y de la teligión cistlana existio el emporador, en cuyo tempo no tuvo superior alguno en lo temporal. Luego ningün sucesor suyo tiene superior alguno en lo

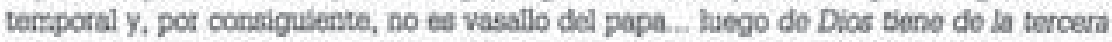
manera la proplodad que es propiannonte propla de la suprema potestad laica' la irall. ca es nuestra).

Con respecto al papel que juega Dios en el pacto, a fin de diferenciar entre Ockham y demás contractualistas, cabe el siguiente comentario. Dios sigue existiendo en el esquema, pero iniclalmente, porque da al conjunto de hombres los bienes en custodia y estos nombran su principe, cediendo sus derochos, pot lo tanto consienten que los gobierne a cambio de algo; y también finalmente, porque Dios es una instancia posterior al pacto, como una garantia de no anulación.

Esto se corrobota, una ver mis, en su tratado titulado: S el principe puede para ayuda propis, a saber, de guerra, recibur blenes eclesidsticos aun contra la voluntad del papa, en el cual queda definitivamente denotada la posición que Ockham scstenia en las Ocho cuestiones., pero aquil, como io dice el traductor, Primitivo Marilio Gómez, en la introduccido a la obra, lo declara enstivcamente, $\sin$ ponetlo en duda, nil alegaindolo por boca de "alguien" que supuestamente lo menciond. Tampoco piesde tiempo en exponer los argumentos que otros opondrian a ésta, su posición, ni los contraargumentos, obviamente; la prueba y punto, incluso generalmente la tefuerza con citas biblicas y documentos eclesíásticos, puesto que "todo esto - según Ockham - puede defendetse con la Sagrada Escritura y lo dicho pot los Santos Pa-

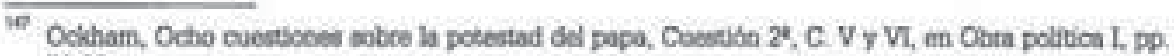
$76-80$. 
dres", ie y cita a Clemente, Ambeosio, Jerónimo, etc. Queda asi rematcoda con claridad la posición de Ockham en las Ocho cuestiones., donde afirmaba la oventualldad del poder temporal del papa, pues de derecho tal poder le cortespondia al pueblo, aunque Dios le otorga tal derecho, el cual se manifiesta en su capacidad de elegir a su gobernante - tey o emperadot - pero queda salvaguardada la instancia de que el papa, de no haber más remedio, pueda intervenir en lo temporal, recalcamos, stempre oventualmente (ocssionaliter).

Resumiendo, debe entenderse la potestad ya saa que se haya obtenido "pot concesión expresa o tácita de principes o por costumbre razonable y prescrita, y ello debe hacarse can todo tigor en caanto toca los derechos de los otros... sea por concesión expresa o tácita de los mismos reyes, o bien por costumbte razonable y prescrita, ast hay que entender el tener potestad..." Bl papa no podria prohabir a los clerigos que ayuden "al rey en tan grande necesidad, y st lo prohibbese, su prohiblcion seria nula, los clérigos deben resistirle abiertamente, no obedecerle en esto en absoluto, y pecarian mortalmente st presumiesen de obedecerle* " $"$ "Esto lo dice papa a proposito de los dectetos papales que derogan pactos, de aquil la relevancia que adquieren éstos en a peraamiento politico critico:

De lo ticho y de otras muchas cosas no sclo se infere claramente que el papa no tieno aquella pienitud de potestad que lo arrituyen loe ya mencicondos que bo atirman... De las Bscrituras aparcoe claramente gue el papa no tiene en espectal el universal dominio y propledad o posesibn de todos los blenes ternporales. pues Cristo a Puxteo que abardono todo por Cristo, no le dio en geceral el doeninio de todos los blenes... Bh segundo lugar, de lo antes escrito se tiene que el papa pot institución y ardenación de Cristo no sólo no tene el docnimio universal de todos los bienes, stno que ri siquilera es setor de loe demits, como se sfirma en la peimera atutoridlad, que es de San Pedrc, en la cuarta que es de San Jertoimo, en la duodicema que es de San Bernardo.. no solio se afirma impletita, sino tamblén explicitamente. Lo tercero digno do toner en cuinta. Es quo no sollo ha sido instituda por Dios la potestad papal, sino tamblen otras muchas, a saber, las secu. lates fuerco instituldas pot of mismo... sin embargo, lat potastades seculares, a saber, ia imperial y la rogia y otras de princtpes pecooden do Dioa, no por la autoridad papel sino por autoridad de los hombres, que no la recibleron del papa, sino de Dioe. De donde la potestad reqtis no procede del papa, stino de Dios medlante el puebio, que recibio de Dics la potestad de impconerse un tey por el bien comain" "

Finalmente cabe tamblen cortobotar lo antes expuesto con sus escritces politicos del Breviloquium, en el cual Ockham une varios de los temas politicos tratados antes, enfatizando como principeles asuntos: la cuestión del ongen da la propiedad,

at

$\operatorname{set}$

ris

at)

th

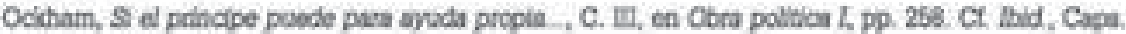
Il y III. pp. 250-263.

Dhid, C. XL, p. 294.

tec elt.

Buid, C. N, pp. $253 \cdot 254$

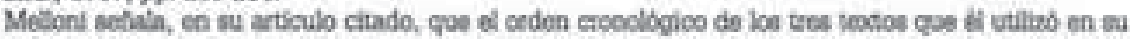

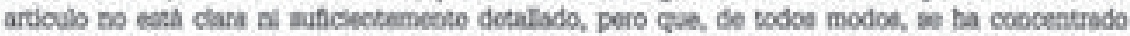
(en su trabajo) en uns de las fases miks impertastes de la polimica tecibgica entes Oekham y el po-

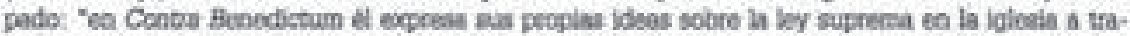

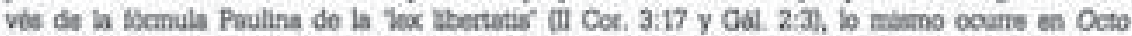

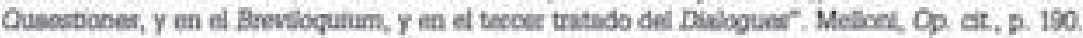


bajo la idea de que se trata de un mal necesario instituido por Dioe a partir de ia entrada det pecado en el mundo, la sobetania del pueblo otorgada por Dios mismo para que eljija a sus gobemantes, el respeto a cuion detenta el poder a partir del pacto, y la posible intromisión non regulariter del papa en el poder terrenal solo en caso de extrema necesidad.

En relación con la propiedad, dice Ockham que los infieles tuvieron dominio sobte las cosas temporales y que Abraham mismo dio sus propias cosas a infieles, como asl también doclara que en el libro del Génesis "aparoce claramente que los fieles tuvieron con los infieles contratos de compraventa, donación y otros seme: jantes, por los que se transmite el dominio de io temporal de uno a otro". " $\mathrm{Y}$ el verdadero dominio esta en aquellos a quienes Dios otorgo las coeas, de manera que nadie podrá afirmar de forma retorcida que "tales contratos entre fieles e infleles no eran verdadercs contratos. Luego -los infieles tambien - tuvieton verdadeto dominio de estas mismas cosas... Por tanto, entre algunos infieles había verdadera furisdicción temporal" " Cuando Ockham se refiere al dominio de las cosas temporales, se está explayando especilicamente sobre la propiedad. Se trata de un tipo de dominio, diferente de la potestad existente en el estado de incoencla, de Adán y Eva. Este dominio propio es denominado, tanto en las ciencias juridicas como en las Bscrituras, como "ptopledad", lo cual define como "la facultad besica de disponer de las cosas temporales, conferida a una persona, a clertas personas 0 a un colegio especial. Tal potestad varia segùn sea mayor o menor" ${ }^{*}$ Primeramente existió como común a todo el genero humano, lo que implicaha que las cosas no estaban de modo alguno adjudicadas a nadie, excepto para su uso. No exista entre ellos avaricia alguna, mientras tanto no existio el pecado, pero luego de este:

- fur fue uttl y conveniente paza retreast el inmoderado apetito do las depravados do poseer bienea temporalas y para disipar ha negligoncio en torno a la debida disgcsicion y procutación de las cocas temporales, pues ocdinariamente las coeas cornunes son derpseciadas por los malvados, y ari so apropiasen de las coesa temporales y dojasen de ser comunes",

is

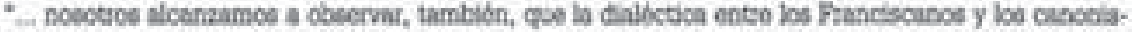

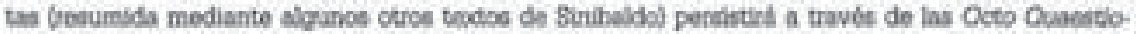

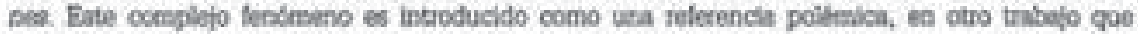

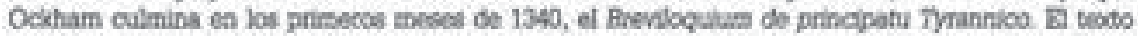
toe hallade pameramente por R. Schola se 1928 en un marsacrito de Ulm, y publicsdo on uns odr.

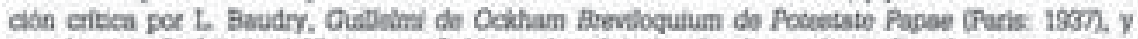

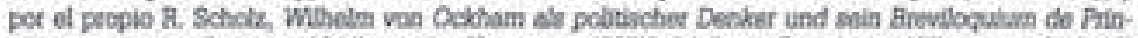

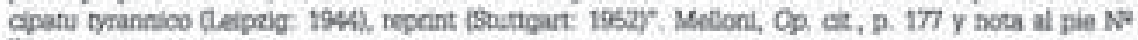
71

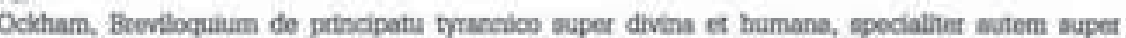

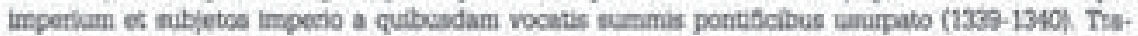

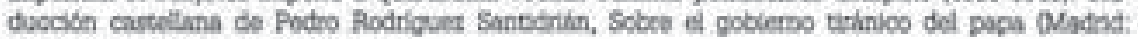
Tecnod, 1992 , Litro 3 , C. 2, p. 92

Loc. cit. 
La propiedad fue introducida por derecho divino y no inmediatamente después del pocado, por voluntad de Dios, pues ti era y es el duetho de todas las cosas, "por derecho

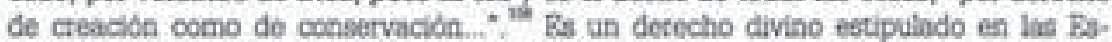
crituras. Dice que les dio tal poder de propiedad, tanto para si, como para sus descendientes, a fin de poder vivir bien " $y$ en comunidsd perfecta" "no

$Y$ aqui prosigue, entonces, con un párafo muy importante que Ockham quiere resaltar, en el cual aparece con nitidez, a colación de lo que Dios otorga al géneto humano, la idea de pacto, relacionada con la de propiedad:

-... Pero dentro de los perfectos, o que tianden con todas sus fuerzas a la perfecison, sucede to contrario, ya que peefeten y se preocupan mís por las coeas del común que por las propian. Así leemos que ciertos romanos, incluso infieles, tuwhoron un cuidado de las cosas comsunes mocho mayor que de las propias. La facultad, pues, de adjudicat las coess temporalos a una doterminada perscrsa, a personas o a un cologio, fue dada por Dios el género humano. Y, por semejante razón, fue dada poe. Dics - sin ayuda y ministerio humanos - la potestad de establecer autoridades que tengan furisdicción tempotal. Potque la juriscioción vempceal pertenece ol mimeto de las coeas que aon necosarina y útiles paca vivir bien y de forma civilizada (political. Asi b atestigua Salomda cuando dice: 'Dande no hay buen gobierno, el pueblo cae" la italloa ee muestra).

Cristo dijo que algunas casas eran en verdad del Celsat, de lo contrario no hubiera dicho lo que dijo, por tanto: "Dod a César lo que es de Cetsar (Mat. 22:21)" significa "todo lo que por derecho se le debe"." También manda el Apćstol someterse a las autoridades constituidas, puesto que todas han sido constituidas por Dios. Aunque lo hayan sido en forma indirecta mediante el pueblo que ellge a aus gobernantes, pero detrás del pueblo que pacta, parece - segrín lo dicho por Ockham aquil y en otros escritos - que siempre esta Dios inspirándolo. Por ello ordena Cristo dar a cada cual lo que se le debe: tributo, impuestos, respeto, honor. De modo que quien se revela contra la autoridad, contra Dios se revela, pues Ek la ha constituido. Luego Ockham se reflere a las razones de obedecer a los gobernantes opresores del pueblo, pues se les debe obediencia en procura de evitar una ira mayor, lo cual no implica que tamblen se les deba obediencia en conciencia."

Pot ejemplo, en el capitulo 16, trata sobre lo que debe exceptuarse de las palabras pronunciadas por Cristo: "lo que atares...". Se trata aquil de los derechos de los emperadores y reyes, sean fieles o infieles, siempre y cuando no "se opongan a

\author{
IRid, D. 112. \\ Bid, p. 113. \\ Loc. es. \\ Deid, Lewo 39, C. 2, po. 90.91
}

IDid, Libeo 3\%, C. 3, pp. 97-99. Aqui pareciena qoe Ockham preconiza el penamiento de Hobbes,

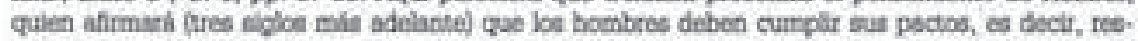

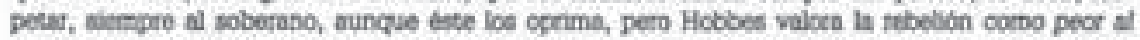
peor gobiemo, puesto que acarnoa guema chit, de todos modoe, perritte li libe concicocia de loe

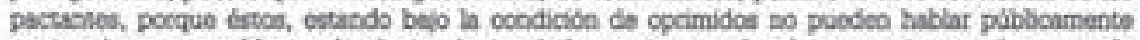
contra el rey. peto si lo pueden hacor dentro de las cuatto parodes de su propla casa, lo que ea bo mismo decit que se manda obedecer, sunque no se lo baga a conciencia. 
jas buenas costumbres, al honor de Dios y a la observancia de la ley evangélica" " El papa no puede alterar tales derechos puesto que existieron desde antes de la ley evangelica, de modo que los fieles, "están obligados a obedecer, si quieren salvarse - de necessitate salutis - a los pincipes y gobernantes, incluso a los intieles, en lo que respecta a sus derechos legitimos" "*

Ockham tesume todo su alegato diciendo que en asuntos de conciencia, creencia, de ayuno y otros por el estilo, cualquier ley de este tipo u "otras materias semejantes, no obligan a sus súbditos sin el consentimiento de los mismos y, en consecuencia, quedan anuladas por la práctica en contra de los interesados, incluso aunque no quiera el pape. Éste no puede... establecer leyes obligatories contra la voluntad de los súbditos"," De hacerlo, el papa estarla oprimiendo "de iure., a los criatlanos con mayores cargas que lo estuvieron los judics, cosa evidentemente contrarta a la libertad evangelica" "

De acqul, se extraen varlas atimaciones de relevancia capital, como por efernplo, que el poder del papa ante sus subditos-siendo que tal poder trata sobre cuestiones espirituales, de conclencia-no se asemela, ni de cerca, al poder del emperador o rey sobre sus subditcs, a quienes éstos sf deben cbedecer sus leyes, no solo por el poder civil que éstos detentan, sáno porque su autoridad, si bien deviene indirectamente de Dios, le es dada directamente del pueblo, quienes los eligieron, de modo que luego, al estilo contractualista y hobbesiano, deben obedecer, con absoluta responsablidad, entendiendo que las leyes dadas, lo son para el sostenimiento del bien comuin, y en definitiva, tales leyes no son más que el fin pot el cual existe un gobiemo clvil. Bl gobiemo espiritual, en cambio, el que ejerce el papa sobre sas súbditos en las cosas espirituales, no es un mandato de fire, sino de Mbre consentimiento por parte de los sulbditos, por tanto posee cierta indole voluntarista y con ello, un tinte antiegalista o espiritualista. Finalmente sefala que *Cristo rechazb totalmente no solo el gobiemo tiránico e injusto del mundo, sino tambièn el legitimo y justo... Cristo excluy $\delta$ con palabras y ejemplos - si bien vetbalmente no exceptuó nada - todo principado secular, de hecho y de nombre, del poder prometido a Pedro por las palabras: 'Lo que atares...". ."

\section{Sentido y finalidad de sus escritos politicos}

La excrema objetividad que pretende Ockham al aplicar el método de la disputa escolástica, a través de los temas abordados en las Ocho cuestiones, no es lograda totalmente, puesto que oon sutileza puede deslindarse de entre la marafia de argumentaciones diversas y contrarias, su propta postura, además de poder conflimarla

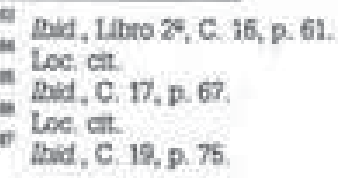


en sus otras cbras mencionadas." ${ }^{\text {in }}$ El pensamiento propio de Ockham, sogin to seflalado por Offer, el editor de sus obras politicas en latín, "no es otro que la separacion de las dos potestades, la espiritual y la tempotal, por su naturaleza, origen y fin, pero sin ánimo de enfrentarlas, sino de cocrdinarlas" ".

Ockham utliza como fuentes primotdiales a las Sagradas Bscrituras y las Decre. tales - aunque desde su bptica particular, por supuesto, lo cual lo empuja a cometer ciertos sesgos - filtradas por la médula central de su pensamiento metafisico y politico, dando muestras - esto debe ser fustamente dicho - de un excenso y profundo conocimiento de la enorme tradición doctrinal. Su formulación precisa, sintéticamente expresada, es: "¿Puede incidir en una sola persona la potestad espiritual y la temporal?", a lo cual, en las Ocho cuestiones, responde de tres maneras diferentes, sin comprometerse, a prion, con ninguna, pero si finalmente con la ultima. Bstas son: a) la de contradiccion, puesto que son de distinta naturaleza; b) la de plena potestad del papa, como verdadero y legitimo titular de ambos poderes; $y$ c) una intermedia, por lo cual se acepta la superposición de potestades a favor del papa en caso de necesidad extrema, cuya fórmula típica latina se expresa asl: "casualiter, non regulaniter ${ }^{* 0}$ Bsta ultima postura, que è adopta, le permite contemplar sin inconvenientes su propia concepción con respecto a la construcción de la sociedad politica y la administración de justicla en ella, es decir, una posición contractualista, que podemos tildar de "moderada", puesto que no se trata de un pacto ni de una construcción convencionalista do la justicta que hayan surgido de la nada, sino por la mediatez del pueblo, soberano, dirigido por la voluntad divina. ${ }^{m}$

Ockham define asl estas tres pcsiciones:

1. Potestad temporal tiene por objoto lo temporal, personas y blenes con los que se busca el bien comuln. Potestad espiritual tiene por objeto lo espiritual, con lo cual se dirige la sociedad hacia la vida eterna. No precisa bienes para reallzarse. Seguin la primera postura esto daria como resultado una sola cabeza con dos cuerpos, lo cual seria contradictorio, a lo que agrega Ockham que el papa no precisa del dominjo, concepto que ell ve exclusivo de la sociedad temporal, para realizar sus fines espirituales. Bsta concepción, llevada a sus ultimas consecuencias luego en la Reforma, conduce "a una Iglesia totalmente alejada de las realidades temporales", "tr

- Celer, en su introducceibn a su ediclen do la Opera Poltioa, de Codham, se eqpesea sobce el lagar donde apasocen reCojadas las peoplas ideas de Ockharn. Ev wa articulo de su butoria también dis.

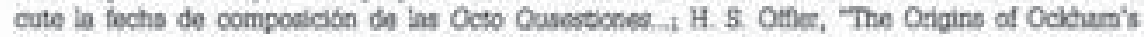
'Octo Oudesbicnes", Rnglinh Historicul Review, 82, 1967, p9. $323-392$

10

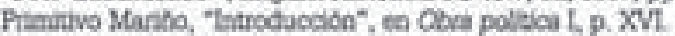

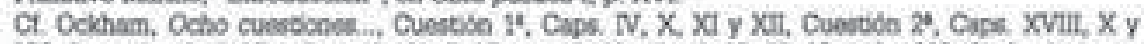

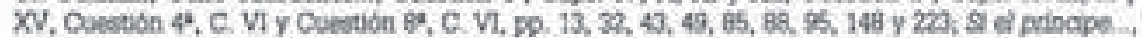

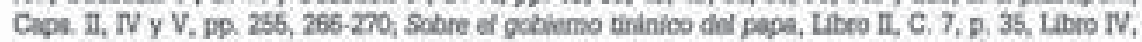
Cega 3 y 4, D9. $142-143$

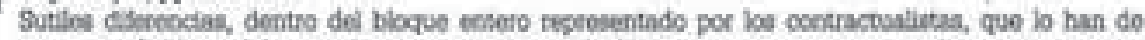
suparar a Ockham del resto de sus compaferos ideciloficos, peso que, a su ver, lo conetiryen co: mo lass intectnedio - al lgal que a Geoclo ea selacibo con wu concepelbe del derocho natural y la Fo las modernos - con elles.

Premitivo Maribo, Op ct, $p . x v m$. 
2. Ockham no comparte la segunda opinión de la corriente curlalista, que otorga plenitud de potestad al papa, lo que constituyo fuente de conflicto con las autoridades temporales constituidas. "Ios elementos claves para la concepción de una sociedad lalca es la corriente que en la exégesis deja de lado el orden natural, el derecho natural y la filosofia natural. Dice que esta segunda opinín que concede plenitud de potestad al papa "tiene un soporte muy debe en cuanto que se piensa ser verdad revelada lo que es interpretacion". Loe canonistas se basaban en el cellebre texto de Mateo: Todo lo que atares so. bre la terra" y en otro texto que mentaba "he ahl las dos espadas", todo lo cual, interpretado simbolicamente, dio luggat a la elaboración de la doctrina de la potestad del papa. A ello se arladieron decrotales y bulas de pontiflices: Gregorio VII, Bonifacio VII, los Inocenclos, quienes tecogen textos biblicos que aducen para sostener la plenitud de potestad. Bl punto de partida de es. tos textos es la realiza de Cristo y su transmisido de lo espiritual y temporal a Pedro como su vicario en la tierra. Pero Ockham argumenta que esto traeria como consecuencia que tal concepción deja a un lado dos derechos y libertades de los hombres, produclendo una Iglesta de hombres no thres, "sino de stervos sometidos al arbitrio del papa". Asi, tal potestad papal no colaborarla con el bien comín de los fieles y sus derechos quedarian lestonados."

3. Ockham suscribe una tercera optnión, intermedia, de que Cristo no expresó la doble potestad en una misma persona, sino la excluyo, encomendando al papa no entrometerse en asuntos temporales, además de que promulgó una lay de libertad, que no rompe derechos y libertades establecidos ya pot derecho natural. Tal ley de libertad "no pone en tela de fuicio los derechos y libertades de emperadores y reyes", por lo cual "las relaciones entre los miembros de la sociedad se concibieron en términos de derechos y lbertades, obligaciones reciprocas de los individuos y derechos y libertades respetados" in Su concepto de Iglesia no absorbe derechos y libertades naturales, sino que es un cuerpo mistico, espiritual, "más que una realidad social organizada o una persona juridica" "s Ockham no penso en la anarquia que esto puede entrañar para la misma vida de la Iglesia, con lo cual ya preanuncia "la libertad que más tarde hará suya Lutero":t" y ésta es una tendencia espiritualista que ya se inicio en el siglo XI, con la finalidad de dejarle manos libres a la autoridad termporal Como consecuencia de esto se produce una exaltacion de lo individual, ya

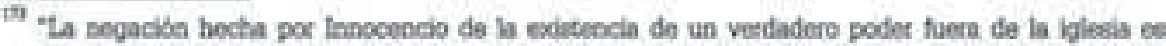

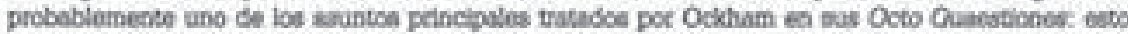
en preseetudo, al mence, coeno algo absusdo, incoberente, tai coeno paedo apcociatso tarto en ef

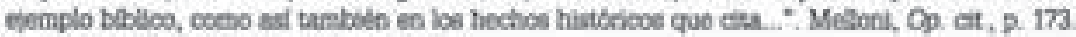

a Primitwo Mariho, Op. at, pp. XVIII-XCX.

is Did, $\mathrm{DP}, \mathrm{XDX}-\mathrm{XX}$.

in lied, $D, X X$

loc et:
} 
que es el individuo quien responde ante Dics, 10 cual no conduce, segin Lagarde ${ }^{m}$, a ctra cosa que a la anarquia. ${ }^{\text {in }}$

Su posicion con respecto a la administracion de la justicis, queda establecida sobre el final de la Cuestión $2^{t}$, de sus Ocho cuestiones...: "... el papa, al estat vacante el Imperio, por lo regular no debe entrometerse en absoluto en asuntos del Imperio, mixime si otro vicario del Imperio hubbere sido establecido por el emperador o también por los romanos, o pot aquellos a quienes los tomanos confirieron la potestad de ordenat en of Imperio..." No faltará alguien que dirá que si el Imperio quedara vacante "hay que recurrir al sumo pontifice para obtener fusticia"; por lo tanto a ell le compete "entrometerse en asuntos del Imperio cuando éste se halla vacante": ta respuesta que aquil resulta mis adecuada es que, de acuerdo con Inocencio, se *entiende que debe haber recurso al papa al estar vacante el Imperio, cuando no hay un vicario del impotio ni quien haga fusticia en lo temporal a las que son optimidos injustamente* (la negrita es nuestra); ${ }^{\text {in }}$ lo cual el mismo habria tratado de insinuar cuando difo: "Hay que apelar al papa en tiempos en que, al estar vacante el Imperio, no pueden recurnir al juez secular quienes son oprimidos en su fusticia por los superiotes" in Con esto queda claro que la justicia debe siempre - regulanter - estar en manos de jueces seculares, salvo si no los hublere.

\section{Conclusiones relevantes que pueden extraerse de sus escritos politicos}

A partir de los propios textos de Ockham podemos extraer varios elementos de carácter contractualista, sunque también deben marcarse las diferencias que hacen de este tipo de teorla politica algo mucho menos secular que la que vendrat desde Hobbes en adelante: 1) Bl hombre es malo por naturaleza. Claramente sehlala Ockham que esto es un hecho a partir del ingreso del pecado en el Bdén, pot Adán y su mujer. 2) Peso el derecho de ptopiedad no se instituye automáticamente - por Dios - después del pecado, por tanto se deja entrever, implicitamente, que hubo un tiempo en que los hombres pecaminosos - malcs por naturaleza, en lenguaje hobbesiano - luchaban unos con otros por la posesión de las cosas, hasta que Dios instituyo (para evitur tales males, pues en el Bdón la propiedad era común y no hubiera cambiado de no haber entrado el pecado), el derecho de propledad, a fin de que los hombres puedan vivir bien y en comunidad. 3) Niega - apoyándose en Aristóteles - la posiblidad planteada por Platón en La Republica, donde affrma la comunidad de biones; por tanto, segün la lectura que de Aristoto-

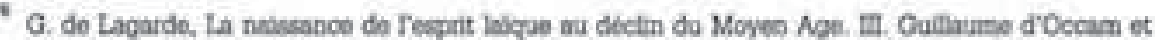

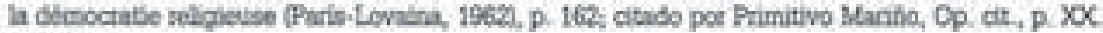
100 cit

Ociham, Ocho cuestionest.., Cocestibn 14, C. XV, p. 94

Inid, P. 96.

loc dt.

Inocenclo, De fro competent, c. Licot, 89, cteado por Dhid, D. 95.
} 
les hace Ockham, stendo que el hombre se inclina hacla el mal y no aprecia ni culda lo que es común, debe existir el derecho de propiedad, porque es preferible la apropiación que el dominio común de las cosas. Con esto no significa que esté negando la sociabilidad natural de los hombres scstenida por Aristoteles, pero si queda claro que la está acotando, o hasta transformando si se quiere, debido a la existencia del mal, que reclama una delimitación de derechos entre los hombres. Con ello esta diciendo, implicitamente, que los hombres pueden comvivir en paz, si, pero en tanto $y$ en cuanto esté bien definido dande termina el derecho de uno y comienza el derecho del otro. Nos atrevemos a pensar que Aristiteles, aunque negó la propledad cormún preferida por Platón, no Degó nunca tan lejcs como Ockham, puesto que tampoco los griegos tienen en su cosmovisión un concepto tan claro, preciso y definido de mal, como lo tiene Ockham, a ralz de su absoluta creencia en el relato biblico del Génesis y el hecho de poner el aconto en el tema del pecado original, diferenciándose también aqui con Hobbes, quien no explica el origen religioso del mal, sino que simplemente existe, can lo cual ha llegado a una cosmovisión inversa que la griega y por tanto también a la de Aristóteles, 4) Luego, Ockham quiere decantar diferentes tipos de hombres, con lo cual fundamentara en otra parte de sus escritce su concepción religiose de los derechos, acerca de la diferencia entre uso y propiedad. ${ }^{\text {th }}$ Afirma que para quienes buscan la perfección o son perfectos, sucede lo contratio a lo que pasa con el hombre común, puesto que aquellos no buscan mas la propiedad individual que el bien comuln." ${ }^{\text {in }}$ 5) Sobre el derecho de propiedad, como asi tambièn el de jurisdicción, declara que nada en la Escritura dice que tales derechos fueron introducidos por la "sola intervención divina, sin intervenir la ordensción humana", ya que la primera delimitación do derechos propietarios acontecio, aparentemente, entre Cain y Abel, pues es mucho más verosimil pensar, no que Dios habria distribuido individuaimente algunas cosas a Cain y otras a Abel, sino que debido a la malicia y violencia de su hermano, éste se vio obligado a establecer una primera división de las coses, introduciéndose de tal modo entonces la propiedad. ${ }^{\text {* }}$ 6) De tal modo, continua Ockham, debe ser afirmado que la propiedad no la introduce Dios, sino que se da por "ordenación humana, lo cual no quita que ciertos dominios si hayan sido introducidos por derecho divino, de manera que algunas propledades lo son por derecho divino y otras por derecho humano. Con ello concluye afirmando que las juriadicciones temporales, fueron croadas en clertos casos "por derecho divino y natural" y en otros "por detecho humano-" 7) Luogo se ocupa de dejar bien en claro, que el podor de los gobernantes no les vione dado por derecho divino o natural, como en algunos casos biblicos citados OMolsés, Josué y algunos otros fueces instituidos por ordenación divina)," "sino parcialmente de derecho humano". Puesto que,

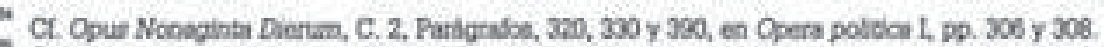

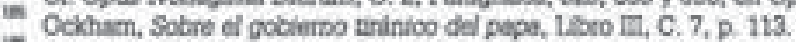

in Pid, L. II, C. 9, D. 116.

iv Beid, L II. Ceps. 9, 10 y 11, pD. $117-118$

10

Itid., L. III, C. 11, p. 119
} 
solo en unos pocos casos, por derecho divino o natural, se les otorgo a los bombres poder para establecer a sus gobernantes, incluyendo la capacidad de obligar a los súbditos (como ocurrio con Molsés y Josue), pero, en cambio, la gran mayoría de "los demás obtuvieron la jurisdicosion sobre otros por elección y designación de los hombres". Asi es como aperece, con total rigor, el hecho del pacto del pueblo con sus gobernantes, exceptuando tal procedimiento para alguncs casos ocurridos entre los gobernantes del pueblo judio, quienes ejercieron su poder por expreso mandato divino, por tanto, sin injerencia humane, $y$ en consecuencla sin pacto de ningún tipo. 8) De todo lo dicho precedentemente, afirma Ockham que "tuera de la Iglesia hubo algruna vez verdadeto poder ordenado y concedido, y no sólo permitido" te Tal es asi que consta que el proplo Constantino el Grande lo tuvo antes de convertirse al cristianismo. Por ello critica la forma erronea, herética e irracional con que Juan XXII se expresa sobre la introducción del dominio de los bienes temporales y dice que para probar esto debe saberse que:

- ... el poder de dar leyes y derechos humanos estuvo primera y peincipalmente en el pueblo. Y el pueblo traspasd esta potestad de dar leyes al emperador. Del mismo modo, el puebio - tanto el romano cocno otrce - traspaso el poder de dar leyes a otros, unas veces a los reyes y otras a ctros de menot rango o inferior poder. Todo esto se podria probar no sollo por las histocias y cónicas, sino tambilan por las Sagradas Escrituras. De todo to cual se deduce con toda evidencia que les derechos humanos no solo fuerch derechos de los emperadoxes y reyes, sino tambshon de los pueblos y do otros que tecihteron el poder de estahlecer y promulgar derechos de otros pueblos, asf como otnas laudubles y uetles costumbres introducidas por los mismos. Dado, pot tanto,

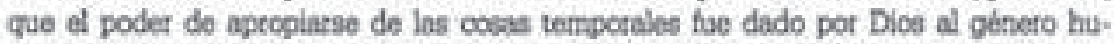
mano, los biones termpotales adquiridces en witud de un derecho humano no sclo podilan posootso por las loyes de ernperadoces y teyes, sino tambien por costumbers Jaudables y razonables, por derechos y ardenacianes humanas introducidos por loe pueblos $y$ otras persones ocn podor $y$ autoridad trunsterida por esos miamas pueblos. $Y$, de becho, antes de que existieran emperadores y reyes hubo verdadera propiedad do muchos bienes basada en este derecho" la ltalica es nuestra).

Con esto Ockham declara la posiblilidad de transterencia de derechos - de poder, en rigor de verdad - del pueblo al rey. Asi mismo, debe ser acotado aquí, que a partir de la palabras de esta ultima cita, queda fortajecida la posición que manthenen Villey y otros acerca de la importancia dada por Ockham a los derechos subjetivos.

\footnotetext{
Loc. cit.

in Ind, L III, C. 13, p, 123

Ihid, C. X $\mathrm{CV}, \mathrm{DP}, 125-126$.
} 


\section{Conclusiones epistemológico-metafísicas (y teológicas) que pueden desprenderse a partir de la fllosofia politica de Ockham}

Alyunas cosas nos han quedado claras, luego de lo expuesto.

En primer lugat debe decirse que contra toda propuesta universalista formulada por la institución del Papado - hay que recordar aquí que Ockham no polemizo solamente contra Juan XXII (1316-1334), sino también contra Benedicto XII (1335. 1342) y Clemente VI (1342-1352), " Luego cabe acotar que al iniciar sa confrontación contra Juan XXII, a proposito de los derechos (subjetivos) de sus compaferos de Orden, loe Franciscanos, si bien éste ha sido el punto de partida, no creemos que haya sido su objetivo o meta, sino que puede percibirse con claridad que éstos están situados mucho más alli. Influenciado o no por los canonistas de los sigics XII y XIII - tal como scstiene Terney - lo cierto es que lo que le discutia al propio papa eran asuntos sobte el poder, queriéndole restringirselo a una esfera puramente espiritual, ámbito que aún le recorta, ya que prevalecen ante el universaismo eclestástico clertas prenogativas propias e inherentes a los individuos, para quienes el papa no pasa de ser un mero teferente - no más que esto - espiritual, y no mis ya el vicarius de Cristo en la tierra.

Esta restricción del poder papal en la esfera de lo politico repercute directamente en la conoepction sobte la formación de la sociedad civil o politica; ya no más como una comunídad que se rige por procesos y procedimientos que devienen en sentido descendente, sino a la inversa, conformíndose a partir de un grupo de individuos que, hablendo perdido el sentido stgnificado por la propledad $c 0-$ mún, y debiendo ahora controlarse mutuamente su egolsmo natural, plensan y poseen como entes individuales en un mundo que les fue dado por Dios para vivir en èl.

Bso sf, el derecho natural mantiene ciertos rasgos de universalidad, poesto que, en Ockham sigue en vigencia la idea de emana plenamente de Dios, y puede seguir constituyendo la gula fundamental de su conducta, por lo tanto se mantiene siempre latente la natural tendencla (puesta por Dios) a congregarse en sociedad, pudiendo con ello continuar cuidando del Blen comuin, tal como Aristoteles, provisto de un concepto más fuerte y nacionalista de ciudadania, habla establecido como pledta angular de todo su sistema politico. La gran diferencia con tste es que ahora los individuos societarice deben pactat la cosión de sus derechos hacia alguien que los gobieme, con lo cual se efectiviza la separación de poderes que Ockham deseaba establecer $\mathrm{y}$ in conformación de gobbernos universales a partir de las voluntades de los individuos particulares. Pero al mismo tiempo, cabe setialat que se le habla presentado a Ockham una problemattica totaimente ausente en el mundo en que vivib Aristoteles y en toda in flosolia griega: ell problema de la entrada del pecado en el mundo - el problema del mal está prácticamente ausente en el mundo griego - y de alguna manera habla que hallarle una respuesta, la cual pasara por solucionar el tema de la propiedad y de dónde la obtienen los seres

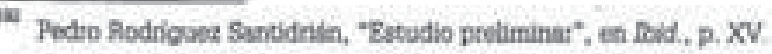


humanos una vez que ocurrib la ruptura edenica. Ockham explicark esto haciendo uso del derecho natural, que es dado a los hombres directamente por Dios y del derecho de gentes, humanamente instituido. Luego, de aquil al pacto entre seres libres e iguales que accuotdan transferti sus detechos a partit de un poder que les ha sido legado por Dics, solo hay un pequeño poso, que el mismo Ockham recorre.

Bpistemológica y metafisicamente explicado, eato significará que el poder otorgado por Dice a cada individuo se ha transformado, acotde a una interpretación ascendente de la formación del gobierno on el argano decisot de la actividad y la realidad polisicas. Bate poder, que por derecho natural han adquirido, Dios mediante, los seres humanos, es incluso retornable a sus portadores, ya que esta furidicamente autorizada - por derecho natural y divino - la rebelión contra el gobernante, ser universal que rectbio su naturaleza entitativa sustanclal por transferencia de los derechos politicos de cada uno de loe individuos particulares, a partir de entonces, los gobernados, sus subditos. Por supuesto, el fundamento de egta instancia ùltima ha quedado salvaguazdada por sí acaso aquél no cumplere cabalmente con la función que le corresponde, y se transforme en un trano de quienes lo eligieron transfiriendo sus poderes. En definitiva, los individucs particulares (atomos sociales) son las verdaderas unidades decisoras y soberanas, quienes para cumplir acabadamente con su verdadera realidad sustancial: la convivencla social en paz, pactan entre si la cesión de sus derechos a una entidad universal que los gobieme. Luego de la entrada del mal en el mundo, la paz y la sociedad continian quedando aseguradas gracias a la vigencia permanente del derecho natural puesto por Dios en todos los hombres.

\section{Conclusión final: Ockham a la luz de la Modernidad}

Carlos Massini Correas, fildosofo del derecho argentino, cuya especialidad es la ética juridica, sen̂ala cuatro causes fundamentales del individualismo que impulso una revolución de la mentalidad: el humanismo, el protestantismo, el idealismo cartesiano y el nominalismo de Ockham y los ockhamistas, quienes con su empirismo antimetafisico y su afirmación de lo singular, influyeron fuertemente en Suárez y sobre todo en Hobbes. En el ámbito de la moral, en el mundo británico, esto darb origen al establecimiento de un sentido de lo ético que la conciencia moderna adquiere a partir de la petcapción de las costumbres sociales. Ast se va formando la noción de moral convencional y de un sentido convencional de la fusticla, fundados en el signo que expresa la sustantividad de los mismos:

* debe comprenderse que hay dos clases de universalas: hay una clase que es natutalmento unversal; en otras pelibeas, es un signo naturalmonte ptodicable de muchas cosas. Semejantemente un universat no es otta cosa mis que un contenido de la mente; y de ninguna manera una suatancia foera de la mente y tarnpoco un acoidente fuera de la mente puede ser un universal. La otra clase do unlversal es por convendidn. De este modo, una simple cualidad es un universal; pars esto un signo convencional llega a rigniflioar varias cosas. Tan exacto como to dico la palabra, eso pvede ser 
llamado como universal. Pero esto no es por naturaleza, sho slio por una canvencidn" (ta italica es nuestra) ${ }^{\text {in }}$

De aquí al contractualismo, caracteristico de todo el pensamiento angiosajón posteriot, hay apenas un paso. No por nada el mismisimo Hobbes, adoptará una postura epistemológica nominalista, cuando en el capitulo 4 de la $1^{4}$ Pte. del Leviathan se refiere a la invención del lengraje y el uso de los terminos y de las definiciones. La cuestion, pues, dentro de este macroesquema que opera en el pensamiento britänico, será determinar las sutilezas del mismo, Cuándo hay un pacto expreso y cuándo el pacto es tácito y se trata de un acuerdo que está ya instaurado en la sociedad. Es entonces cuando vienen a colación las diferenclas que separan los pensamientos de Hobbes, Locke, Rousseas y Kant, por una parte, es decir toda la tradición contractualista y Hume, por la otra, tepresentando la tradición convenclonalista. Las sutilezas de las diferencias no hacen a la cuestión, porque la taiz no está sino en una nueva actitud intelectual y vital que se congtruye a partir del sujeto, cuya más directa manifestación esta dada por el hecho de que todos los elementos de la convivencia social han de quedar, a partir de esta imupción de la conciencia moderna, subordinados al interés individual. ${ }^{\text {"W }}$

- Toda convivencia humana, bea famaliar o estatal, se reduce a una compensación o equalibrio de intereses entre individuos absolutamente equiparados en derecho'." En ripot, desde esta perspectiva todo se teduce a contrato $\mathrm{y}$. lo que es mila, a conteato conserssual: las relaciones laborales, internacionales, politicas, farnalintes, van a set concebidas y reguladas como el resultado libee de la voluntad autb́roma de las partes. De acqui a la cuentión sociat, la petedida de la unidad familiar, la discordla nacional e internacional, no habed más que un paso....

"La actitud insolidaria que se sigue de este individualismo declamatorio y milltante, va a ponerse de manifiesto, sobte todo, en el ámbito do las telaciones laborales, los contratce, ia economia y el reggimen de propiedad" " As lo manifiestan varios pensadores modemos, como Leibniz, por ejemplo, evidenclando el sesgo indivi. dualista que ha tomado el pensar furidico, "al colocar el principio de no dañar al otro

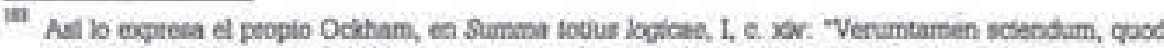
universale daplex est: Quoddam est unversalo naturaliber, quod scilioes taturahtot est signum

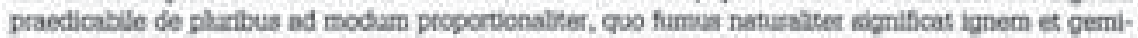
bat infirmi dolorem et thua imseriorem lacotian et vale untversule non est bisi intentio animbe, ita quod nulla sabetamia ecoa animsen nec abgood accidens exten animam eat tale uriversab. B. de

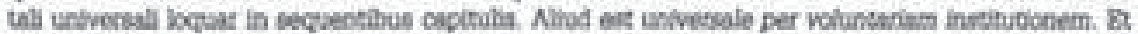

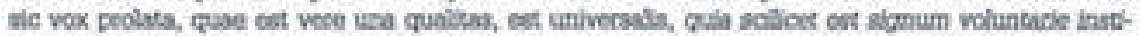

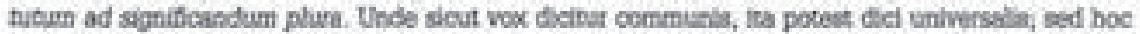

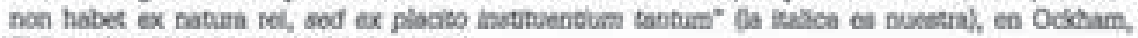
Philoogphical Whishos. A Solocoion, D. 34.

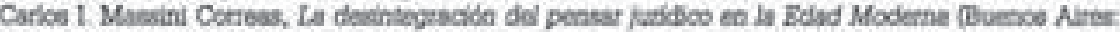
Abelodo-Fertot, 1980, pp. 5 - 18 .

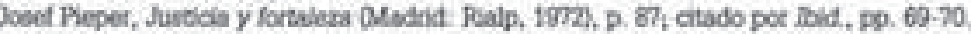
Mid, DD. $70-71$.

ind, D. 47. 
en primer logar, a la invessa de los juristas romanos", o Grocio, ${ }^{\text {in }}$ afirmando que hay que abstenerse del bien del otro, mantener ia patabra y reparar los daffos causados por errotes propica, principios todos estos basados en la justicia conmutativa, con Ios cuales el fundador del derecho moderno levanta todo au sistema y del cual provendra, en definitiva, su "pancontractualismo" is"

Si comparamos la institución del pacto según Ockham con la que más tarde ba de formular Hobbes, notaremos que la gran difetencia ractica en la existencia de la ley natural divina puesta por Dios en los hombres y la capacidad que les ha dado para su autogobiemo. La conformación del procodimiento contractual (explicito en su origen) en Hobbes, habia desterrado a Dios por completo del proceso. Algo similar - quizals más protundamente - ocurre con la concepción artifictalista de la politica scstenida por Hume. El escocés no es contractualista - aunque se bo podrh situar como una especie de contractualista implicito, en los tiempos remotos sobre los cuales ya no hay memoria histórica, por eso lo de "implicito" - pero sostiene que la scciedad, es dectr, las normas sociales de convivencia, se produce pat costumbre y asł ha pesado de generación en generación. Lo mismo ocurre con su noción cons. tructivista $^{\text {mit }}$ de la justicia, que proviene del orden social emanado de la costumbre y no de un soberano que encama la josticla traneferida, detechos del pueblo mediante, como en Hobbes, bajo procedimiento contractual y menos o más diferente aún que la concepcicon de la fusticta en Ockham, también de indole contractual, pero con un resto que es stempre detentado por el pucblo, que la obtiene de Dics por detecho natural o divino, y que mantiene para siempre la capacidad de ponerla en ejercicio en caso de que una situación extrema - como puede serlo la opresión o tirania ejercida por el monarca - la justifique.

Está claro, asi mismo, que en ninguin momento Odibam justifica afirmaciones politicas con sus anteriores de indole metafisica o epistemológica; su pensamiento carece de la sistematicidad de un Santo Tomás, por ejemplo, aunque su metodologla no deja de set tipicamente escolástica. Pero a lo sumo, uno puede Degar a afirmar que luego de su ncminalismo metafisico y epistemolkgico, no podia llegar a otro tipo de pensamiento práctico (ético, politico y juridico) que al que legó, máxime al tenemos en cuenta la muy factible infuencla que ejercieron los canonistas que lo precedieron y el polémico periodo de tiempo, en lo cue a materia poitica se reflere, en que le toco vivir.

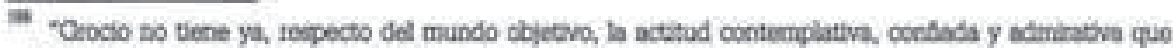

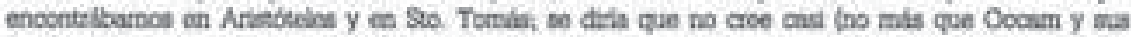

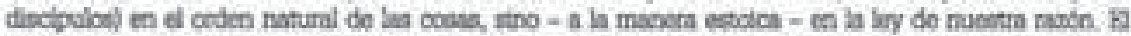

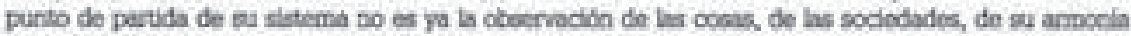

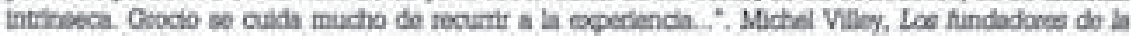

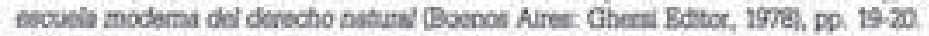

บ

- soguin el cas todas las inetinudiones juríticas y politicas deblan tevolverso en un contrato, fuen este expeso, coms en el caso de la sociedad poltica y la familss, o ticita, coeno en el eupuesto do

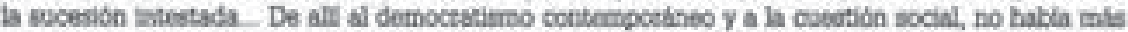
que un Daso, que Buropa dio alegremecke, sin vatualint las cocoscuenciss que habelat de lievar.

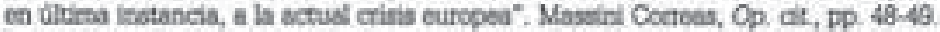

$2 \pi$

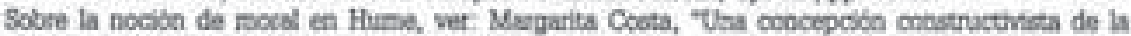
inca" 
Bs dificl confirmar la influencia de su filceofla teorica sobre la practica; Ockham nunca lo dice explicitamente, ni tampoco pretende basar sus aseveraclones politicas en sus fundamentaciones teodricas, pero, siguiendo el pensamiento inverso, tampoco es posible dectr que lo niegue en parte alguna, por lo cual queda el terreno despejado pata la mass licita especulación. Aunque, en todo caso, esta espoculacion podra estat guiada, si se accede a ello, por la simple idea de que, por lo general, hay en todo pensador, y particularmente en quien elabora ciencia polftica, un conjunto congruente de ideas que constituye el eje central de toda elabo. raction de ideas, ya que, por esencia, la filoeotia potitica - como asf tambien la juridica y motal, y todo aquello que puedo denominarse filosolia práctica - se ha de fundar en un concentrado ideologgico, el cual no es otra cosa que el sustrato bistico del cual emanan todas ins ideas y ramificactones del pensamiento. 